Check for updates

Cite this: J. Mater. Chem. A, 2020, 8 24833

Received 29th September 2020 Accepted 6th November 2020

DOI: $10.1039 / d 0 t a 09553 b$

rsc.li/materials-a

\section{Probing the charged state of layered positive electrodes in sodium-ion batteries: reaction pathways, stability and opportunities}

\author{
Jennifer H. Stansby, (D) ab Neeraj Sharma (D) a and Damian Goonetilleke (iD) *c
}

Sodium-ion batteries have received significant interest as a cheaper alternative to lithium-ion batteries and could be more viable for use in large scale energy storage systems. However, similarly to lithium-ion batteries, their performance remains limited by the positive electrode materials. Layered transition metal oxides, with chemical formula $\mathrm{Na}_{x} \mathrm{MO}_{2}$, have been extensively investigated and appear to show the most promise. However, the inability to reversibly extract large amounts of sodium ions from these layered structures, by charging to high voltages, has limited the useful capacity and cycle life of these materials. To address this, numerous studies have attempted to resolve the structural and chemical changes that take place in positive electrode materials upon cycling. This is particularly important at and near the charged state, which is where the materials' structures are highly sodium deficient. Following a brief introduction into the status of sodium-ion battery positive electrodes, this work focuses on the development of knowledge and understanding into the structure of layered oxides at the charged state by highlighting cutting edge characterisation techniques that have been utilised. Finally, a perspective on future development is provided to direct further structural characterisation research which will enable the rational design of new and improved energy storage materials.
${ }^{a}$ School of Chemistry, University of New South Wales, Sydney, NSW 2052, Australia ${ }^{b}$ Australian Nuclear Science and Technology Organisation, Locked Bag 2001, Kirrawee DC, NSW 2232, Australia

'Battery and Electrochemistry Laboratory, Institute of Nanotechnology, Karlsruhe Institute for Technology (KIT), Hermann-von-Helmholtz-Platz 1, 76344 EggensteinLeopoldshafen, Germany. E-mail: damian.goonetilleke@kit.edu

\section{Introduction and nomenclature}

Commercialisation of the lithium-ion battery has revolutionised the world. These batteries offer high energy density and reliable cycling performance which has enabled the development of a variety of portable electronic devices which are critical

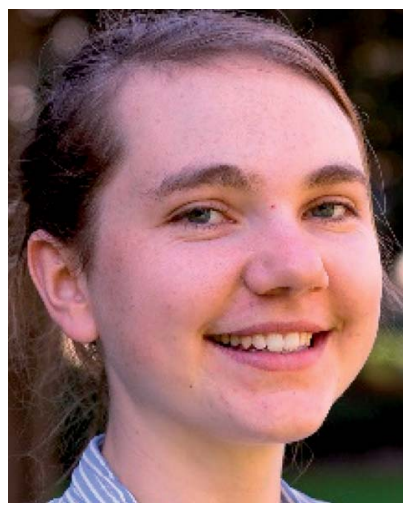

Jennifer Stansby received her MChem in 2017 from Durham University, England. She is currently completing her PhD with Assoc. Prof. Neeraj Sharma at the University of New South Wales, Australia, with ties to the Australian Nuclear Science and Technology Organisation (ANSTO). Her research focuses on structure-function relationships in layered oxide positive electrode materials for sodiumion batteries.

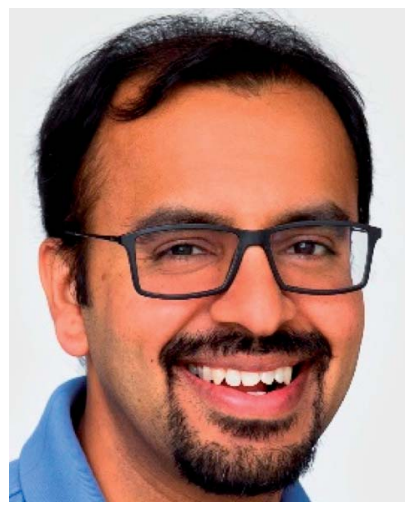

Neeraj Sharma completed his PhD in 2009 with Prof. Chris Ling at the University of Sydney, followed by postdoctoral research at the Bragg Institute within the Australian Nuclear Science and Technology Organisation (ANSTO) until 2012. He is currently an Associate Professor and Australian Research Council Future Fellow in the School of Chemistry at the University of New South Wales, Australia. Dr Sharma's research interests are based on solid-state chemistry, in particular designing new materials and investigating their structure-property relationships with a particular emphasis on in situ or operando studies of materials inside energy storage devices, especially batteries. 
for the functioning of modern society. Further advances in battery technology have the potential to help address the global energy crisis and mitigate climate change. ${ }^{1}$ To achieve a sustainable yet high quality of life, our consumption of fossil fuels must be replaced by energy from renewable sources such as solar, wind and waves. Due to the scarcity of resources used to produce lithium-ion batteries, coupled with growing demand for their utilisation in electric vehicles, alternative battery technologies are required for large scale energy storage applications. ${ }^{2-4}$

When considering large scale stationary energy storage, emphasis is placed on cost, accessibility and abundance of resources, in addition to the battery lifetime and hence electrode-level structural stability. ${ }^{5-7}$ As such, sodium-ion batteries, which can behave similarly to lithium-ion batteries, are a promising candidate. ${ }^{\mathbf{8}}$ Sodium is uniformly distributed across the earth and is the fourth most abundant element, which presents an opportunity to significantly reduce the cost of positive electrode materials. Layered oxides, Prussian blue analogues and polyanionic materials have been prominently reported as potential positive electrodes for sodium-ion batteries. ${ }^{9-11}$ Due to their high specific capacity and in many cases facile synthesis, layered oxides $\left(\mathrm{NaMO}_{2}, \mathrm{M}=\mathrm{Ti}, \mathrm{V}, \mathrm{Cr}, \mathrm{Mn}\right.$, $\mathrm{Fe}, \mathrm{Co}, \mathrm{Ni}, \mathrm{Cu}, \mathrm{Zn}, \mathrm{Li}$, and a mixture of multiple of these elements) are currently dominating the field of research. ${ }^{12,13}$ Through incorporation of multiple elements (electrochemically active and/or electrochemically inactive) on the $\mathbf{M}$ site significant improvements to the structural stability and hence reversible capacity have been made. Additionally, the voltage cut off and/or capacity limit can be tuned to minimise undesirable structural changes during cycling; the potential and capacity limit will likely be the same when charging at a slower current rate, whereas at higher current rates the voltage cut off is likely to be accessed before reaching the capacity limit yielding a lower capacity. This capacity in turn effects the amount of $\mathrm{Na}$ reversibly extracted upon charging and thus the charge compensation mechanism. Therefore, it is important to report the voltage, capacity, and current rate alongside structural data. ${ }^{\mathbf{1 4}}$

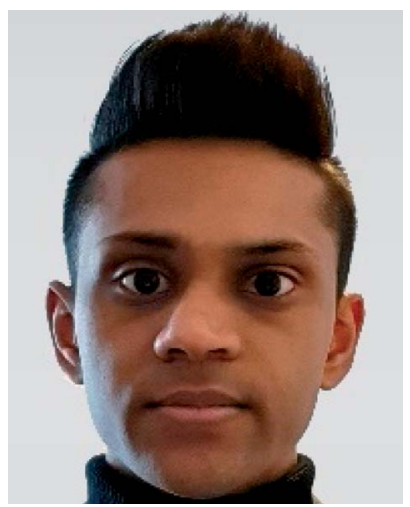

Damian Goonetilleke completed his PhD in Chemistry under the guidance of Assoc. Prof. Neeraj Sharma at the University of New South Wales, Australia (2019). His research focused on the operando characterisation of materials for energy storage devices. He is currently a postdoctoral researcher at the Battery and Electrochemistry Laboratory (BELLA), a joint lab of BASF SE and the Karlsruhe Institute of

Technology (KIT, Germany), where he investigates cathode materials for lithium-ion batteries.
The structure of layered oxides consists of repeating sheets of edge-sharing $\mathrm{MO}_{6}$ octahedra, which can (de-)intercalate alkali metal ions in between these layers. Differences in the relative orientation of adjacent metal oxide layers and hence stacking order gives rise to several unique crystal structures, for example, P2 (...ABBA...), O2 (...ABAC...), O3 (...АBCABC ...) and P3 (...ABBCCA...), see Fig. 1. The two main groups of sodium layered oxides are classified based upon the sodium co-ordination environment, P-type (trigonal prismatic) or O-type (octahedral). Unique phases are also labelled with a number which represents repeated $\mathrm{MO}_{6}$ layers within the unit cell. Finally, a prime symbol is used to indicate a monoclinic distortion. ${ }^{15}$ Upon synthesis, the total sodium content has a significant influence on the phase that forms. For $\mathrm{Na}_{x} \mathrm{MO}_{2}$, the P2 phase typically forms when $x \approx 0.7$, the O3 phase when $0.7 \leq$ $x \leq 1$ and the P3 phase when $x \approx 0.5$. Due to the varying thermodynamic stabilities of each phase, the synthesis temperature can also be used to control the polymorph that forms. For example, O3 and P3 phases typically form at lower temperatures than P2-type phases. ${ }^{16}$ The phase has important implications on electrochemical performance. For example, the P2 phase has a low diffusion barrier enabling faster diffusion kinetics. Whereas the O3 phase normally displays a higher capacity on the initial charge due to the higher Na content. ${ }^{17}$

The structural evolution of electrode materials during cycling provides valuable information about battery failure mechanisms. Upon charging, $\mathrm{Na}$ removal destabilises the structure resulting in rearrangement or layer gliding and in some cases phase transformation. For example, a P2 $\rightarrow \mathrm{O} 2$ transition results in a change in the $\mathrm{Na}$ co-ordination environment from trigonal prismatic to octahedral. ${ }^{19} \mathrm{As} \mathrm{Na}$ ions present a larger ionic radii than $\mathrm{Li}$ ions, larger volume changes often take place during cycling resulting in more complex structural evolution. As such, the performance of many primary layered materials $\left(\mathrm{Na}_{x} \mathrm{MO}_{2}\right.$, where $\mathrm{M}$ is a single transition metal element), which were initially studied, are plagued by undesired, irreversible phase transitions and hence unacceptable capacity fade upon cycling. ${ }^{20}$ Researchers have made significant progress in finding materials with minimal structural changes during operation, particularly through different doping regimes. In this review, pertinent examples of primary, secondary, tertiary and quaternary layered oxide systems $\left(\mathrm{Na}_{x}-\right.$ $\mathrm{MO}_{2}, \mathrm{M}$ is one, two, three or four different elements respectively) are presented. As the charged state is the most interesting from a structural viewpoint and the most common point of failure, (and arguably the most difficult to probe) this review focuses on the charged state structure of layered oxides and the associated techniques that have been used to probe the charged state.

\section{Stability of layered oxide positive electrodes during cycling}

The energy density which can be achieved from a sodium-ion cell (or any type of secondary battery) is given by the product of the specific capacity and the working voltage of the cell. The 


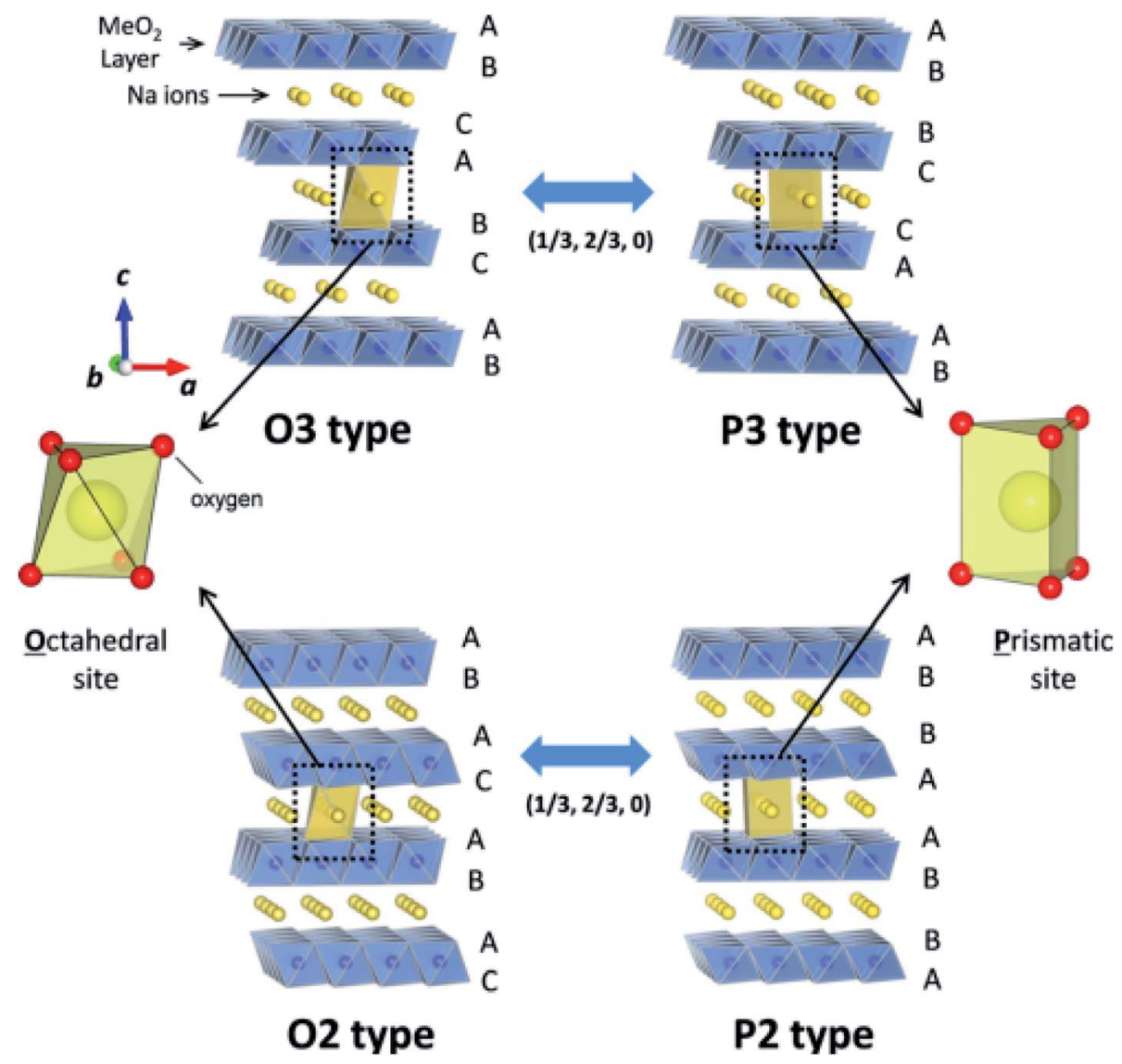

Fig. 1 Schematic illustration of the prominent crystal structures adopted by sodium layered oxides ( $\mathrm{NaMO}_{2}$ ), namely $\mathrm{O} 3$-type, $\mathrm{P} 3$-type, O2 type and P2-type according to the notation developed by Delmas et $a . .^{15}$ The $\mathrm{O}$ and $\mathrm{P}$-type structures are related via gliding of the transition metal slabs $\left(\mathrm{MO}_{2}\right)$ as depicted by the arrows. Reproduced with permission from ref. 18. Copyright 2014 American Chemical Society.

sodium content in the positive electrode decreases as the cell is charged to higher voltages, and hence in order to achieve high energy densities, a host material should be able to reversibly intercalate a large fraction of its sodium content. The ionic radius of $\mathrm{Na}(1.02 \AA)$ compared to $\mathrm{Li}(0.76 \AA)$ means that almost all first-row transition metal elements can form a layered $\mathrm{Na}_{x} \mathrm{MO}_{2}$ structure, and exhibit redox activity. In contrast, only Co and $\mathrm{Ni}$ can form primary layered $\mathrm{Li}_{x} \mathrm{MO}_{2}$ compounds. ${ }^{21}$ However, the different redox activity of these elements gives rise to complex phase transformations during cycling, particularly at the charged state. Irreversible phase transformations lead to rapid capacity fade and therefore ideally should be avoided. Gliding of the $\mathrm{MO}_{2}$ slabs may lead to $\mathrm{P} \rightarrow \mathrm{O}$ or $\mathrm{O} \rightarrow \mathrm{P}$ transitions which may be accompanied by large changes in the lattice parameters. ${ }^{20}$ The conversion between P-type and O-type stacking is thought to adversely affect the battery performance with regard to energy efficiency, rate capability and cycle stability. ${ }^{21}$ As such, the design and synthesis of novel layered transition metal oxides with high structural stability at the charged state, and minimal structural changes/rearrangements during cycling, could present a route towards more stable sodium-ion battery systems with higher energy densities.

\subsection{Phase transitions at the charged state}

The emergence of in situ characterisation techniques has enabled the identification of phase transitions and complex vacancy ordering mechanisms which take place at low sodium concentrations. In situ X-ray diffraction (XRD) has manifested as a particularly powerful tool for studying the structure-function relationships in layered oxide positive electrode materials. As such, irreversible phase transitions at the charged state have been identified as a major contributor to capacity fade. The various polymorphs of $\mathrm{Na}_{x} \mathrm{MO}_{2}$ undergo unique electrochemically driven phase transitions, with varying effects on battery performance. The characteristic behaviours of the different polymorphs are detailed below.

2.1.1 P2-type. The P2-type stacking sequence (...ABBA...) typically forms for $\mathrm{Na}_{x} \mathrm{MO}_{2}(0.5 \leq x \leq 0.75)$. Due to the open framework of the P2 structure, which presents direct sodium ion diffusion pathways between adjacent trigonal prismatic $\mathrm{Na}$ sites and therefore low activation energies for sodium ion diffusion, and excellent rate performance has been reported for P2-type materials. ${ }^{22}$ The lower Na content in P2-type materials (cf. O3-type) does however lead to smaller capacities. Furthermore, the formation of vacancies at high voltages may induce ordering of sodium ions and the vacant sites, leading to structural transitions which can have detrimental effects on the 
electrochemical performance of P2-type materials. ${ }^{23}$ At high voltages, sodium deficient P2-type electrodes may transition to an O2-type structure, with the stacking sequence (...ABAC....). Electrochemical formation of the $\mathrm{O} 2$ monophase in sodium layered oxide materials was first identified in the $\mathrm{P} 2-\mathrm{Na}_{2 / 3} \mathrm{Ni}_{1}$ / ${ }_{3} \mathrm{Mn}_{2 / 3} \mathrm{O}_{2}$ system above $4.35 \mathrm{~V}$, as illustrated in Fig. $2 .{ }^{24}$ The phase transformation takes place via gliding of the $\mathrm{MO}_{2}$ layers upon extraction of sodium from the P2 phase and has been reported to induce the formation of stacking faults. ${ }^{25}$

The greater stability of the O2-type structure at high voltages/ low Na content ( $c f$. P2-type) has since been demonstrated by computational calculations. ${ }^{22}$ The phase transformations upon cycling were characterised via synchrotron XRD and confirmed using first principle calculations. Similarly, the mobility of sodium ions in the starting P2-type $\mathrm{Na}_{2 / 3} \mathrm{Ni}_{1 / 3} \mathrm{Mn}_{2 / 3} \mathrm{O}_{2}$ structure was determined both experimentally and theoretically by the galvanostatic intermittent titration technique (GITT) and Nudged Elastic Band (NEB) calculations respectively. ${ }^{22}$ Both techniques revealed that the mobility of sodium ions in the P2 structure is faster than lithium ions in the analogous $\mathrm{O} 3$ structure, within the $1 / 3<x<2 / 3$ concentration region, demonstrating that these materials can deliver comparable performance to conventional positive electrode materials used in lithium-ion batteries. Significant shrinkage of the lattice parameters accompanies the $\mathrm{P} 2-\mathrm{O} 2$ transition. Consequently, the large volume change has detrimental effects on the electronic conduction path and may also give rise to voltage hysteresis, leading to poor battery performance. ${ }^{26}$ To achieve improved cyclability and capacity retention, it has been proposed that gliding of the transition metal layers should be avoided. ${ }^{27}$ The undesirable $\mathrm{P} 2-\mathrm{O} 2$ phase transition may be avoided by decreasing the voltage cut-off thereby limiting the amount of $\mathrm{Na}$ that is extracted from the structure. Cycling P2$\mathrm{Na}_{2 / 3} \mathrm{Ni}_{1 / 3} \mathrm{Mn}_{2 / 3} \mathrm{O}_{2}$ within the voltage range of 2.0-4.1 $\mathrm{V}$ leads to significantly improved capacity retention of $95 \%$ after 50 cycles, in comparison to a retention of $64 \%$ after 10 cycles when cycled between 2.0-4.5 V. ${ }^{22}$ Alternatively, at the cost of capacity, changing the composition of $\mathrm{P} 2-\mathrm{Na}_{2 / 3} \mathrm{Ni}_{1 / 3} \mathrm{Mn}_{2 / 3} \mathrm{O}_{2}$ with dopants such as $\mathrm{Cu}, \mathrm{Zn}$ or $\mathrm{Mg}$ enables the $\mathrm{P} 2-\mathrm{O} 2$ transition to be mitigated, as discussed in greater depth in Section $4 .^{28-30}$
While doping may evade the $\mathrm{P} 2-\mathrm{O} 2$ phase transition, the $\mathrm{P} 2-$ OP4 phase transition can instead be promoted. The OP4 phase is characterised by alternating stacking of octahedral $(\mathrm{O} 2)$ and trigonal prismatic (P2) layers along the $c$ axis. Consequently, the sodium ion vacancies are suggested to be located in the O-type layers, while the sodium ions remain in the P-type layers and can be considered as an intermediate, intergrowth phase between the $\mathrm{P} 2$ and $\mathrm{O} 2$ end members. ${ }^{31}$ Since the extent to which the transition metal layers glide upon extraction of sodium ions is minimised, the $\mathrm{P} 2-\mathrm{OP} 4$ phase transformation is more reversible ( $c f$. $\mathrm{P} 2-\mathrm{O} 2)$ and therefore leads to an improvement in the battery performance. ${ }^{32}$

The OP4-type phase was first reported for the $\mathrm{P} 2-\mathrm{Na}_{0.67}$ $\mathrm{Fe}_{0.5} \mathrm{Mn}_{0.5} \mathrm{O}_{2}$ material, upon charging above $4.1 \mathrm{~V}$. It was found to transition into a less crystalline phase with OP4-type stacking (Fig. 3)..$^{33}$ Below 3.8 V Yabuuchi et al. proposed that sodium ions are uniformly extracted from all layers, whereas above $3.8 \mathrm{~V}$, sodium ions are selectively extracted resulting in the P2-OP4 phase transition. Similarly, the $\mathrm{P} 2-\mathrm{Na}_{2 / 3} \mathrm{Fe}_{2 / 3} \mathrm{Mn}_{1 / 3} \mathrm{O}_{2}$ composition was also found to transform into the OP4 phase when charged above $4.0 \mathrm{~V}^{34}$ By increasing the Mn content to yield P2$\mathrm{Na}_{2 / 3} \mathrm{Fe}_{0.6} \mathrm{Mn}_{0.4} \mathrm{O}_{2}$, the P2-OP4 phase transition can be avoided. ${ }^{35}$ However, for the endmember $\left(\mathrm{P} 2-\mathrm{Na}_{0.67} \mathrm{MnO}_{2}\right)$ in which the $\mathrm{MO}_{2}$ layer is fully occupied by $\mathrm{Mn}$, the onset of the P2-OP4 was found to occur around $3.5 \mathrm{~V}$, corresponding to a plateau in the voltage profile. Interestingly, the detrimental effect of the P2-OP4 transition, namely larger polarization and greater capacity fade, was found to be more prominent in the quenched $\mathrm{P} 2-\mathrm{Na}_{0.67} \mathrm{MnO}_{2}$ sample compared to the analogous slow-cooled material, thereby demonstrating sensitivity of these materials to synthesis conditions. ${ }^{36}$

Removal of sodium ions upon charging gives rise to the formation of O-type stacking faults within the P2 structure. Consequently, the long-range order in layered oxide materials is modified or lost. In an XRD pattern, the loss of long-range order manifests as weaker, more diffuse peaks, as observed by Pang et al. upon extraction of sodium ions from $\mathrm{P} 2-\mathrm{Na}_{0.67} \mathrm{Fe}_{0.5^{-}}$ $\mathrm{Mn}_{0.5} \mathrm{O}_{2}$. Direct observation of the structural evolution via operando synchrotron XRD showed that the P2-OP4 transition proceeds via a solid-solution-like two-phase reaction. ${ }^{38}$ This

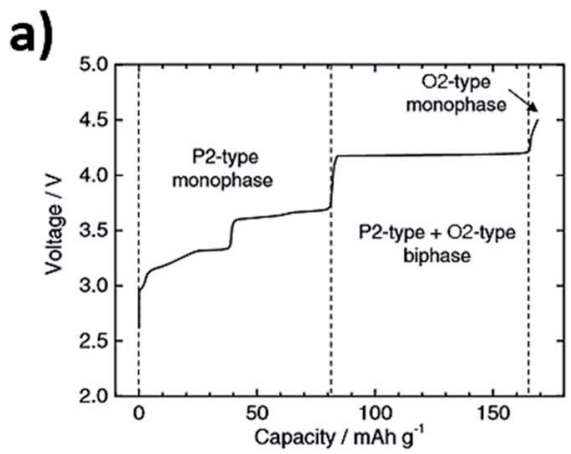

b)

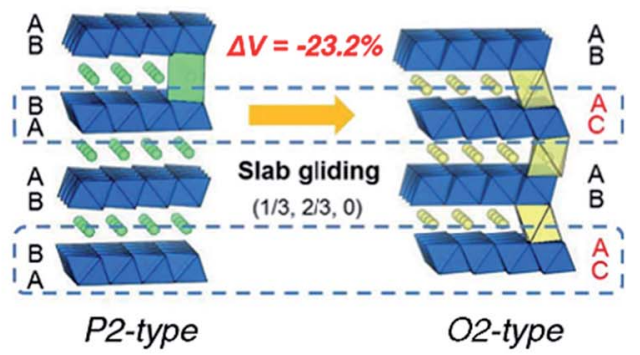

Fig. 2 (a) Voltage profile of $\mathrm{P} 2-\mathrm{Na}_{2 / 3} \mathrm{Ni}_{1 / 3} \mathrm{Mn}_{2 / 3} \mathrm{O}_{2}$ vs. $\mathrm{Na} / \mathrm{Na}^{+}$highlighting the formation of the O2-type phase. (b) Schematic illustration for the reversible $\mathrm{P} 2-\mathrm{O} 2$ phase transformation which takes place via gliding of the $\mathrm{MO}_{2}$ layers. Reproduced from ref. 24 under a CC BY 4.0 licence. 
a)

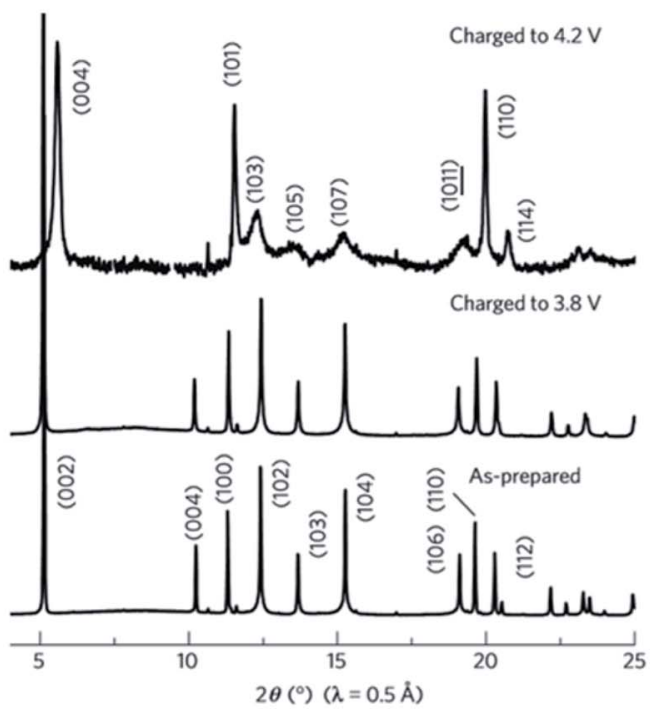

b)

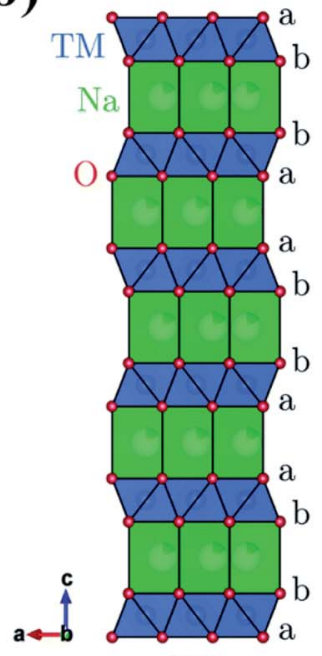

$\mathrm{P} 2$

Crystal Structures

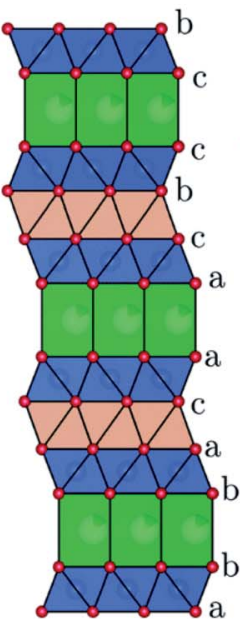

OP4

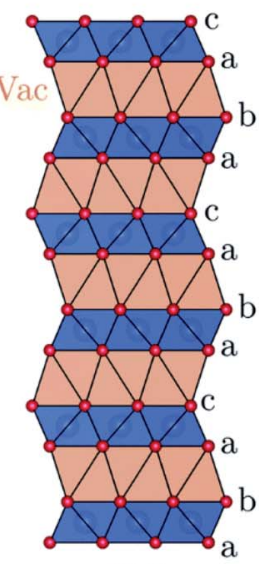

$\mathrm{O} 2$

Fig. 3 (a) XRD patterns showing the formation of the OP4-type phase when $\mathrm{P} 2-\mathrm{Na}_{x} \mathrm{Fe}_{1 / 2} \mathrm{Mn}_{1 / 2} \mathrm{O}_{2}$ is charged to $4.2 \mathrm{~V}$. (b) Projections of the P2, OP4 and $\mathrm{O} 2$ type crystal structures perpendicular to the stacking axis, highlighting the different stacking sequences. Reproduced from ref. 37 under a CC BY 3.0 licence.

solid-solution-like phase, associated with highly broadened XRD peaks, has since been termed the "Z phase". ${ }^{39}$

The " $\mathrm{Z}$ phase" can be thought of as a continuously changing intergrowth structure which may evolve from the initial P2-type structure to the O2-type structure, going through the ordered OP4 intermediate, see Fig. $4 .^{40}$ Upon charging, sodium ions which reside in between the $\mathrm{MO}_{2}$ layers are removed from the layered oxide structure leading to an increase in $\mathrm{O}-\mathrm{O}$ repulsion. The repulsion between the oxygen layers continues to destabilise the layered structure until gliding of the $\mathrm{MO}_{2}$ layers results in the formation of octahedral Na sites, which may be considered as O-type stacking faults. ${ }^{41}$ When the proportion of O-type stacking faults in a material reaches close to $50 \%$, the ordered OP4 phase can form and on further charging more Otype stacking faults may form until eventually the pure $\mathrm{O} 2$ structure is formed.

Overall, the structural damage from gliding of layers is less severe and more reversible for the $\mathrm{P} 2-\mathrm{OP} 4$ phase transition when compared with the $\mathrm{P} 2-\mathrm{O} 2$ transition. However, there is still a large and undesirable reduction in volume associated with the $\mathrm{P} 2-\mathrm{OP} 4$ transition and even with a transition to the " $\mathrm{Z}$ " phase. ${ }^{42}$ Significant improvements in the long-term electrochemical performance of layered oxide positive electrode materials have been reported when phase transitions at high potentials are avoided. ${ }^{43}$

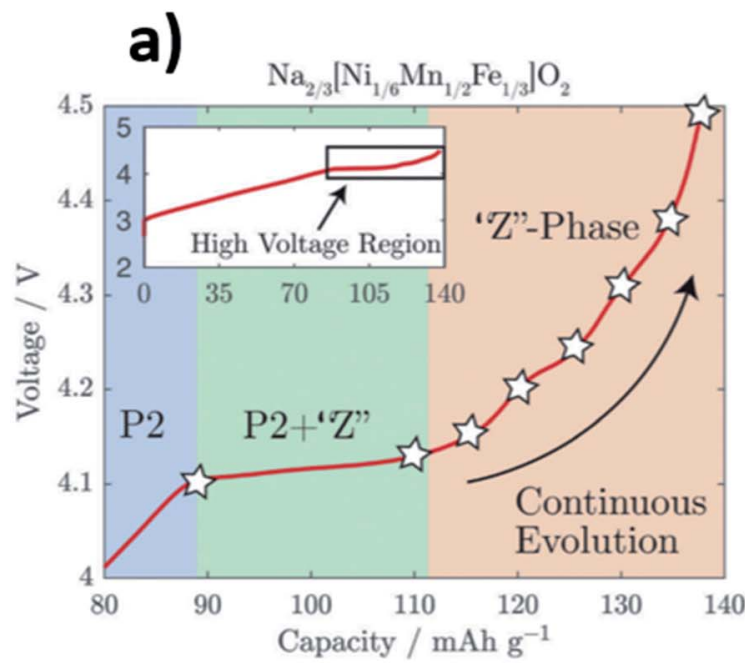

\section{b)}

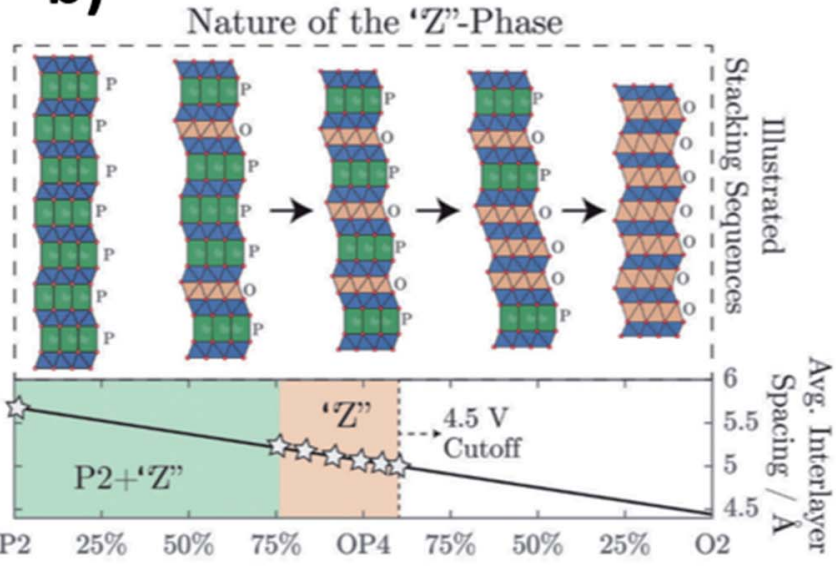

Fig. 4 (a) Voltage profile of $\mathrm{Na}_{2 / 3}\left[\mathrm{Ni}_{1 / 6} \mathrm{Mn}_{1 / 2} \mathrm{Fe}_{1 / 3}\right] \mathrm{O}_{2}$ highlighting the regions in which the " $\mathrm{Z}$ " phase forms. (b) Schematic illustration depicting the "Z" phase as a continuously changing intergrowth structure between P2 and O2. Reproduced from ref. 40 under a CC BY 3.0 licence. 


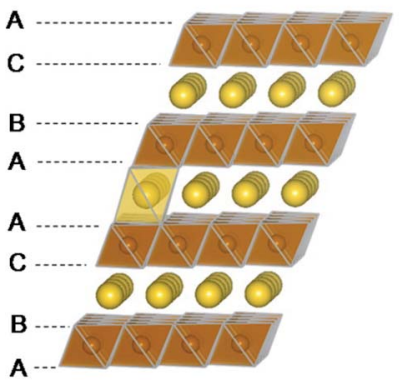

03

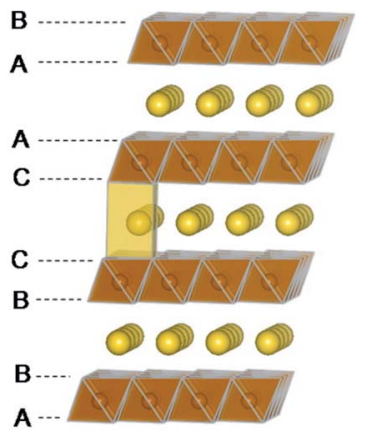

P3
Fig. 5 Illustrations of the O3-type and P3-type structures. The two structures are related to each other via layer gliding. Reproduced with permission from ref. 46. Copyright 2015 American Chemical Society.

2.1.2 O3-type. The O3-type (or $\alpha$-NaFeO ${ }_{2}$ ) stacking sequence is typically found for layered oxides with high $\mathrm{Na}$ concentration, $\mathrm{Na}_{x} \mathrm{MO}_{2}(x \geq 0.9) .{ }^{16}$ Owing to the higher $\mathrm{Na}$ content, O3-type materials usually display higher capacities than comparable P2-type compositions. However, the O-type framework is unfavourable for fast sodium ion diffusion and so O3-type materials also typically display poor rate capabilities. A high activation energy is required for diffusion of the relatively large sodium ions due the presence of a smaller tetrahedral site as part of the diffusion pathway between two adjacent octahedral sites. An O3-P3 phase transformation upon charging, which arises due to the gliding of $\mathrm{MO}_{2}$ layers (Fig. 5), is commonly observed in O3-type electrode materials. ${ }^{21}$ The transformation alters the $\mathrm{O} 3$ stacking sequence from ...ABCABC..., with an octahedral sodium environment, to ...AABBCC... with a trigonal prismatic sodium co-ordination environment in the P3-type phase. ${ }^{\mathbf{4 4}}$ Consequently, faster diffusion of sodium ions takes place throughout the material because there is a lower activation barrier for migration between adjacent prismatic sites. Therefore, presence of the O3-P3 transition is thought to enhance the rate capability of O3type electrodes. ${ }^{45}$

$\mathrm{NaVO}_{2}, \mathrm{NaFeO}_{2}, \mathrm{Na}_{2 / 3} \mathrm{Fe}_{2 / 3} \mathrm{Mn}_{1 / 3} \mathrm{O}_{2}$ and $\mathrm{Na}_{0.66} \mathrm{Mg}_{0.34} \mathrm{Ti}_{0.66} \mathrm{O}_{2}$ are a few exceptions of O3-type positive electrode materials that do not display the O3-P3 phase transformation upon charging. ${ }^{46-49}$ Alternatively, the O3-O' 3 monoclinic distortion of the original rhombohedral phase is observed for $\mathrm{NaVO}_{2}$ and $\mathrm{NaFeO}_{2}$, giving rise to poor rate capability in comparison to materials that display the O3-P3 transition. ${ }^{46,47}$ For $\mathrm{Na}_{2 / 3} \mathrm{Fe}_{2}$ / ${ }_{3} \mathrm{Mn}_{1 / 3} \mathrm{O}_{2}$ and $\mathrm{Na}_{0.66} \mathrm{Mg}_{0.34} \mathrm{Ti}_{0.66} \mathrm{O}_{2}$, a stable single-phase reaction mechanism is observed throughout the initial charge/ discharge cycle. ${ }^{\mathbf{4 8 , 4 9}}$

More complex structural evolution for O3-type positive electrodes has also been reported. For example, the quaternary O3- $\mathrm{Na}\left[\mathrm{Mn}_{0.25} \mathrm{Fe}_{0.25} \mathrm{Co}_{0.25} \mathrm{Ni}_{0.25}\right] \mathrm{O}_{2}$ positive electrode material undergoes the $\mathrm{O} 3-\mathrm{P} 3-\mathrm{O}^{\prime}-\mathrm{O}^{\prime \prime}$ sequence of phase transitions upon extraction of sodium ions, when cycled between 1.9-4.3 V at $\mathrm{C} / 10 .^{50}$ Kubota et al. synthesised a solid solution of $\mathrm{NaFeO}_{2}-$ $\mathrm{NaCoO}_{2}$ and found that upon charging up to $4.0 \mathrm{~V}$, the O3$\mathrm{NaFe}_{0.5} \mathrm{Co}_{0.5} \mathrm{O}_{2}$ composition transforms into a $\mathrm{P}$ 3-type phase via a biphasic reaction, and subsequently transforms to the monoclinic $\mathrm{P}^{\prime} 3$ type phase which was found to be coupled with sodium ion/vacancy ordering. Finally, as the composition approaches $\mathrm{Na}_{0.3} \mathrm{Fe}_{0.5} \mathrm{Co}_{0.5} \mathrm{O}_{2}$, an $\mathrm{O}^{\prime}$ type phase evolves, yielding an $\mathrm{O} 3-\mathrm{P} 3-\mathrm{P}^{\prime} 3-\mathrm{O}^{\prime}{ }^{\prime}$ sequence of phase transitions, see Fig. $6 .^{51}$

The insertion and extraction of sodium ions from the O3$\mathrm{NaNi}_{1 / 3} \mathrm{Mn}_{1 / 3} \mathrm{Co}_{1 / 3} \mathrm{O}_{2}$ composition was also found to be associated with several phase transitions. Upon charging, the structure was found to evolve through the O3-O1-P3-P1 sequence; significant changes in the $c$ lattice parameter were detected whereas the $a$ lattice parameter remained almost unchanged. ${ }^{52}$

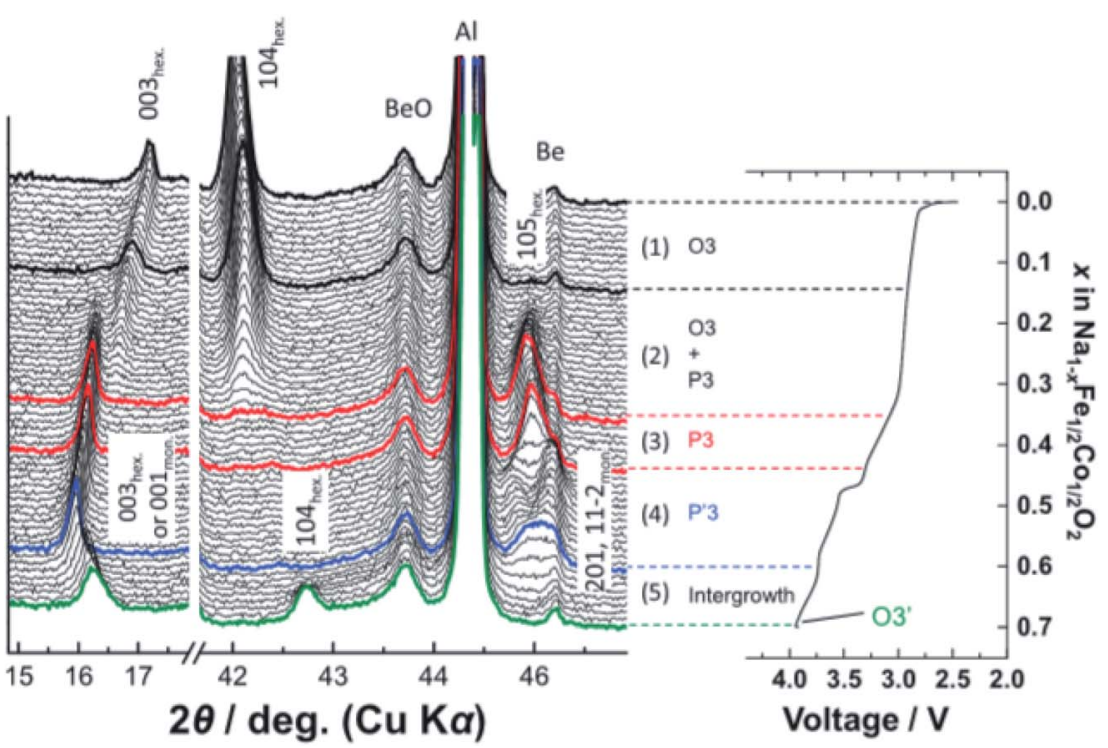

Fig. 6 In operando XRD data of $\mathrm{O} 3-\mathrm{NaFe}_{1 / 2} \mathrm{CO}_{1 / 2} \mathrm{O}_{2}$ which displays an $\mathrm{O} 3-\mathrm{P} 3-\mathrm{P}^{\prime} 3-\mathrm{O}^{\prime}$ sequence of phase transitions upon extraction of sodium ions. Reproduced with permission from ref. 51. 


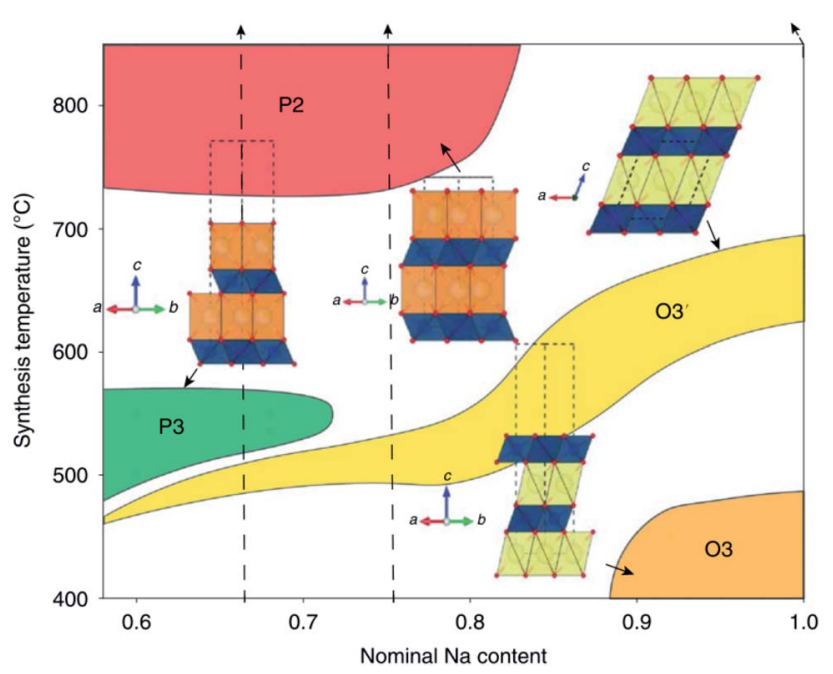

Fig. 7 Schematic illustration depicting the synthetic accessibility of $\mathrm{Na}_{x} \mathrm{CoO}_{2}$ polytypes. Reproduced with permission from ref. 16 .

Starting with the monoclinic $\mathrm{NaNiO}_{2}$ positive electrode material, new transient phases were discovered through investigations into the structural evolution. During charging, multiple phase transitions corresponding to the sequence: $\mathrm{O}^{\prime} 3-\mathrm{O}^{\prime \prime \prime \prime} 3-$ $\mathrm{P}^{\prime} 3-\mathrm{P}^{\prime \prime} 3-\mathrm{P}^{\prime \prime \prime} 3-\mathrm{O}^{\prime \prime} 3-\mathrm{O}^{\prime \prime \prime} 3$ were identified. ${ }^{53}$ The occurrence of so many structural transitions has since been associated with poor rate capability in layered oxide positive electrode materials. ${ }^{21}$ In particular, the large volume changes and thermodynamic instability of the high voltage $\mathrm{O}^{\prime \prime}$ phase has been associated with inferior cycling and rate performance for the Ni-rich O3-Na $\left[\mathrm{Ni}_{x} \mathrm{Fe}_{y} \mathrm{Mn}_{1-x-y}\right] \mathrm{O}_{2}(x=0.6,0.7$ and 0.8$)$ series. $^{54}$

2.1.3 P3-type. P3-type materials are typically formed by the extraction of sodium ions from O3-type positive electrodes upon charging. However, in some cases, it is possible to obtain the P3type phase through utilisation of lower sintering temperatures as shown in Fig. $7 .{ }^{16}$ Similar to P2 and O3-type phases, doping may also help to improve the performance of P3-type layered oxides. For example, Wang et al. found that substitution of a small quantity of oxygen for fluorine to form $\mathrm{Na}_{0.65} \mathrm{Mn}_{0.75^{-}}$ $\mathrm{Ni}_{0.25} \mathrm{~F}_{0.1} \mathrm{O}_{1.9}$ could suppress the P3-O1 transition. ${ }^{55}$

A unique feature of the P3-type layered oxides such as $\mathrm{Na}_{y^{-}}$ $\mathrm{Co}_{1-2 x} \mathrm{Ni}_{x} \mathrm{Mn}_{x} \mathrm{O}_{2}(x=1 / 2,1 / 3)$ is their ability to reversibly intercalate both $\mathrm{Na}$ and $\mathrm{Li}$ ions. ${ }^{56} \mathrm{P} 3-\mathrm{Na}_{0.67} \mathrm{Ni}_{1 / 2} \mathrm{Mn}_{1 / 2} \mathrm{O}_{2}$ can reversibly intercalate both $\mathrm{Na}$ and $\mathrm{Li}$ ions whereas the similar $\mathrm{P} 2-\mathrm{Na}_{0.67} \mathrm{Ni}_{1 / 3} \mathrm{Mn}_{2 / 3} \mathrm{O}_{2}$ composition does not display any reversible lithium intercalation. Desodiation of $\mathrm{P} 3-\mathrm{Na}_{0.67} \mathrm{Ni}_{1 /}$ ${ }_{2} \mathrm{Mn}_{1 / 2} \mathrm{O}_{2}$ in $\mathrm{Na}$ cells to form $\mathrm{Na}_{0.3} \mathrm{Ni}_{1 / 2} \mathrm{Mn}_{1 / 2} \mathrm{O}_{2}$ around $4.0 \mathrm{~V}$ instigates a monoclinic distortion accompanied by a large interlayer expansion. However, upon further desodiation, charging up to $4.5 \mathrm{~V}$, the monoclinic distortion disappears. In contrast, the $\mathrm{P} 2-\mathrm{Na}_{0.67} \mathrm{Ni}_{1 / 3} \mathrm{Mn}_{2 / 3} \mathrm{O}_{2}$ system retains the P2-type structure up to $4.0 \mathrm{~V}$ but displays the deleterious $\mathrm{P} 2-\mathrm{O} 2$ transition when charged to $4.5 \mathrm{~V} .^{57}$

Lithium intercalation into a sodium containing lattice has also been explored for the $\mathrm{P} 3-\mathrm{Na}_{x} \mathrm{Co}_{1 / 3} \mathrm{Ni}_{1 / 3} \mathrm{Mn}_{1 / 3} \mathrm{O}_{2}(0.38 \leq x \leq$ 0.75 ) system..$^{58}$ During cycling, the initial P3-type structure was found to transform into the O3-type structure, where both lithium and sodium ions coexist in the alkaline layers. Counterintuitively, a higher reversible capacity and improved cycling stability was found for sodium rich oxides $(0.75 \geq x \geq 0.67)$, compared to the equivalent sodium poor oxide $(0.38 \geq x \geq 0.5)$, suggesting reversible intercalation of both lithium and sodium following the initial discharge cycle. Cycling in sodium cells was not tested, likely due to the dominance of P2 and O3-type phases for sodium-ion batteries. In a comparison between analogous $\mathrm{P} 2$ and $\mathrm{P} 3-\mathrm{Na}_{x} \mathrm{Cr}_{0.63} \mathrm{Ti}_{0.37} \mathrm{O}_{2}$ compositions, Guo et al. found that the $\mathrm{P} 2$ phase displays better rate capability and cycling stability compared to the $\mathrm{P} 3$ phase, which can in part be explained by the lower Na diffusion barrier predicted by density functional theory (DFT) calculations for the P2 phase. ${ }^{59}$

\subsection{Gliding of transition metal layers}

As demonstrated above, interlayer gliding is widespread among $\mathrm{Na}_{x} \mathrm{MO}_{2}$ layered positive electrode materials and clearly plays a pivotal role in determining the structural stability near the charged state. To gain an atomistic understanding into the glide driven P- to O-type transitions, Arcelus et al. performed DFT calculations on the $\mathrm{Na}_{x} \mathrm{VO}_{2}$ system. ${ }^{60}$ The calculations showed that the energy barrier for gliding increases nearly linearly with increasing $\mathrm{Na}$ content and that the gliding process is mainly governed by electrostatic interactions. At low Na concentrations, the O-type structure becomes more thermodynamically stable, while at higher Na concentrations, the presence of $\mathrm{Na}$ in octahedral sites which share both edges and faces with neighbouring $\mathrm{VO}_{6}$ octahedra, as opposed to trigonal prismatic sites which only share either edges or faces, destabilises the structure. A special case is observed at $x=0.5$, characterised by the presence of two energy barriers in the calculated energy pathways for layer gliding, where reordering of the sodium ions appears to be a prerequisite to the gliding process. The authors also found that during a $\mathrm{P}$ to $\mathrm{O}$ transformation each individual sodium ion is swept into a distorted co-ordination environment by the moving transition metal layers. Depending on whether the Na ions originate from edge-sharing or face-sharing prismatic sites, they are either forced into a distorted square pyramidal, which presents a much higher energy barrier, or tetrahedral site, respectively. Due to the high energy barrier, sodium ions may diffuse to adjacent edge-sharing sites prior to gliding, as observed for the $\mathrm{Na}_{x} \mathrm{VO}_{2}(x=0.5)$ case. Moreover, the gliding can be mitigated by the presence of sufficient sodium ions occupying face-sharing sites which can be achieved at high Na concentrations $(x \geq 0.5)$, in keeping with the enhanced structural stability reported for the high Na-content P2-type $\mathrm{Na}_{45 / 54} \mathrm{Li}_{4 / 54} \mathrm{Ni}_{16 / 54} \mathrm{Mn}_{34 / 54} \mathrm{O}_{2}$ material, or via the introduction of electrochemically inactive elements to facilitate sodium ion/ vacancy disorder. ${ }^{\mathbf{6 0}, 61}$ Further computational and experimental studies on more complex transition metal layered oxide materials (containing multiple transition metals and/or Jahn Teller active transition metals) are welcomed to provide a deeper understanding into glide-driven processes at the charged state.

The wide variety of stacking sequences in $\mathrm{Na}_{x} \mathrm{MO}_{2}$ systems enables many complex phase transformations to take during 
sodium (de)intercalation. These phase transitions, associated with interlayer gliding to avoid oxygen-oxygen contacts, are unfavourable for battery performance and so the design of novel $\mathrm{Na}_{x} \mathrm{MO}_{2}$ layered materials should focus on suppressing gliding of the transition metal layers during cycling. Even reversible transformations are not desirable because they can have negative impacts on capacity retention by inducing stacking faults and lattice volume changes which can give rise to shear lattice strain. ${ }^{62}$ A comprehensive review into the adverse effect of interlayer gliding on the electrochemical performance of sodium layered transition metal oxides can be found in ref. 21 .

\subsection{Transition metal migration}

In addition to lateral movement of the transition metal layer, vertical migration of transition metal ions into the adjacent alkali layer may also take place upon charging. The structural stability of layered oxide materials at the charged state can be strongly correlated to migration of transition metals into the sodium layer, which is therefore a critical performance limiting factor. In particular, irreversible transition metal migration upon extraction of sodium ions may contribute towards poor thermal stability, fast capacity fading and voltage decay. ${ }^{63}$ Due to the similar ionic radii of $\mathrm{Li}^{+}$and the transition metal ions, cation migration behaviour is particularly prevalent in Li-based positive electrode materials. ${ }^{64-66}$ Despite the larger ionic radius of sodium ions, migration of transition metal ions upon charging has also been proposed for sodium-based positive electrode materials, primarily occurring in O3-type layered oxides such as O3-NaTiO $, 03-\mathrm{NaVO}_{2}, \mathrm{O} 3-\mathrm{NaCrO}_{2}$ and O3$\mathrm{NaFeO}_{2} \cdot{ }^{47,67-69}$

Migration of transition metal ions from the $\mathrm{MO}_{2}$ layer into the interlayer spacing in which sodium ions reside was first proposed in 1983 for the $\mathrm{Na}_{x} \mathrm{TiO}_{2}$ system to explain the occurrence of irreversible structural modifications at high voltages. ${ }^{67}$ A strong decrease in interslab distance and concomitant loss of cycling reversibility upon increasing the upper voltage limit was also observed for $\mathrm{Na}_{x} \mathrm{VO}_{2}$ and $\mathrm{Na}_{x} \mathrm{CrO}_{2}$ suggesting that migration of vanadium and chromium ions may take place in a similar manner. ${ }^{47,68} \mathrm{~A}$ follow up study by Bo et al. revealed that up to a composition of $\mathrm{Na}_{0.4} \mathrm{CrO}_{2}$ no $\mathrm{Cr}$ migration could be detected. However, upon further extraction of $\mathrm{Na}$, formation of a rock salt structure via an intermediate phase that contains $\mathrm{Cr}$ in both the $\mathrm{Na}$ and transition layer takes place. ${ }^{20}$

The high abundance and low cost of Fe makes Fe containing electrodes appealing for sodium battery applications. However, akin to the compositions mentioned above, the reversibility of Fe-rich materials can, in some cases, be limited by the migration of Fe into the sodium layer. This idea was first proposed by Yabuuchi et al. for $\mathrm{O} 3-\mathrm{Na}_{1-x} \mathrm{FeO}_{2}(x>0.5)$ and later supported by Li et al. via high resolution transmission electron microscopy (HRTEM) as well as Silvan et al. who tracked the migration of Fe with electrochemical impedance spectroscopy (EIS), operando XRD and the potentiostatic intermittent titration technique (PITT). ${ }^{69-71}$ The $\mathrm{O} 3-\mathrm{NaFeO}_{2}$ material exhibited migration of $\mathrm{Fe}$ into the sodium layer when charged beyond $40 \%$ of its theoretical capacity, and when charged above $4.0 \mathrm{~V}$ the migration became irreversible, as depicted in Fig. 8. The migration was found to shrink the interlayer distance, in contrast to the expansion observed as sodium is extracted from the majority of layered positive electrodes, due to $\mathrm{O}-\mathrm{O}$ repulsion. This limited the available capacity likely by blocking sodium ion diffusion, highlighting that transition metal migration can be a significant source of performance degradation at high voltages. Of note was the finding that a proportion of the transition metal migration could be reversible with electrochemical cycling, acting to both stabilise the structure and deliver capacity. This suggests that transition metal migration can be optimised to preserve structure and deliver optimal capacity.

The irreversible migration of transition metal ions has also been shown to inhibit structural transitions during cycling. For
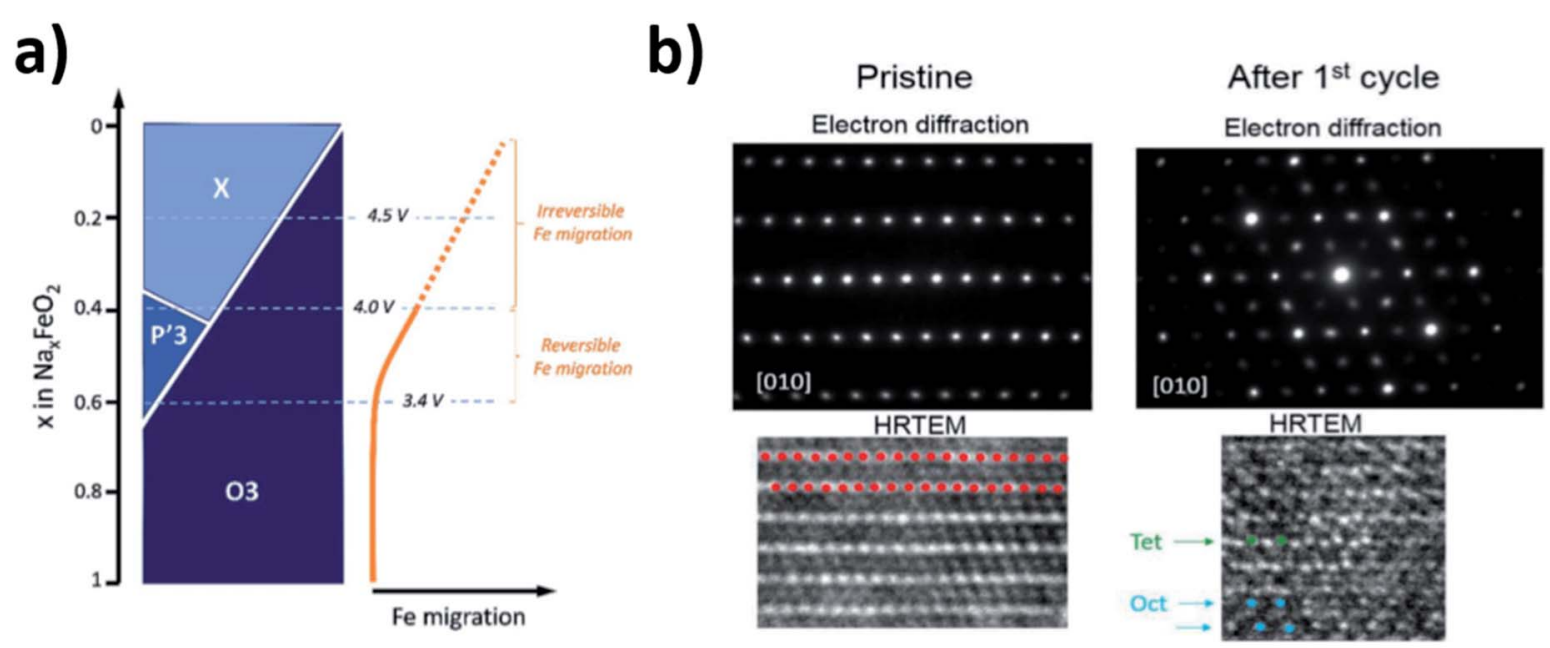

Fig. 8 (a) Schematic illustration of the phase evolution and Fe migration upon extraction of $\mathrm{Na}$ for $\mathrm{Na}_{x} \mathrm{FeO}_{2}$. Reproduced with permission from ref. 74. (b) Electron diffraction and HRTEM images of $\mathrm{Na}_{x} \mathrm{FeO}_{2}$ after 1 cycle between 2.0 and $4.5 \mathrm{~V}$ at a rate of $\mathrm{C} / 10$. Red dots represent the transition metal layer, green dots represent Fe migrated to tetrahedral sites and blue dots represent Fe migrated to octahedral sites. Reproduced with permission from ref. 70. Copyright 2016 American Chemical Society. 
example, migration of transition metal ions into the Na layer of O3 $-\mathrm{Na}_{0.8} \mathrm{Ni}_{0.3} \mathrm{Co}_{0.3} \mathrm{Ti}_{0.6} \mathrm{O}_{2}$ during the initial charge cycle was found to inhibit the reversibility of the O3-P3 phase transformation, thus leading to rapid capacity fade upon subsequent cycling. ${ }^{72}$ Furthermore, transition metal cations located on tetrahedral sites in the alkali metal layer are thought to block the diffusion of sodium ions, giving rising to poor rate performance. ${ }^{73}$ However, if the reversibility of the cation migration is regulated, these drawbacks can be mitigated. In fact, transition metal migration in $\mathrm{P} 2-\mathrm{Na}_{0.67}\left[\mathrm{Mn}_{0.66} \mathrm{Fe}_{0.2} \mathrm{Cu}_{0.14}\right] \mathrm{O}_{2}$ was found to coincide with anionic redox activity, which allows additional capacity to be extracted from a battery. ${ }^{27}$

Through utilisation of X-ray pair distribution function (PDF) analysis, Talaie et al. showed that reversible migration of $\mathrm{Fe}$ in P2- $\mathrm{Na}_{0.67-z} \mathrm{Fe}_{0.5} \mathrm{Mn}_{0.5} \mathrm{O}_{2}$ takes place at high potentials. ${ }^{43}$ Migration of the transition metal ions into a tetrahedral coordination within the Na layer perturbs the long-range order. As such PDF analysis, a technique that can be used to probe semi crystalline phases with short range order, was employed to confirm the reversible migration of the transition metals. More migration was found to take place upon extracting $\mathrm{Na}$ from the Fe-rich $\mathrm{Na}_{x} \mathrm{Fe}_{0.5} \mathrm{Mn}_{0.5} \mathrm{O}_{2}$ material in comparison to $\mathrm{Na}_{x} \mathrm{Fe}_{0.2^{-}}$ $\mathrm{Mn}_{0.65} \mathrm{Ni}_{0.15} \mathrm{O}_{2}$. DFT calculations performed by Li et al. show that the energy barrier for Fe migration reduces as the $\mathrm{Fe}$ content in Fe rich transition metal oxides increases. Furthermore, they reported Fe migration to be fully suppressed in compositions that contain less than $\approx 30 \%$ Fe in addition to quaternary $\left(\mathrm{Na}_{x} \mathrm{MM}^{\prime} \mathbf{M}^{\prime \prime} \mathbf{M}^{\prime \prime \prime} \mathrm{O}_{2}\right)$ compositions. ${ }^{70}$

Utilising high-angle annular dark field (HAADF) scanning transmission electron microscopy (STEM), direct observation of reversible transition metal migration in the $\mathrm{O} 3-\mathrm{Na}_{0.8} \mathrm{Co}_{0.4} \mathrm{Ti}_{0.6^{-}}$ $\mathrm{O}_{2}$ positive electrode material has been reported. ${ }^{63}$ The HAADFSTEM images, shown in Fig. 9, enabled direct visualisation of the structure on an atomic scale; upon charging significant presence of transition metal ions in the sodium layers can be seen. The observations were supported by operando XRD which show a decrease in the $c$ lattice parameter deep into charging, attributed to the larger positive charge of the transition metal ion $\left(c f . \mathrm{Na}^{+}\right)$residing in the sodium layer, thereby reducing electrostatic repulsion between oxygen atoms. Furthermore, electron density maps of the difference between observed and calculated XRD patterns revealed presence of electron density for the transition metal ions in the sodium layer. A schematic plot of the reversible transition metal migration process, along with the phase transitions, upon charging for $\mathrm{O} 3-\mathrm{Na}_{0.8} \mathrm{Co}_{0.4^{-}}$ $\mathrm{Ti}_{0.6} \mathrm{O}_{2}$ is shown in Fig. 10.

Inevitably, a number of works have since associated $c$ lattice contraction close to the charged state with transition metal migration. While transition metal migration can be expected to induce a contraction in the interlayer distance, shrinkage of the $c$ lattice parameter upon extraction of sodium ions has also been related to ordering of the sodium ion vacancies and phase transitions. ${ }^{71,75,76}$ However, rationalising these alternative explanations is somewhat more challenging. As such, uncertainties regarding the role of transition metal migration in phase transformations, such as formation of the " $Z$ phase" from an initial P2-type structure, still remain. Therefore, advanced techniques such as HAADF-STEM, PDF or Mössbauer spectroscopy that enable the direct observation of transition metal

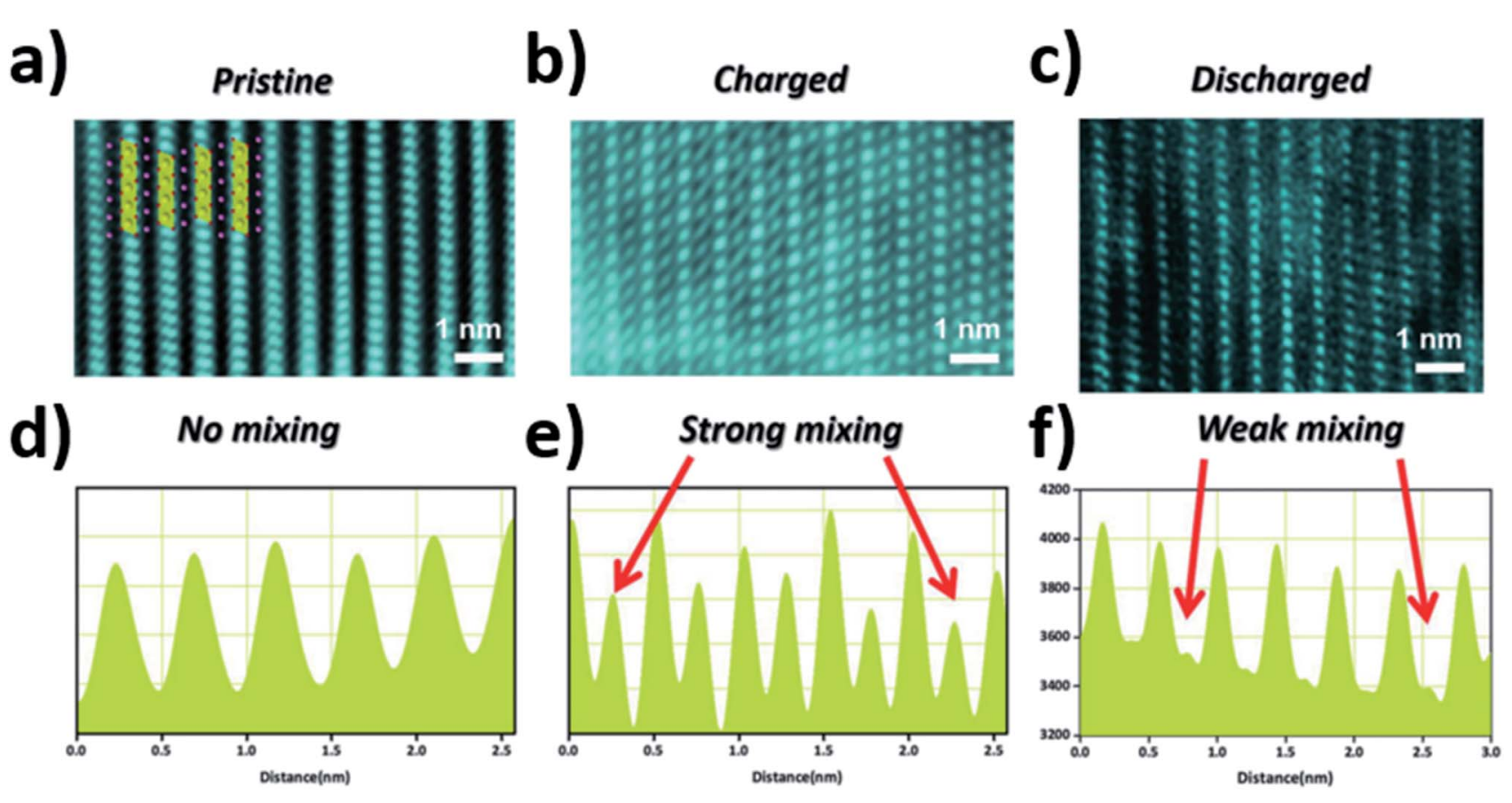

Fig. 9 STEM images of the (a) pristine (b) charged (c) discharged electrodes viewed along the [010] direction and (d-f) their corresponding line profiles where the red arrows highlight the intensities corresponding to transition metal migration from the transition metal layers to the sodium layers. Reproduced with permission from ref. 63. 
Pristine material (03 Structure)

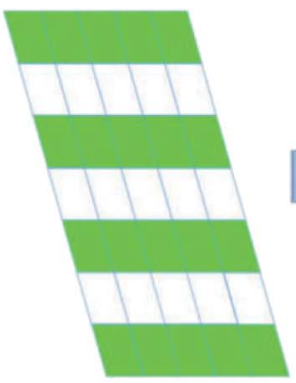

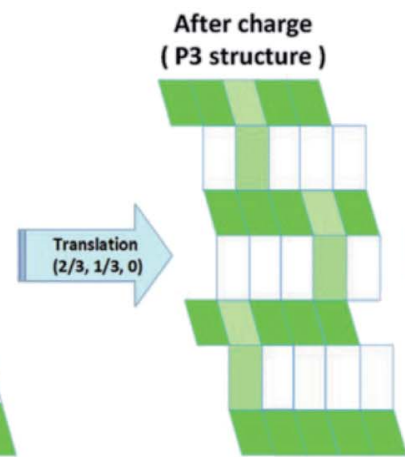

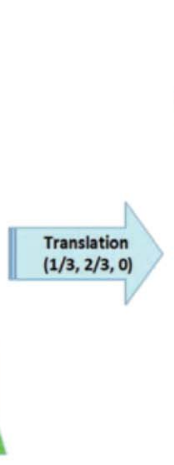

After discharge

( 03 structure)

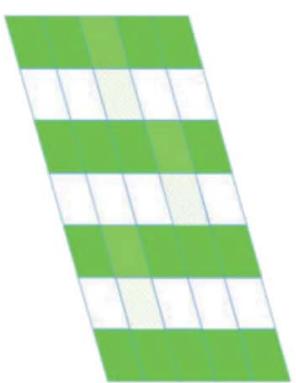

Transition metal

Occupancy Fraction

1

Transition metal slab

Sodium metal slab in $\mathrm{O3}$

Sodium metal slab in P3

Transition metal migration

Fig. 10 Schematic plot of the reversible transition metal migration upon cycling for $\mathrm{O} 3-\mathrm{Na}_{0.8} \mathrm{CO}_{0.4} \mathrm{Ti}_{0.6} \mathrm{O}_{2}$. Reproduced with permission from ref. 63.

migration should ideally be utilised to confirm its occurrence and overall mechanism.

There are two possible sites available in the O3-type structure for transition metal migration into the alkali metal layer: octahedral or tetrahedral sites. ${ }^{6}{ }^{8}$ Since the energy difference between the tetrahedral and octahedral $\mathrm{Na}$ sites in the $\mathrm{NaCrO}_{2}$ material is small, $\approx 40 \mathrm{meV}$, Kubota et al. proposed that both sites may be almost evenly occupied by $\mathrm{Cr}$ ions. ${ }^{68}$ For the $\mathrm{Na}_{0.8} \mathrm{Co}_{0.4} \mathrm{Ti}_{0.6} \mathrm{O}_{2}$ system, Zhang et al. used Fourier difference maps to locate migrated transition metal ions within the sodium layer. ${ }^{77}$ The maps suggest that the migrated ions are situated on the octahedral interstitial sites directly in line with the oxygen atoms and are not pinned directly below the vacancy in the transition metal layer.

To identify the preferential site for Fe migration in $\mathrm{NaFeO}_{2}$ Silván et al. performed simulations to model the migration of $\mathrm{Fe}$ to $\mathrm{Na}$ octahedral sites or $\mathrm{Na}$ tetrahedral sites in different proportions. ${ }^{71}$ By comparing these results with operando XRD pattern evolution it was possible to identify that the $\mathrm{Fe}$ in $\mathrm{NaFeO}_{2}$ preferentially migrates to the tetrahedral sites. This suggests that tetrahedral sites in the Na layer need to be available for transition metal migration to occur. The preferential migration to the tetrahedral site in the Na layer has also been reported by Li et al. on the $\mathrm{NaFeO}_{2}$ system, ${ }^{78}$ as well as Talaie et al. on the $\mathrm{P} 2-\mathrm{Na}_{2 / 3}\left[\mathrm{Mn}_{1 / 2} \mathrm{Fe}_{1 / 2}\right] \mathrm{O}_{2}$ composition (upon transformation to an O2-type structure at high voltages)..$^{43}$ Due to the absence of tetrahedral sites within the Na layer in P-type structures, this would imply that transition metal migration is inhibited in P-type phases, or it is only observed when there is sufficient local O-type ordering (considering the gliding of planes described in Sections 2.1 and 2.2).

To gain a greater understanding of which transition metal ions preferentially migrate into the Na layer during electrochemical cycling, Chen et al. used atomic resolution scanning tunnel electron microscopy in combination with energy dispersive X-ray spectrometry (STEM-EDS) elemental mapping to study the quaternary $\mathrm{NaNi}_{0.3} \mathrm{Co}_{0.12} \mathrm{Mn}_{0.12} \mathrm{Fe}_{0.4} \mathrm{O}_{2}$ composition. ${ }^{79}$ They found that Fe migrates into both tetrahedral and octahedral sites within the Na layer, as depicted in Fig. 11. In contrast, Ni was found to predominantly migrate to the octahedral sites while $\mathrm{Mn}$ and Co mostly remained in the transition metal layers. Similarly, Guo et al. found that upon charging $\mathrm{Na}_{0.8} \mathrm{Ni}_{0.3} \mathrm{Co}_{0.1} \mathrm{Ti}_{0.6} \mathrm{O}_{2}$ some $\mathrm{Ni}$ atoms do reside in the $\mathrm{Na}$ layers whereas $\mathrm{Ti}$ and $\mathrm{Co}$ atoms mainly reside in the transition metal layer..$^{72}$ The strong electrostatic interactions (attraction with the oxygen layers, leading to a decrease in the interlayer spacing, and repulsion with the approaching sodium ions) induced by the migrated transition metal ions is thought to have a detrimental impact on the reinsertion of sodium ions. ${ }^{79}$

Using DFT simulations, Zhang et al. went on to show that the energy penalty for migration of a transition metal ion is influenced by its neighbouring transition metal ions. ${ }^{80}$ More specifically, they showed that the shortened $\mathrm{Fe}-\mathrm{O}$ bond length with neighbouring $\mathrm{Cu}$ (due to the large electronegativity of $\mathrm{Cu}$ ) can significantly enhance the energy penalty, effectively preventing the $\mathrm{Fe}$ migration into the Na layer. Oxidation of $\mathrm{Fe}^{3+}$ to produce Jahn-Teller active $\mathrm{Fe}^{4+}$ ions accompanied by ligand to metal charge transfer (LMCT) from O orbitals to Fe orbitals thereby weakening the bonding to neighbouring atoms has also been suggested to facilitate migration of Fe into the Na layer. ${ }^{27,78}$ To support this idea, Li et al. performed DFT calculations on $\mathrm{NaMO}_{2}(\mathrm{M}=\mathrm{Mn}, \mathrm{Co}, \mathrm{Ni}, \mathrm{Fe})$ systems to show that when $\mathrm{Fe}$ is forced to be in the low spin, Jahn-Teller inactive spin state, the energy barrier for migration significantly increases to values as high as those in non-Fe containing systems. ${ }^{70}$

In lithium-rich layered oxides, transition metal migration has been identified as a critical factor in triggering anion redox, allowing extra capacity to be extracted upon charging. ${ }^{66}$ Furthermore, transition metal migration in the $\mathrm{Li}\left(\mathrm{Li}_{0.2} \mathrm{Ni}_{0.4}{ }^{-}\right.$ $\left.\mathrm{Mn}_{0.4}\right) \mathrm{O}_{2}$ system was found to be reversible but asymmetric; upon deintercalation, transition metal migration into the alkali metal layer is followed by random hopping (displacement) and subsequently upon intercalation, the transition metal ions do not follow precisely the reverse pathway, thus inhibiting or influencing lithium diffusion. Similar mechanistic insights regarding transition metal migration and the (de)intercalation mechanism close to the charged state in sodium-based systems would help to facilitate the development of sodium-ion battery positive electrodes with improved electrochemical performance. 
a)

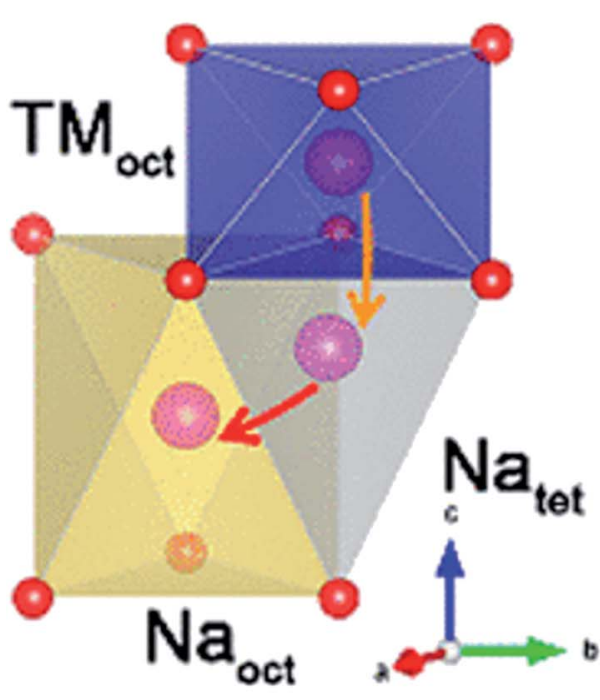

b)
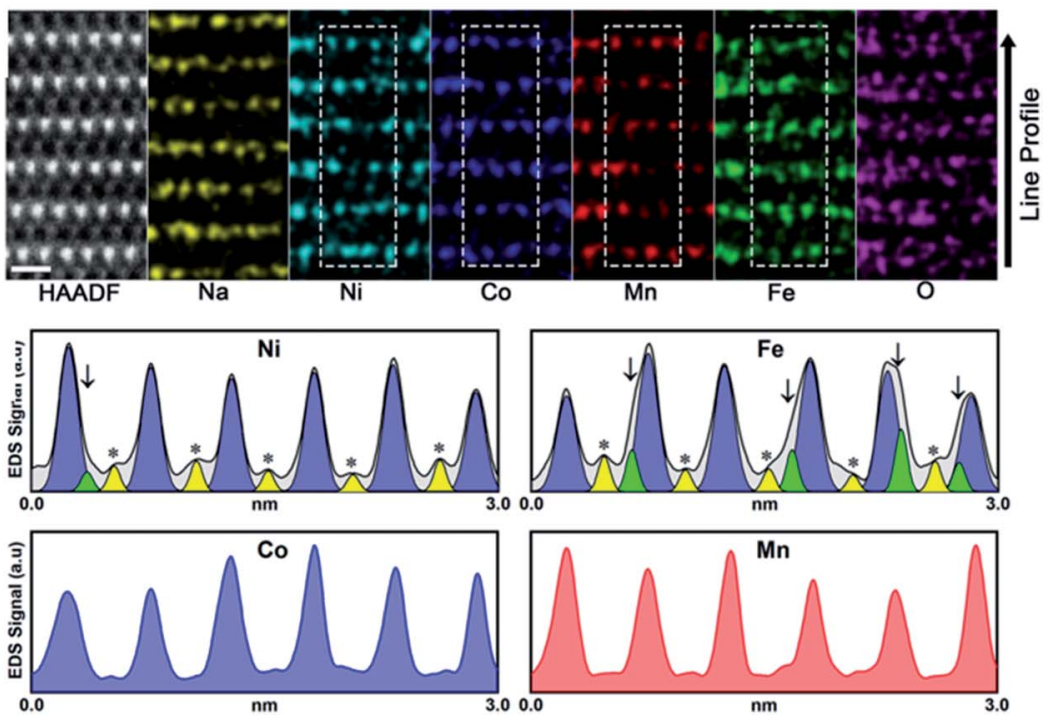

Fig. 11 (a) Schematic of the transition metal migration pathway in an O3-type material showing the available Na tetrahedral and Na octahedral sites. (b) Atomic resolution STEM-HAADF image and EDS elemental mapping of the $\mathrm{NaNi}_{0.3} \mathrm{Co}_{0.12} \mathrm{Mn}_{0.12} \mathrm{Fe}_{0.4} \mathrm{O}_{2}$ material after 50 cycle shown along the [100] axis together with EDS mapping line profiles of $\mathrm{Ni}, \mathrm{Fe}, \mathrm{Co}$ and $\mathrm{Mn}$. Yellow peaks marked with asterisks indicate transition metal octahedra in the Na layer and green peaks marked with arrows indicate transition metal tetrahedral in the Na layer. Reproduced with permission from ref. 79. Copyright 2020 American Chemical Society.

In summary, irreversible transition metal migration upon charging sodium layered oxides should be avoided to achieve an improved electrochemical performance. Reversible transition metal migration on the other hand may help to stabilise the charged state structure of sodium layered oxides and deliver additional capacity, alongside anionic redox activity.

\subsection{Anionic redox activity}

Operation of batteries at high voltages may also enable the redox activity of anions in layered oxide materials, such as $\mathrm{O}$, to be accessed through anionic redox reactions (ARR). ARR active materials allow for extra capacity to be extracted from positive electrodes by utilising the charge on oxygen atoms. ${ }^{81}$ This behaviour has been documented in several metal oxide systems for lithium-ion batteries, for example $\mathrm{Li}\left[\mathrm{Li}_{0.2} \mathrm{Ni}_{0.2} \mathrm{Mn}_{0.6}\right] \mathrm{O}_{2}$ among others, ${ }^{82-86}$ and a detailed explanation into the science underlying anion redox chemistry can be found in ref. 87. ARR activity has also been observed in various layered positive electrode materials for sodium-ion batteries, including Na-rich materials ${ }^{88,89}$ as well as P2-type and O3-type materials. ${ }^{90,91} \mathrm{~A}$ recent review article regarding the mechanism of anionic redox specifically in sodium layered oxides together with a table summarising the pertinent sodium-based materials that have been reported to display anionic redox activity can be found in ref. 92.

In both $\mathrm{Na}$ and $\mathrm{Li}$ based transition metal oxide systems, there are two distinct mechanisms associated with oxygen redox activity. In their simplest form, these are reversible anionic redox between oxo- $\left(\mathrm{O}^{2-}\right)$ and peroxo-like $\left(\mathrm{O}_{2}\right)^{n-}$ species and irreversible anionic redox during which $\mathrm{O}_{2}$ gas is released. ${ }^{93}$ High metal to oxygen covalency has been identified to play a critical role in stabilising the highly reactive intermediate $\left(\mathrm{O}_{2}\right)^{n-}$ species, thereby enabling reversible ARR. ${ }^{86}$ The metastable $\left(\mathrm{O}_{2}\right)^{n-}$ species may also be stabilised by reorganisation of the oxygen network (the reductive coupling mechanism) or localisation via the generation of localised electron holes on the oxygen atoms. ${ }^{94}$ If the $\left(\mathrm{O}_{2}\right)^{n-}$ species cannot be stabilised through metal-oxygen interactions, they may react with the electrolyte, or break free from the adjacent transition metal ion, resulting in the complete oxidation of $\mathrm{O}^{2-}$ to elemental oxygen and release of $\mathrm{O}_{2}$ gas, characteristic of irreversible ARR. ${ }^{95} \mathrm{While}$, oxygen redox activity may be concomitant with migration of transition-metal ions, House et al., showed that, vacancies in the transition metal layer are not required to trigger loss of oxygen. ${ }^{27,96}$ In summary, the goal is to develop materials that display fully reversible redox activity i.e. no loss of $\mathrm{O}_{2}$ gas during the process.

The difference in ionic radii and electronegativities between sodium and lithium ions means that the knowledge and understanding of anionic redox in lithium-ion batteries cannot necessarily be directly transposed to sodium-based systems. For example, the $\mathrm{Li}_{2} \mathrm{MnO}_{3}$ system displays a high capacity of up to $200 \mathrm{~mA} \mathrm{~h} \mathrm{~g}^{-1}$ with a long plateau in the voltage profile around $4.5 \mathrm{~V}$, characteristic of anion redox activity. However, likely due to the mismatch in size between $\mathrm{Mn}^{4+}(0.53 \AA)$ and $\mathrm{Na}^{+}(1.02 \AA)$, the $\mathrm{Na}$ counterpart $\mathrm{Na}_{2} \mathrm{MnO}_{3}$ is yet to be synthesised. ${ }^{97}$ Additionally, in contrast to the Li series, formation of $\mathrm{O}_{2}{ }^{n-}$ species 
via anionic redox processes for $\mathrm{Na}_{2} \mathrm{Ru}_{1-y} \mathrm{Sn}_{y} \mathrm{O}_{2}(y>0.5)$ is followed by the irreversible loss of $\mathrm{O}_{2} \cdot{ }^{98}$

Existing investigations into anion redox activity in positive electrodes for lithium-ion batteries provide a good foundation for exploration of ARR in sodium-ion batteries. Considering the high capacity and redox activity reported for Li-rich layered materials such as $\mathrm{Li}_{1.2} \mathrm{Nb}_{0.5} \mathrm{Mn}_{0.5} \mathrm{O}_{2}{ }^{99}$ and $\mathrm{Li}_{4} \mathrm{Mn}_{2} \mathrm{O}_{5},{ }^{100}$ Perez et al. investigated the possibility of exploiting anionic redox participation in the Na-rich layered material $\mathrm{Na}_{2} \mathrm{IrO}_{3}$; simultaneous cationic and anionic redox processes were found to take place at potentials as low as $2.7 \mathrm{~V} v s$. $\mathrm{Na} / \mathrm{Na}^{+} \cdot{ }^{101}$ Furthermore, no cationic migration or release of $\mathrm{O}_{2}$ took place upon cycling. Similar redox reactions have been reported in other Na-rich layered oxides including $\mathrm{Na}_{3} \mathrm{RuO}_{4},{ }^{89} \quad \mathrm{Na}_{2} \mathrm{SeO}_{3},{ }^{102}$ $\mathrm{Na}_{2} \mathrm{Mn}_{3} \mathrm{O}_{6.85},{ }^{103} \mathrm{Na}_{2} \mathrm{Mn}_{3} \mathrm{O}_{7},{ }^{104}$ and $\mathrm{Na}_{1.2} \mathrm{Mn}_{0.4} \mathrm{Ir}_{0.4} \mathrm{O}_{2} .{ }^{105}$

Inspired by the prominent $\mathrm{Li}_{2} \mathrm{MnO}_{3}$ system, in which $\mathrm{Mn}$ has an oxidation state of $4+$, the $\mathrm{P} 2-\mathrm{Na}_{0.6} \mathrm{Li}_{0.2} \mathrm{Mn}_{0.8} \mathrm{O}_{2}$ composition was investigated, where the $\mathrm{Mn}$ atoms also adopt a $4+$ oxidation state. De la Llave et al. proposed, based upon electrochemical data and DFT calculations, that anion redox processes contribute to the capacity at high voltages. ${ }^{97}$ In alignment with these observations, Maitra et al. used P2- $\mathrm{Na}_{2 / 3}\left[\mathrm{Mg}_{0.28} \mathrm{Mn}_{0.72}\right] \mathrm{O}_{2}$ as an example to further demonstrate that excess alkali metal ions are not required to activate oxygen redox activity. ${ }^{\mathbf{1 0 6}}$ Moreover, they proposed that removal of alkali metal ions from both the alkali ion and transition metal layers of alkali rich layered oxides such as $\mathrm{Li}\left[\mathrm{Li}_{0.2} \mathrm{Ni}_{0.13} \mathrm{Co}_{0.13} \mathrm{Mn}_{0.54}\right] \mathrm{O}_{2}$ leads to under co-ordinated oxygen and non-bonded, electron deficient $\mathrm{O} 2 \mathrm{p}$ states which promotes the release of $\mathrm{O}_{2}$. Since the oxygen in $\mathrm{P} 2-\mathrm{Na}_{2 / 3}\left[\mathrm{Mg}_{0.28} \mathrm{Mn}_{0.72}\right] \mathrm{O}_{2}$ is always co-ordinated to at least three cations no oxygen loss, was observed experimentally, in line with the theory. Overall, the work highlights that suppressing oxygen loss is imperative if the ARR is to be practically used in battery applications.
$\mathrm{P} 2-\mathrm{Na}_{2 / 3} \mathrm{Mn}_{1-y} \mathrm{Zn}_{y} \mathrm{O}_{2}(0<y<0.23)^{107}$ and $\mathrm{P} 2-\mathrm{Na}_{0.78} \mathrm{Li}_{0.25^{-}}$ $\mathrm{Mn}_{0.75} \mathrm{O}_{2}{ }^{96}$ are additional examples of Na-deficient compositions that display ARR without loss of oxygen upon charging up to $4.5 \mathrm{~V}$. Alike the $\mathrm{Mg}$ counterpart, their anionic redox activity is thought to arise from presence of $\mathrm{O} 2 \mathrm{p}$ nonbonding orbitals, created by substituting Mn for elements that form bonds with oxygen which are more ionic in character. ${ }^{\mathbf{1 0 7}}$ When charged up to $5 \mathrm{~V}$ loss of oxygen can be detected from $\mathrm{P} 2-\mathrm{Na}_{0.78} \mathrm{Li}_{0.25}$ $\mathrm{Mn}_{0.75} \mathrm{O}_{2}$. At such high voltages, $\mathrm{Li}^{+}$may be removed from the structure. Consequently, oxygen becomes co-ordinated to less than 3 cations and is lost from the structure. ${ }^{96}$ In contrast, the low mobility of $\mathrm{Mg}^{2+}$ in $\mathrm{P} 2-\mathrm{Na}_{2 / 3}\left[\mathrm{Mg}_{0.28} \mathrm{Mn}_{0.72}\right] \mathrm{O}_{2}$ means that at least three cations co-ordinate to oxygen $\left(2 \times \mathrm{Mn}^{4+}\right.$ and $1 \times$ $\left.\mathrm{Mg}^{2+}\right)$, even at the surface, and so the oxygen does not become under bonded, hence mitigating oxygen loss.

Taking advantage of the high operating voltage of Ni containing positive electrodes and the oxygen redox activity displayed by $\mathrm{Na}_{2 / 3}\left[\mathrm{Zn}_{0.3} \mathrm{Mn}_{0.7}\right] \mathrm{O}_{2},{ }^{108}$ Konarov et al. designed and synthesised the $\mathrm{Na}_{2 / 3}\left[\left(\mathrm{Zn}_{0.5} \mathrm{Ni}_{0.5}\right)_{0.3} \mathrm{Mn}_{0.7}\right] \mathrm{O}_{2}$ electrode. ${ }^{109}$ Through utilising the $\mathrm{Ni}^{2+/ 4+}$ and $\mathrm{O}^{2-} / \mathrm{O}^{-}$redox pairs, $\mathrm{Na}_{2 / 3^{-}}$ $\left[\left(\mathrm{Zn}_{0.5} \mathrm{Ni}_{0.5}\right)_{0.3} \mathrm{Mn}_{0.7}\right] \mathrm{O}_{2}$ is an exemplar high voltage anionicbased positive electrode material for use in sodium-ion batteries. ${ }^{\mathbf{1 1 0}}$

More recently, increasing the covalency of the TM-O bond has been shown to be effective in suppressing oxygen release, hence improving electrochemical performance. ${ }^{86}$ The TM-O distance and TM-O bonding energy have also been identified as important factors in determining the activity and reversibility of the oxygen redox reaction. For example, Kong et al. showed that the shortening of TM-O bonds and enhanced TM-O bonding energy through synergic $\mathrm{Cu} / \mathrm{Mg}$ co-doping improves the oxygen redox reversibility. ${ }^{111}$

Participation of oxygen anions in the charge compensation mechanism has also been explored in the transition metal

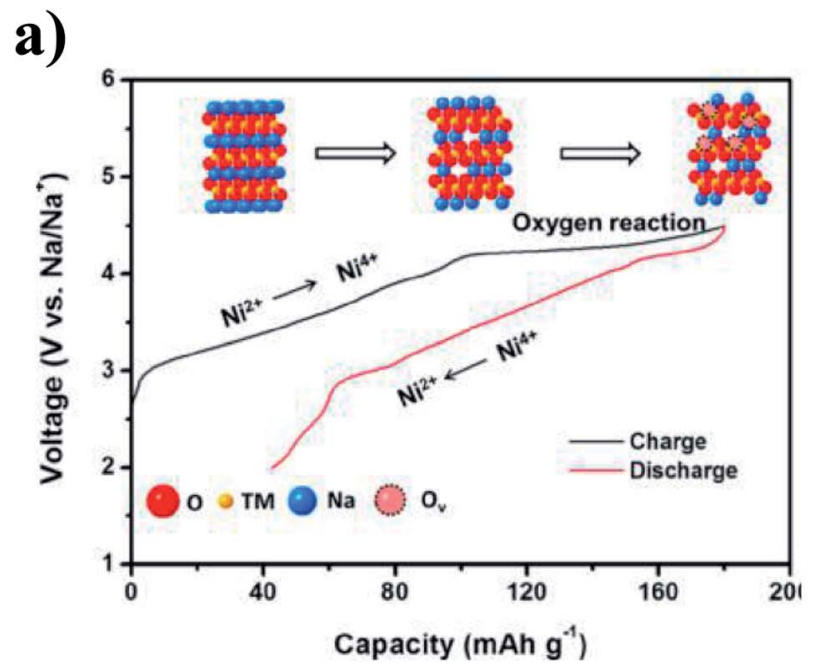

b)

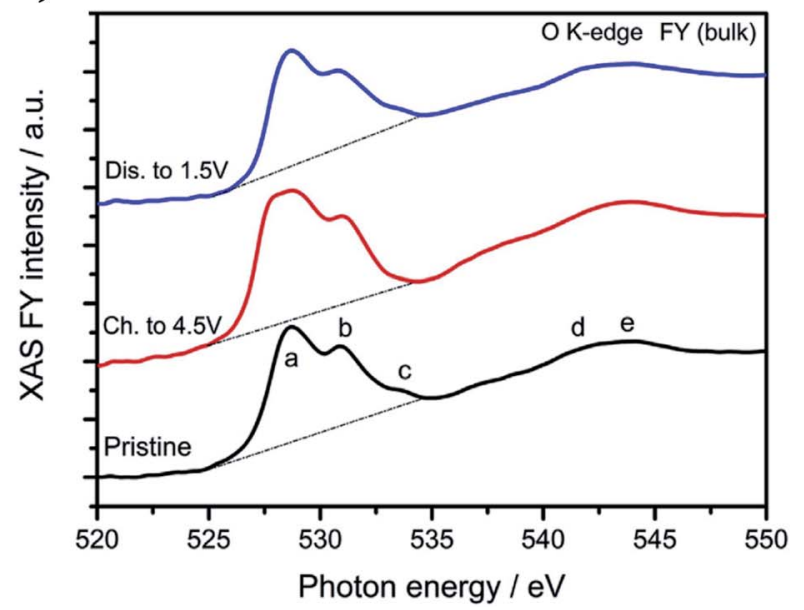

Fig. 12 (a) Observed voltage profile for $\mathrm{P} 2-\mathrm{Na}_{0.78} \mathrm{Ni}_{0.23} \mathrm{Mn}_{0.69} \mathrm{O}_{2}$, highlighting the charge compensation mechanisms involved. Reproduced with permission from ref. 113. Copyright 2017 American Chemical Society. (b) O K-edge XAS data collected from the pristine $\mathrm{P} 2-\mathrm{Na}_{2 / 3} \mathrm{Ni}_{1 / 3} \mathrm{Mn}_{2 / 3} \mathrm{O}_{2}$ material, and after extraction at the charged and discharged states during the first electrochemical cycle. Reproduced with permission from ref. 112. 
a)
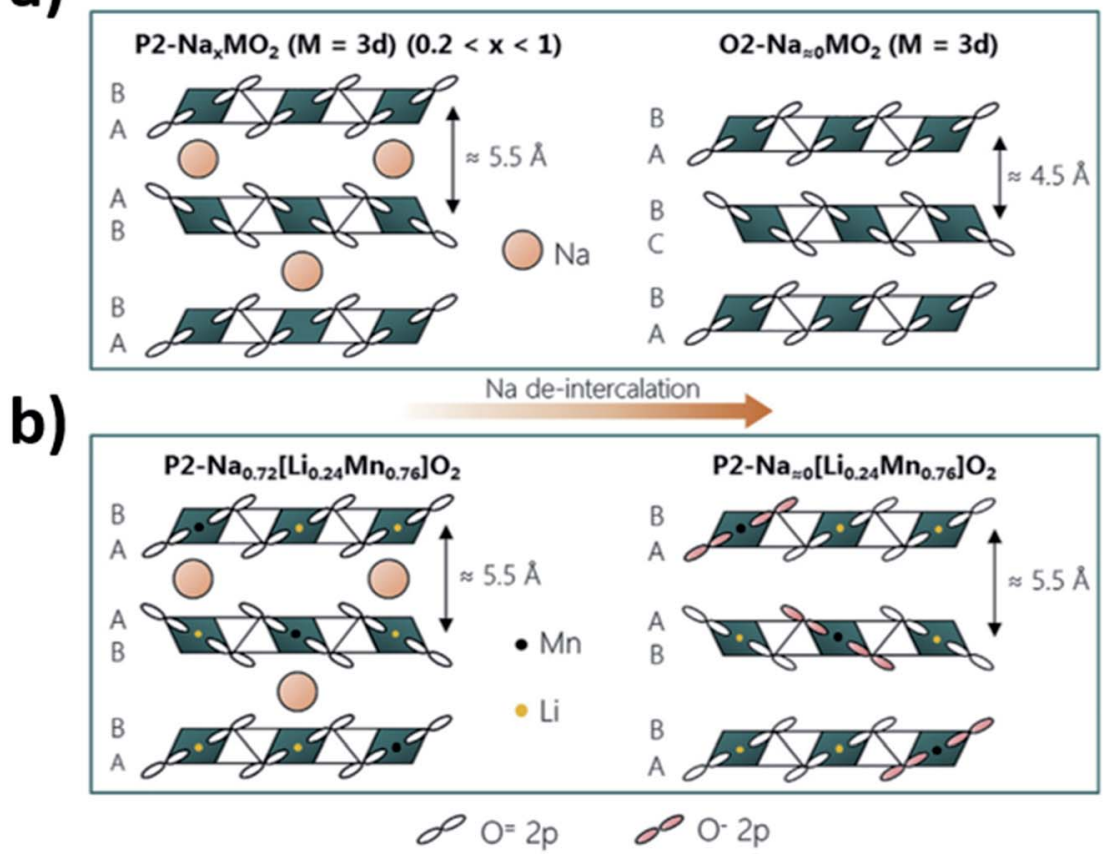

Fig. 13 Comparison of the structural changes that may take place upon extraction of sodium ions from (a) P2-type layered oxides that do not display oxygen redox activity and (b) the $\mathrm{P} 2-\mathrm{Na}_{0.72}\left[\mathrm{Li}_{0.24} \mathrm{Mn}_{0.76} \mathrm{O}_{2}\right.$ phase for which oxygen oxidation (highlighted in pink) partakes in the charge compensation mechanism. Reproduced with permission from ref. 115.

deficient $\mathrm{P} 2-\mathrm{Na}_{0.78} \mathrm{Ni}_{0.23} \mathrm{Mn}_{0.69} \mathrm{O}_{2}$ and sodium deficient O3$\mathrm{Na}_{0.6} \mathrm{Li}_{0.2} \mathrm{Fe}_{0.4} \mathrm{Ru}_{0.4} \mathrm{O}_{2} \cdot{ }^{26,82}$ At high voltages, a plateau region associated with oxygen redox reaction was found to account for the $60 \mathrm{~mA} \mathrm{~h} \mathrm{~g}{ }^{-1}$ of capacity in excess of the theoretical capacity of $\mathrm{Na}_{0.78} \mathrm{Ni}_{0.23} \mathrm{Mn}_{0.69} \mathrm{O}_{2}$, as highlighted in Fig. 12a. Moreover, electron energy loss spectroscopy (EELS) data showed the ARR behaviour to be concurrent with the particle-level formation of a surface to bulk transition metal oxidation state gradient as well as structural transformations at the surface of the cycled particles. Similar to $\mathrm{Na}_{0.78} \mathrm{Ni}_{0.23} \mathrm{Mn}_{0.69} \mathrm{O}_{2}$, a gradient in the valence state of $\mathrm{Ni}$ ions from the bulk to the surface was observed for the charged electrode, which coincided with a change in intensity of the $\mathrm{O}$ K-edge peak, as shown by Fig. $12 \mathrm{~b}$. The ARR activity in $\mathrm{P} 2-\mathrm{Na}_{2 / 3} \mathrm{Ni}_{1 / 3} \mathrm{Mn}_{2 / 3} \mathrm{O}_{2}$ accounts for the observed capacity of $228 \mathrm{~mA} \mathrm{~h} \mathrm{~g}{ }^{-1}$ which is much higher than the theoretical value of $172 \mathrm{~mA} \mathrm{~h} \mathrm{~g}^{-1}$ based on cationic redox. ${ }^{112}$

Through comparison of X-ray photoelectron spectroscopy (XPS), operando Raman spectroscopy and electrochemical data, Jia et al. found that compared to the sodium deficient O3$\mathrm{Na}_{0.6} \mathrm{Li}_{0.2} \mathrm{Fe}_{0.4} \mathrm{Ru}_{0.4} \mathrm{O}_{2}$, reversible anionic redox activity is more easily triggered in the $\mathrm{P} 2-\mathrm{Na}_{0.6} \mathrm{Li}_{0.35} \mathrm{Fe}_{0.1} \mathrm{Ru}_{0.55} \mathrm{O}_{2}$ material when charged up to $4.0 \mathrm{~V}$, enabling the P2-type material to deliver a larger capacity. ${ }^{\mathbf{8 2}}$ Furthermore, when the two similar materials were charged beyond $4.3 \mathrm{~V}$, only the O3-type structure displayed evidence of irreversible oxygen evolution and superoxide species which is in keeping with the more stable cycling performance reported for $\mathrm{P} 2-\mathrm{Na}_{0.6} \mathrm{Li}_{0.35} \mathrm{Fe}_{0.1} \mathrm{Ru}_{0.55} \mathrm{O}_{2}$ in comparison to the O3-type material.
Reversibility of oxygen redox at high rates was first reported in $\mathrm{P} 2-\mathrm{Na}_{0.6}\left[\mathrm{Mg}_{0.2} \mathrm{Mn}_{0.6} \mathrm{Co}_{0.2}\right] \mathrm{O}_{2}{ }^{110}$ DFT calculations suggest that the overlapping Co $3 \mathrm{~d}$ and $\mathrm{O} 2 \mathrm{p}$ orbitals as well as the reduced bandgap of $\approx 0.61 \mathrm{eV}(c f$. $\approx 2.65 \mathrm{eV}$ for the analogous Co free composition) upon incorporation of Co facilitates facile electron transfer, enabling long term oxygen redox reversibility. Transition metal (Ni) 3d-O 2p hybridization has also been reported to play an important role in stabilizing the anion redox activity of $\mathrm{P} 3-\mathrm{Na}_{0.67} \mathrm{Ni}_{0.2} \mathrm{Mn}_{0.8} \mathrm{O}_{2}$, which displays oxygen redox activity when charged to $4.4 \mathrm{~V}^{114}$

The utilisation of the anion redox reaction has been associated with increased structural stability of layered oxide materials upon cycling. This is thought to be due to a reduced coulombic repulsion achieved via anion redox. Upon deintercalation, the negative charge carried by oxygen decreases with the oxidation of oxygen, minimizing the repulsions between the two oxygen layers between the empty or low concentration Na layers. As shown by Fig. 13, smaller variations in the interslab distance may take place upon cycling P2 materials that undergo ARR compared to those that do no display oxygen redox activity. ${ }^{\mathbf{1 1 5}}$ Utilization of ARR in Mn-rich materials, such as $\mathrm{P} 2-\mathrm{Na}_{0.72}\left[\mathrm{Li}_{0.24} \mathrm{Mn}_{0.76}\right] \mathrm{O}_{2}$, could be particularly beneficial as distortions associated with Jahn-Teller active $\mathrm{Mn}^{3+}$ can be mitigated if $\mathrm{Mn}$ retains an oxidation state of $4+$.

The additional capacity that can be accessed by triggering anion redox activity may be associated with some of unfavourable side effects such as irreversible cation migration, lower sodium ion diffusion and the release of $\mathrm{O}_{2}$ gas, resulting in accelerated capacity and voltage decay upon cycling. ${ }^{\mathbf{1 0 1}}$ 
Although limiting the voltage cut-off can be an effective method to mitigate unwanted phase transformations, it also means that all the additional capacity from ARR is not accessed. Through incorporation of small amounts of electrochemically inactive elements such as Li, these structural transitions can be delayed to higher voltages. ${ }^{26}$ Overall, if the deleterious release of $\mathrm{O}_{2}$ gas and irreversible phase transformations can be avoided while accessing the high voltage ARR of oxygen, a significant improvement in capacity can be achieved. A synergistic optimisation of sodium extraction, reversible oxygen redox and reversible transition metal migration could help to minimise lattice-based structural distortions at high voltage and therefore better stability and energy density from these electrodes.

\section{Improving the structural stability of layered oxides at the charged state}

\subsection{Chemistry and composition}

In layered oxide materials, when sodium ions occupy sites between the $\mathrm{MO}_{6}$ layers, their electrons enter the available d orbitals of the transition metals in the host lattice. The mobility of the sodium ions and electrons, and the electrochemical potential of the electrode, is hence heavily dependent on the valance state, ionic radius, electronegativity and local environment of the cations (M) in the host lattice. ${ }^{116,117}$ While most studies have focused on improvements to specific capacity, it is also important to understand and consider the electrochemical potential of the material during cycling, the influence of electrode chemistry on ionic and electronic conductivity, the reversibility of intercalation reactions, and the structural stability of the positive electrode material. In reality, these factors will have a more profound effect on the applicability of new materials in devices which require high energy densities and reliable cycling performance at variable current densities.

In the layered oxide structure, which contains sheets of edge sharing $\mathrm{MO}_{6}$ octahedra, the redox activity of the central, coordinated atom strongly influences the stability of the material during (de-)intercalation from the adjacent sodium layers. The layered structure is stabilised by the large difference in ionic radii between $\mathrm{Na}$ and $\mathrm{M}$, and thus various metals can be incorporated into the structure to influence the electronic state. $^{\mathbf{1 1 8}}$ Initially unary compositions, containing a single element in the transition metal layer, such as $\mathrm{NaCoO}_{2}, \mathrm{NaNiO}_{2}$, or $\mathrm{NaMnO}_{2}$ were reported. ${ }^{119}$ Early investigations of unary compounds were limited to lower working voltages due to the unavailability of electrolytes resistant to oxidation by transition metals such as $\mathrm{Cr}$, Co or Ni. ${ }^{67,120}$ Additionally, these compounds tend to deliver relatively low specific capacities as the upper cutoff voltage must be limited due to structural instabilities at low $\mathrm{Na}$ contents. $\mathrm{NaTiO}_{2}$ suffers from poor reversibility below $x \approx$ 0.7 , as the trivalent state of $\mathrm{Ti}$ is unstable. ${ }^{67}$ More recent studies suggest a capacity of $152 \mathrm{~mA} \mathrm{~h} \mathrm{~g}^{-1}$ can be achieved, accompanied by a reversible $\mathrm{O} 3-\mathrm{O}^{\prime} 3$ transition. ${ }^{\mathbf{1 2 1}} \mathrm{NiNiO}_{2}$ can reversibly intercalate up to $x \approx 0.5$, however extracting further capacity by increasing the cut-off voltage leads to significant reductions in coulombic efficiency due to transitions to an electrochemically inactive phase. ${ }^{122} \mathrm{~A}$ cut-off voltage of $3.75 \mathrm{~V}$ limits the first cycle capacity to $\approx 120 \mathrm{~mA} \mathrm{~h} \mathrm{~g}^{-1}$, in comparison to a capacity exceeding $180 \mathrm{~mA} \mathrm{~h} \mathrm{~g}{ }^{-1}$ when cycled to $4.5 \mathrm{~V}^{123} \mathrm{NaCrO}_{2}$ can similarly reversibly intercalate about half of its sodium content, however the process is accompanied by structural transitions, O3-O' $3-\mathrm{P}^{\prime} 3 .^{120}$ Given the success of its Li-containing analogue, several polymorphs of $\mathrm{NaCoO}_{2}$ have been reported. ${ }^{\mathbf{1 2 4 - 1 2 6}}$ Compared to $\mathrm{LiCoO}_{2}$, all types of $\mathrm{NaCoO}_{2}$ exhibit several plateaus in their electrochemical profiles as the material transitions between structures with different sodium ion/vacancy ordering and varying $\mathrm{Na}^{+}-\mathrm{Co}^{3+/ 4+}$ (low-spin, high-spin) interactions. ${ }^{126}$ Among the unary compounds, $\mathrm{NaMnO}_{2}$ delivers a relatively high capacity of $190 \mathrm{~mA} \mathrm{~h}^{-1}$ in both the O3-type and P2type form. ${ }^{127,128} \mathrm{Mn}$ can achieve several valence states, however the high-spin $\mathrm{Mn}^{3+}$ state is unstable and induces distortion of the $\mathrm{MnO}_{6}$ octahedra due to the Jahn-Teller effect. ${ }^{129}$ Finally, O3$\mathrm{NaFeO}_{2}$, with Fe favoured for its abundance and environmental inertness, can reversibly cycle to $3.5 \mathrm{~V}$, but the narrow working voltage range limits the reversible capacity of just $80 \mathrm{~mA} \mathrm{~h} \mathrm{~g}^{-1} \cdot{ }^{69}$ Further extraction of sodium results in the migration of $\mathrm{Fe}^{3+}$ into tetrahedral sites which can impede the diffusion of sodium ions on subsequent cycles. ${ }^{\mathbf{4 6}, 78}$

Each of these unary compounds clearly exhibits unique electrochemical behaviour despite structural similarity. By combining solid-solutions of elements with varying redox behaviours, interesting co-operative effects can result in improved electrochemical performance. Binary combinations of the above elements, such as $\mathrm{Na}_{x}\left[\mathrm{Mn}_{y} \mathrm{Fe}_{1-y}\right] \mathrm{O}_{2}, \mathrm{Na}_{x}\left[\mathrm{Mn}_{y^{-}}\right.$ $\left.\mathrm{Mg}_{1-y}\right] \mathrm{O}_{2}$, or $\mathrm{Na}_{x}\left[\mathrm{Ni}_{y} \mathrm{Mn}_{1-y}\right] \mathrm{O}_{2}$, have been reported which offer increased working voltages and reversible capacities. ${ }^{33,130-132}$ Incorporation of further elements has led to more complex compositions, including ternary and quaternary or quinary compositions containing several elements. ${ }^{133-137}$ These more complex compositions have been synthesised in an attempt to smooth the electrochemical profile and suppress irreversible phase transitions at the charged state. For example, the combination of $\mathrm{Co}, \mathrm{Mn}$ and $\mathrm{Ti}$ has been reported by Wang et al., in the ternary $\mathrm{P} 2-\mathrm{Na}_{0.66} \mathrm{Co}_{0.22} \mathrm{Mn}_{0.44} \mathrm{Ti}_{0.34} \mathrm{O}_{2}$ material. The material utilises the $\mathrm{Co}^{2+/ 3+}$ redox couple to raise the average oxidation state of $\mathrm{Mn}$ and suppress the structural instability caused by Jahn-Teller distortion of $\mathrm{Mn}^{3+}$, thereby achieving a reasonable reversible capacity of $120 \mathrm{~mA} \mathrm{~h} \mathrm{~g}{ }^{-1} \cdot{ }^{138}$ The oxidation state of $\mathrm{Ti}^{4+}$ is retained during cycling to further enhance structural stability at the charged state, up to $4.3 \mathrm{~V}$. The combination of $\mathrm{Mn}$ with $\mathrm{Fe}$ and $\mathrm{Ni}$ has been suggested to enable additional reversible capacity when charging beyond $4 \mathrm{~V}$. In studies of O3-type $\mathrm{NaNi}_{1 / 3} \mathrm{Fe}_{1 / 3} \mathrm{Mn}_{1 / 3} \mathrm{O}_{2}$, it was found that both the $\mathrm{Ni}^{2+/ 4+}$ and $\mathrm{Fe}^{3+/ 4+}$ redox couples contribute to capacity below $4 \mathrm{~V}$, however the Fe redox couple remains dominant above $4 \mathrm{~V}^{.139}$ Despite stabilization of the $\mathrm{Mn}^{4+}$ state during cycling, Fe migration into the Na layer remains an issue at high voltages. High voltage stability has been observed in $\mathrm{P} 2-\mathrm{Na}_{x} \mathrm{Co}_{2}$ / ${ }_{3} \mathrm{Mn}_{2 / 9} \mathrm{Ni}_{1 / 9} \mathrm{O}_{2}$, delivering a reversible capacity of $140 \mathrm{~mA} \mathrm{~h} \mathrm{~g}{ }^{-1}$ at a charged state cut-off voltage of $4.5 \mathrm{~V} .{ }^{\mathbf{1 4 0}}$ Further characterization of the charged state behaviour revealed that the $\mathrm{Mn}$ retains a $4+$ oxidation state up to $4.5 \mathrm{~V}$. Charge compensation is 


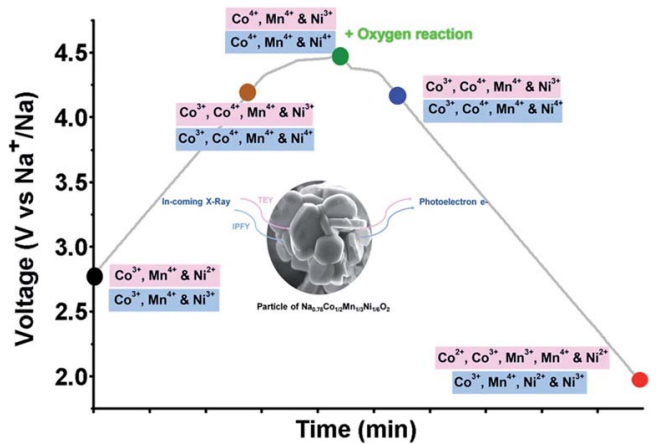

Fig. 14 Oxidation states of $\mathrm{Ni}, \mathrm{Mn}$ and Co observed during cycling of the ternary $\mathrm{Na}_{x} \mathrm{CO}_{2 / 3} \mathrm{Mn}_{2 / 9} \mathrm{Ni}_{1 / 9} \mathrm{O}_{2}$ positive electrode material, determined using $\mathrm{X}$-ray absorption spectroscopy (XAS) and resonant inelastic X-ray scattering (RIXS). Reproduced from ref. 141 under a CC BY 4.0 licence.

instead achieved by oxidation of both the Co and Ni ions to a 4+ oxidation state, accompanied by anionic redox activity from oxygen atoms as depicted in Fig. $14 .^{\mathbf{1 4 1}}$ In situ XRD further confirmed that the P2 structure is preserved over the entire voltage range. These examples highlight the cooperative ability of several elements to compensate for structural instability and deliver higher reversible capacities at higher working voltages.

In contrast to the above-mentioned examples which exploit uniform doping, recently Wang et al. proposed non-uniform doping to be a more effective strategy for enhancing the charged state stability of layered positive electrode materials. ${ }^{\mathbf{1 4 2}}$ A range of Mn-rich layered oxides including $\mathrm{P} 2-\mathrm{Na}_{0.67} \mathrm{Ni}_{0.23^{-}}$ $\mathrm{Mn}_{0.67} \mathrm{Cu}_{0.1} \mathrm{O}_{2}, \quad \mathrm{P} 2-\mathrm{Na}_{0.67} \mathrm{Ni}_{0.33} \mathrm{Mn}_{0.57} \mathrm{Ti}_{0.1} \mathrm{O}_{2}, \quad \mathrm{P} 2-\mathrm{Na}_{0.67} \mathrm{Ni}_{0.23^{-}}$ $\mathrm{Mn}_{0.67} \mathrm{Zn}_{0.1} \mathrm{O}_{2}, \mathrm{P} 2-\mathrm{Na}_{0.67} \mathrm{Ni}_{0.23} \mathrm{Mn}_{0.67} \mathrm{Mg}_{0.1} \mathrm{O}_{2}$, were investigated. Detailed imaging and energy dispersive X-ray spectroscopy (EDS) mapping showed that dopant segregation, leading to the non-uniform distribution of dopants, takes place in the $\mathrm{Zn}$ and $\mathrm{Mg}$ containing samples, which display superior capacity retentions of $85 \%$ and $82 \%$ compared to $69 \%, 55 \%$ and $31 \%$ for the Ti-doped, Cu-doped and undoped samples respectively, when cycled at a rate of $\mathrm{C} / 10$ between $2.0-4.5 \mathrm{~V}$ for 100 cycles. Atomic resolution STEM-HAADF imaging evidenced the presence of $\mathrm{Zn}$ dopants in the sodium layer after 50 cycles at $\mathrm{C} / 10$ between $2.0-$ 4.5 V, which may further contribute towards the enhanced mechanical properties and cycling stability of the Zn-doped material. Overall, the work highlights the importance of considering the role and evolution of electrochemically inactive dopant ions both when synthesized and during cycling which opens new avenues for designing layered oxides with enhanced stability at high voltages.

\subsection{Mixed phase materials}

Combining multiple elements together in a single layered oxide material is widely accepted as an effective method for improving structural stability and hence battery performance of layered oxide materials. An alternative approach that has yet to be widely explored is the integration of multiple phases into a single material. Intergrowth materials, containing multiple polymorphs of the layered oxide structure, were first reported in studies of manganese oxide materials for use in lithium-ion batteries. ${ }^{143-145}$ Each layered oxide polymorph (P2/O3/P3) has their respective advantages and disadvantages. The P2-type polymorph typically displays high rate performance, but the sodium deficient nature of this framework also leads to comparatively low specific capacities. In contrast, the O3-type polymorph generally forms for sodium rich compositions, giving rise to higher capacities. However, the $\mathrm{Na}$ diffusion pathway between adjacent octahedral sites takes place via edge sharing tetrahedral sites, which contributes towards the higher energy barrier for diffusion of sodium ions and therefore poor rate performance. Finally, the P3 phase can be prepared at lower temperatures and may exhibit high reversible capacities but usually suffers from severe capacity fade owing to poor structural stability. ${ }^{146}$

Through integrating more than one phase into a single material, it is possible to enhance the electrochemical performance of sodium layered oxide positive electrode materials. In many cases, biphasic and multiphasic materials have been reported to perform better than the corresponding single phase. However, it may also add further complexity in the possible reaction pathways near the charged state and the ability to probe them using analytical techniques; all of the above mentioned phase transitions for the individual phases are possible in addition to new pathways due to the proximity of different phases e.g. stabilisation and ion transfer. ${ }^{147}$ A table of known biphasic and multiphasic layered oxide materials along with their respective electrochemical performances can be found in ref. 148.

3.2.1 P2/O3. Biphasic materials can be obtained by manipulating synthesis conditions to control the phase composition of a material. For example, when the sodium content in the $\mathrm{Na}_{x} \mathrm{Ni}_{0.2} \mathrm{Fe}_{x-0.4} \mathrm{Mn}_{1.2-x} \mathrm{O}_{2}$ composition is greater than 0.8 , the $\mathrm{O} 3$ structure forms but the biphasic $\mathrm{P} 2 / \mathrm{O} 3$ composite forms when the sodium content is lowered. ${ }^{\mathbf{1 4 9}} \mathrm{Simi}$ larly, the single phase $\mathrm{O} 3-\mathrm{Na}_{0.9} \mathrm{Ni}_{0.45} \mathrm{Mn}_{0.55} \mathrm{O}_{2}$ can be tuned to form the $\mathrm{P} 2 / \mathrm{O} 3-\mathrm{Na}_{0.88} \mathrm{Ni}_{0.45} \mathrm{Mn}_{0.55} \mathrm{O}_{2}$ hybrid material, which displays enhanced cyclability. ${ }^{\mathbf{1 5 0}}$

Another effective way to induce the intergrowth of mixed phase materials is through incorporation of Li. Investigations into $\mathrm{P} 2 / \mathrm{O} 3-\mathrm{Na}_{0.67} \mathrm{Mn}_{0.55} \mathrm{Ni}_{0.25} \mathrm{Ti}_{0.2-x} \mathrm{Li}_{x} \mathrm{O}_{2}(x=0,0.1,0.2)$ indicate that both the $\mathrm{O} 3$ content and rate capability increases with Li substitution. ${ }^{151} \mathrm{Li}$ was found to reside on the transition metal sites of the major $\mathrm{P} 2$ phase as well as alkali metal sites of the $\mathrm{O} 3$ phase. Using $\mathrm{P} 2-\mathrm{Na}_{0.5} \mathrm{Fe}_{0.5} \mathrm{Mn}_{0.5} \mathrm{O}_{2}$ as the parent material, Veerasubramani et al. investigated the criteria for synthesising biphasic positive electrodes via Li substitution. ${ }^{152}$ They found that when more than $10 \% \mathrm{Li}$ is incorporated into the material, the $\mathrm{O} 3$ phase dominates as the main phase over the P2 structure. Having tested a range of compositions, they identified P2rich $\mathrm{Na}_{0.5}\left(\mathrm{Li}_{0.1} \mathrm{Fe}_{0.45} \mathrm{Mn}_{0.45}\right) \mathrm{O}_{2}$ to be the best performing material. In line with these results, Bianchini et al. synthesised a P2rich composite from earth abundant precursors with the formula $\mathrm{P} 2 / \mathrm{O} 3-\mathrm{Na}_{0.67} \mathrm{Li}_{0.18} \mathrm{Mn}_{0.8} \mathrm{Fe}_{0.2} \mathrm{O}_{2}$ and found that the biphasic material displays an improved electrochemical performance relative to the Li-containing, single phase P2- 
$\mathrm{Na}_{0.85} \mathrm{Li}_{0.17} \mathrm{Mn}_{0.64} \mathrm{Ni}_{0.21} \mathrm{O}_{2}$ material. ${ }^{153}$ As such, it was proposed that the presence of a small amount of $\mathrm{O} 3$ phase may help to inhibit gliding of the main phase at high voltages.

Similarly, Guo et al. introduced Li into a P2-type phase to form a P2/O3 biphasic material with the formula $\mathrm{Na}_{0.66} \mathrm{Li}_{0.18^{-}}$ $\mathrm{Mn}_{0.71} \mathrm{Ni}_{0.21} \mathrm{Co}_{0.08} \mathrm{O}_{2}$, and suggested that the larger $c$ axis in the P2 component of the biphasic material relative to the pure P2 phase is beneficial for sodium diffusion. ${ }^{154}$ In contrast, the O3rich $\mathrm{P} 2 / \mathrm{O} 3-\mathrm{Na}_{0.7} \mathrm{Li}_{0.3} \mathrm{Ni}_{0.5} \mathrm{Mn}_{0.5} \mathrm{O}_{2}$ material synthesised via incorporation of $\mathrm{Li}$ into $\mathrm{O} 3-\mathrm{NaNi}_{0.5} \mathrm{Mn}_{0.5} \mathrm{O}_{2}$ was found to display the O3-P3 phase transformation during cycling (Fig. 15), limiting the electrochemical performance and demonstrating that the relative ratio of $\mathrm{P} 2$ and $\mathrm{O} 3$ phases is a critical factor in determining the materials structural stability at the charged state. As demonstrated by the synthesis of $\mathrm{Na}_{x} \mathrm{Li}_{0.18} \mathrm{Mn}_{0.66}$ $\mathrm{Co}_{0.17} \mathrm{Ni}_{0.17} \mathrm{O}_{2+\delta}(x=0.54,0.66,0.78$ and 0.90$)$ the addition of lithium may also induce the formation of $\mathrm{P} 2 / \mathrm{O}^{\prime} 3$ hybrid compositions, where $\mathrm{O}^{\prime} 3$ represents a $\mathrm{Li}_{2} \mathrm{MnO}_{3}$-type phase (space group $C 2 / m$ ). ${ }^{155}$ Increasing the sodium content was reported to influence the surface morphology, leading to the growth of (102) and (104) facets and changing the side surface finish from 'smooth' to 'ravine-like'. The most favourable morphology, comprising smooth surfaces with exposed 102 and 104 facets, was reported for the $x=0.66$ composition, which retained a capacity of $186 \mathrm{~mA} \mathrm{~h} \mathrm{~g}^{-1}$ after 60 cycles.

Realising the importance of $\mathrm{Co}^{-}$and $\mathrm{Ni}$-free materials for sodium-ion batteries, Yang et al. synthesised the biphasic P2 (34\%)/O3 (60\%) $\mathrm{Na}_{0.8} \mathrm{Li}_{0.2} \mathrm{Fe}_{0.2} \mathrm{Mn}_{0.6} \mathrm{O}_{2}$ material, containing a minor phase with $\mathrm{C} 2 / \mathrm{m}$ symmetry. ${ }^{156}$ To investigate behaviour at high voltage, the material was cycled over a wide window of 2.0-4.6 V, which delivered an initial reversible capacity of $174 \mathrm{~mA} \mathrm{~h} \mathrm{~g}^{-1}$ and a capacity retention of $82 \%$ over 100 cycles at $\mathrm{C} / 10$. The capacity contribution was found to be dominated by the $\mathrm{Fe}^{3+/ 4+}$ redox couple, along with contributions from oxygen at high voltages and some reduction of $\mathrm{Mn}^{4+}$ to $\mathrm{Mn}^{3+}$ during discharge. Upon charging, several consecutive phase transitions $(\mathrm{O} \rightarrow \mathrm{P} \rightarrow \mathrm{O})$ as well as a general loss in long-range order were identified using X-ray powder diffraction. Nonetheless, the biphasic nature of the material was preserved throughout cycling. The capacity vs. voltage curves exhibited a decrease in the average voltage over the first 20 cycles, which was attributed to some form of restructuring/ordering in the structure, such as migration of $\mathrm{Fe}$ or $\mathrm{Li}$ from the octahedral site to the sodium site in the material. ${ }^{6 / 7} \mathrm{Li}$ solid-state NMR experiments confirmed the migration of Li from transition metal to alkali metal layers within the first cycle; subsequently the distribution of $\mathrm{Li}$ remained constant and hence it was suggested that lithium could act as a stabilizer.

Applying the principles discussed in Section 3.1, further improvements to $\mathrm{P} 2 / \mathrm{O} 3$ biphasic materials can be made by tailoring the transition metal site occupancy as demonstrated by $\mathrm{Hu}$ et al. who compared the electrochemical performance of the Ti-free P2/O3- $\mathrm{Na}_{0.8} \mathrm{Li}_{0.27} \mathrm{Mn}_{0.73} \mathrm{O}_{2}$ composition with P2/O3$\mathrm{Na}_{0.8} \mathrm{Li}_{0.27} \mathrm{Mn}_{0.68} \mathrm{Ti}_{0.05} \mathrm{O}_{2}$, prepared by Ti-substitution into the Mn site. ${ }^{157}$ The improved performance was attributed to mitigation of the $\mathrm{Mn}^{3+} / \mathrm{Mn}^{4+}$ redox couple, enhanced stability of the oxygen redox activity and retention of $\mathrm{Li}$ ions within the structure during cycling.

Overall, promising electrochemical performances have been reported for both $\mathrm{P} 2$-rich and O3-rich $\mathrm{P} 2 / \mathrm{O} 3$ biphasic materials. The key parameters to consider here remain, the location and spread of the transition metals and dopants across the two phases, the nature of the material, i.e., an intergrowth of structures or mixture of individual particles, the ratio of the P2 : O3 phases, phase evolution and electrochemical activity of each phase, and the influence the secondary or minor phase has on the stability of the primary phase near the charged state.

3.2.2 P2/P3. Coupling the P2-type polymorph together with a P3-type structure has also been explored. The formation of P2/ P3 biphasic materials can be controlled with the choice of
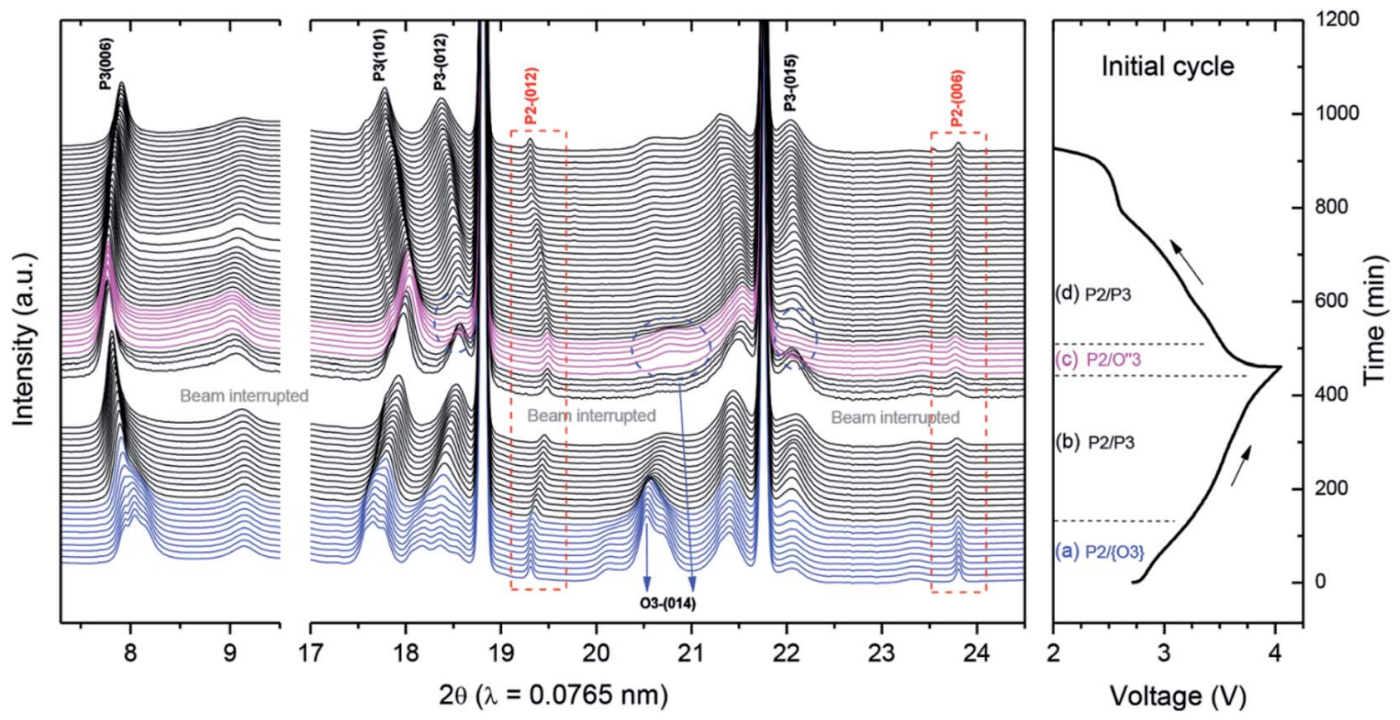

Fig. 15 In situ synchrotron XRD of $\mathrm{P} 2 / \mathrm{O} 3-\mathrm{Na}_{0.7} \mathrm{Li}_{0.3} \mathrm{Ni}_{0.5} \mathrm{Mn}_{0.5} \mathrm{O}_{2}$ during initial charge-discharge. While the $\mathrm{P} 2$ phase is retained, multiple phase transformations take place for the $\mathrm{O} 3$ component of the material. Reproduced with permission from ref. 158. 
synthesis temperature. Taking $\mathrm{Na}_{x} \mathrm{Ni}_{0.22} \mathrm{Co}_{0.11} \mathrm{Mn}_{0.66} \mathrm{O}_{2}$ as an example, a pure P2 phase forms at temperatures exceeding $800{ }^{\circ} \mathrm{C}$ whereas reducing the temperature to $750{ }^{\circ} \mathrm{C}$ facilitates the formation of a P2/P3 biphasic material. Further reduction of the temperature to $700{ }^{\circ} \mathrm{C}$ results in formation of a pure P3-type material. ${ }^{159}$ The best trade-off between high initial capacity and cycling stability was found for the P2-type material synthesised at $800{ }^{\circ} \mathrm{C}$, while the $\mathrm{P} 2(70 \%) / \mathrm{P} 3(30 \%)-\mathrm{Na}_{x} \mathrm{Ni}_{0.22} \mathrm{Co}_{0.11} \mathrm{Mn}_{0.66} \mathrm{O}_{2}$ material displayed improved electrochemical performance compared to the pure P3-type material. The P3/P2- $\mathrm{Na}_{0.66} \mathrm{Co}_{0.5^{-}}$ $\mathrm{Mn}_{0.5} \mathrm{O}_{2}$ biphasic layered material comprising $\approx 76 \%$ of the P3type phase and $\approx 24 \%$ of the P2-type structure was also found to perform better electrochemically relative to the equivalent pure P3-type material. ${ }^{\mathbf{1 6 0}}$ Electrochemical impedance spectroscopy revealed that deintercalation of sodium in the biphasic system is easier compared to the pure P3 phase, giving rise to steady capacities at high rates. Furthermore, no phase transformations were observed for the biphasic material when charged up to $4.2 \mathrm{~V}$, corresponding to the good electrochemical stability observed.

Alternatively, substitution of electrochemically inactive elements such as $\mathrm{Zn}$ may induce the formation of a hybrid material. A core shell structure with the P3 phase located on the surface encompassing the core $\mathrm{P} 2$ phase was identified for the $\mathrm{Na}_{0.78} \mathrm{Cu}_{0.27} \mathrm{Zn}_{0.06} \mathrm{Mn}_{0.67} \mathrm{O}_{2}$ material using high-angle annular dark-field imaging (HAADF) and annular bright field (ABT) imaging techniques. ${ }^{\mathbf{1 6 1}}$ Based on scanning transmission electron microscopy electron energy loss spectroscopy (STEMEELS), $\mathrm{Cu}$ redox was found to take place in both the P2 and P3 phase, whereas $\mathrm{Mn}$ redox activity could only be detected in the P2 phase. The core shell material was found to inhibit formation of any highly disordered phases at high voltages, giving rise to good rate performance and cyclability.

3.2.3 Multiphasic. Upon substitution of $\mathrm{Li}$ into a layered P3/P2 hybrid structure, Huang et al. were able to synthesise a $\mathrm{P} 2 / \mathrm{P} 3 / \mathrm{O}^{\prime} 3$ hybrid material with the composition $\mathrm{Na}_{0.7} \mathrm{Li}_{0.18^{-}}$ $\mathrm{Mn}_{0.66} \mathrm{Co}_{0.17} \mathrm{Ni}_{0.17} \mathrm{O}_{2+\delta}$ that performs even better than the $\mathrm{P} 3 / \mathrm{P} 2$ biphasic equivalent. ${ }^{\mathbf{1 4 6}}$ The material, which is comprised of Narich $\mathrm{P} 2$, Na-rich $\mathrm{P} 3$ and Li-rich $\mathrm{O}^{\prime} 3$ phases, was shown to suppress $\mathrm{P} 3-\mathrm{P} 3$ " and $\mathrm{P} 2-\mathrm{P} 2$ " phase transitions during cycling, leading to enhanced rate capability. ${ }^{\mathbf{1 6 2}}$ It is thought that the cooperative behaviour of different phases may enable more sodium to be extracted at high voltages without inducing irreversible structural changes. The synergetic effect that combines advantages of different polymorphs to achieve better performance was also identified in the $\mathrm{P} 3 / \mathrm{P} 2 / \mathrm{O} 3$ multiphasic $\mathrm{Na}_{0.76}{ }^{-}$ $\mathrm{Mn}_{0.5} \mathrm{Ni}_{0.3} \mathrm{Fe}_{0.1} \mathrm{Mg}_{0.1} \mathrm{O}_{2}$ material. ${ }^{163}$ The mixed phase displays higher capacity than the individual P2-type phase and better cyclability than the O3-type phase.

In a study on $\mathrm{Na}_{x} \mathrm{Ni}_{1 / 3} \mathrm{Co}_{1 / 3} \mathrm{Mn}_{1 / 3} \mathrm{O}_{2}$, Xu et al. make comparisons between single-phase, biphasic, and triphasic layered materials with comparable compositions. ${ }^{164}$ In terms of capacity and rate capability, the triphasic $\mathrm{P} 2 / \mathrm{O} 1 / \mathrm{O} 3$ material showed the best performance followed by the biphasic P2/O3 material and then the pure P2 phase. Operando XRD showed that the triphasic material can inhibit the irreversible $\mathrm{P} 2-\mathrm{O} 2$ transition at high voltages while improving the reversibility of structural transformations in the minor $\mathrm{O} 1$ and $\mathrm{O} 3$ phases. In contrast, the biphasic material displays an irreversible O3-P3 transition upon cycling and the single $\mathrm{P} 2$ phase material transitions to the "Z phase" during high voltage charging as seen in Fig. 16.

Using high resolution $\mathrm{XRD}$, Lee et al. identified the presence of four $\mathrm{Na}$ dominated phases (P2, O3, O'3, P3) and one $\mathrm{Li}$ dominated phase (O3) in the Li substituted sample, $\mathrm{Na}_{0.7} \mathrm{Li}_{0.3^{-}}$ $\mathrm{Ni}_{0.5} \mathrm{Mn}_{0.5} \mathrm{O}_{2} \cdot{ }^{158}$ However, various local environments were identified in the ${ }^{7} \mathrm{Li}$ NMR suggesting that the Li may also reside in the Na phases. The presence of multiple phases, induced by incorporation of $\mathrm{Li}$, was shown to improve the electrochemical performance. In situ XRD shows amalgamation of the Na-rich O3, $\mathrm{O}^{\prime} 3$ and $\mathrm{P} 3$ phases into a single $\mathrm{P} 3$ phase and some irreversible extraction of $\mathrm{Li}$ from the $\mathrm{O} 3$ phase on the first charge. No phase transitions for the P2 phase were observed throughout, while the new $\mathrm{P} 3$ phase transitioned to an $\mathrm{O} 3$ phase at the charged state.

3.2.4 Layered/spinel composites. To improve performance, it is possible to integrate layered oxide materials with a spinel phase. For example, when the $\mathrm{P} 2-\mathrm{Na}_{x} \mathrm{Ni}_{1 / 6} \mathrm{Co}_{1 / 6} \mathrm{Mn}_{2 / 3} \mathrm{O}_{2}$ is mixed with a spinel phase, the electrochemical conductivity increases by 2 orders of magnitude and the material displays enhanced capacity, energy density and rate capability. ${ }^{165}$ The spinel phase is thought to inhibit agglomeration and prevent the formation of flake-shape particles, thereby improving the electrochemical performance.

An improved performance in terms of capacity and average voltage was found for the $\mathrm{O} 3$ layered/spinel composite $\mathrm{Na}_{0.87^{-}}$ $\mathrm{Li}_{0.25} \mathrm{Ni}_{0.4} \mathrm{Fe}_{0.2} \mathrm{Mn}_{0.4} \mathrm{O}_{2+\delta}$ electrode. ${ }^{166}$ The voltage profile of the composite material shows a reversible high voltage plateau while this plateau is irreversible in the spinel free material, suggesting that addition of the spinel phase contributed towards the enhanced structural and electrochemical stability, especially at high voltages, the mechanism of which is yet to be explored. Improved rate capability on the other hand could be ascribed to the improved charge transport kinetics due to direct connection between the $3 \mathrm{D}$ channels in the spinel phase and $2 \mathrm{D}$ channels in the layered phase modifying the diffusion pathway. ${ }^{\mathbf{1 6 6}}$ A highly reversible transition at high voltages was also reported for the layered-tunnel intergrowth structure with the composition $\mathrm{Na}_{0.6} \mathrm{MnO}_{2} \cdot{ }^{167}$ The highly reversible $\mathrm{P} 2 /$ tunnel to OP4/tunnel phase transition was detected using in situ XRD upon cycling the composite up to $4.3 \mathrm{~V}$. Taking this further and combining P2, P3 and spinel structures to form the $\mathrm{Na}_{0.5}[-$ $\left.\mathrm{Ni}_{0.2} \mathrm{Co}_{0.15} \mathrm{Mn}_{0.65}\right] \mathrm{O}_{2}$ nanocomposite, Hou et al. were able to synthesise a particularly stable composition for which no phase transitions were detected via ex situ XRD when cycled between 1.5 and $4.0 \mathrm{~V} v s$. $\mathrm{Na} / \mathrm{Na}^{+}{ }^{168}$

3.2.5 Core-shell structures. A common route to synthesise positive electrode material is from the calcination of hydroxide precursor materials. The metal hydroxide precursors typically present a spherical secondary particle morphology which is inherited by the final lithiated or sodiated positive electrode material after calcination. The spherical shape of the particles is thought to be beneficial for optimising the contact area with the electrolyte, thereby suppressing electrochemical decomposition upon cycling. By varying the concentration of reactants during 

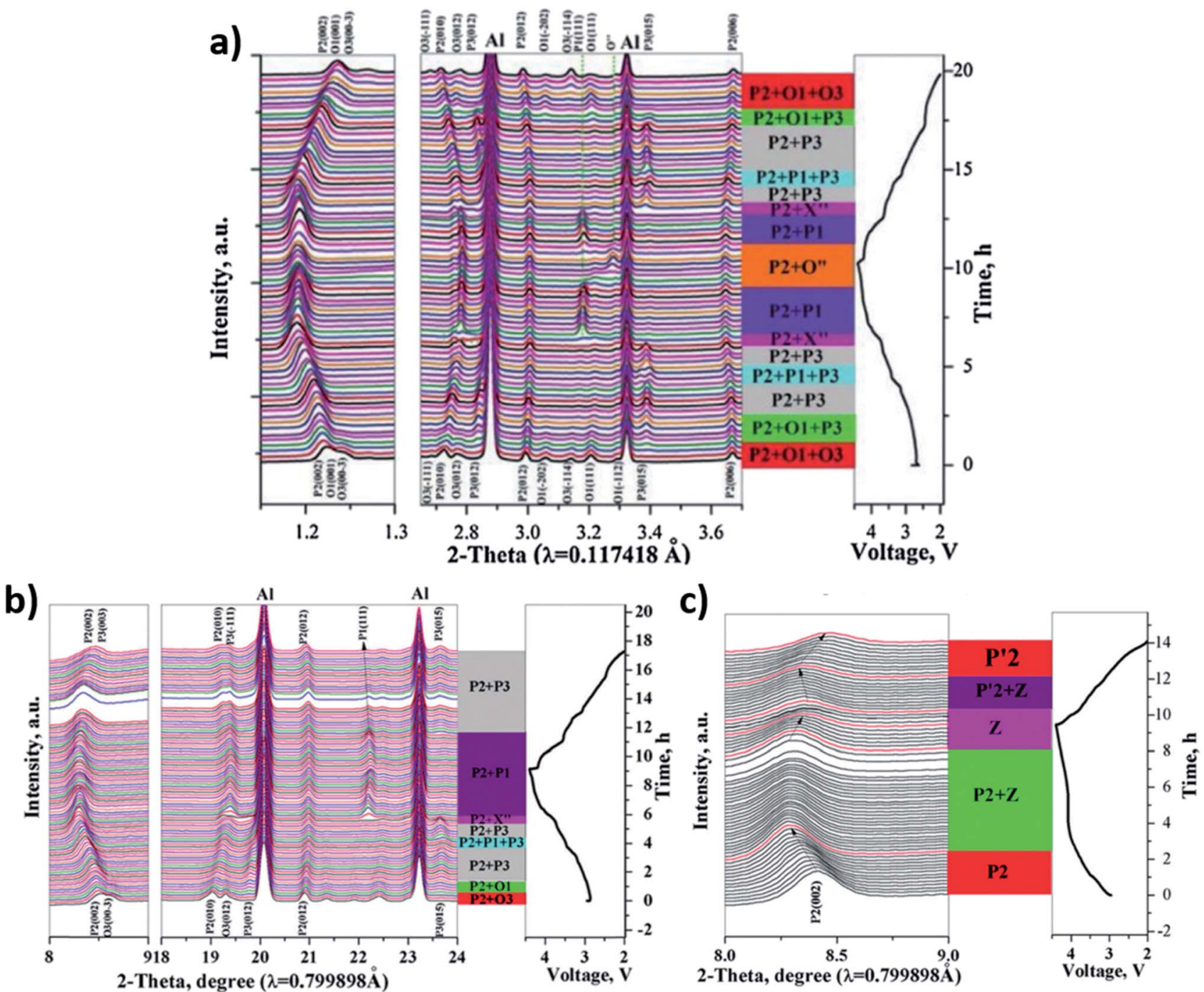

Fig. 16 In operando XRD data for (a) P2/O1/O3 (b) P2/O3 (c) P2- $\mathrm{Na}_{x} \mathrm{Ni}_{1 / 3} \mathrm{Co}_{1 / 3} \mathrm{Mn}_{1 / 3} \mathrm{O}_{2}$ cycling between $2.0-4.4 \mathrm{~V}$ at $0.1 \mathrm{C}$ together with their phase evolution. Reproduced from ref. 164 with permission from The Royal Society of Chemistry.

the co-precipitation reaction, it is possible to prepare spherical particles with a radially varying TM composition. After calcination, this produces materials whose particles are described to have a 'core-shell' structure. For example, the sodium rich positive electrode with a varied composition from $\mathrm{Na}\left[\mathrm{Ni}_{0.75^{-}}\right.$ $\left.\mathrm{Co}_{0.02} \mathrm{Mn}_{0.23}\right] \mathrm{O}_{2}$ at the core to $\mathrm{Na}\left[\mathrm{Ni}_{0.58} \mathrm{Co}_{0.06} \mathrm{Mn}_{0.36}\right] \mathrm{O}_{2}$ at the surface is a pertinent example. ${ }^{169}$ The presence of an inner core was reported to enhance the attainable capacity while the outer shell improved the materials capacity retention. Core-shell type structures were first reported in materials for lithium-ion batteries, ${ }^{170}$ but the method has since been adapted to produce several sodium-ion battery materials. ${ }^{171,172}$ In these studies, a Ni-rich core composition is used to deliver high capacity, while a Mn-rich shell is typically used to improve structural stability. Wei et al. have also reported an interesting material with particles composed of a biphasic core-shell structure containing Ni-rich O-type core and a P2-type Mn-rich shell. ${ }^{173}$ The O-type core provides high specific capacity, while the P-type outer composition also enables good structural stability and rate capability.

\subsection{Electrolytes}

Layered oxide positive electrode materials are generally tested in $\mathrm{Na}$ half-cells against a $\mathrm{Na}$ metal counter electrode. The observed performance of positive electrode materials can be significantly influenced by the choice of electrolyte, application of surface coatings and inclusion of binders because they contribute toward the formation of a surface layer. ${ }^{174}$ The choice of electrolyte is particularly pertinent when considering the charged state of the positive electrode material because typically, the charged state cut off voltage for a cell is limited by the voltage window within which the electrolyte remains stable.

3.3.1 Nonaqueous liquid electrolytes. Conventional sodium-ion battery electrolytes consist of a $\mathrm{Na}$ salt, typically $\mathrm{NaClO}_{4}$ or $\mathrm{NaPF}_{6}$, dissolved in a carbonaceous solvent such as ethylene carbonate (EC), dimethyl carbonate (DMC), propylene 
carbonate (PC), diethyl carbonate (DEC), and dimethyl ether (DME) or a binary mixture of these. The choice of salt and solvent is influenced by the need to meet a number of practical criteria including: good chemical, electrochemical and thermal stability, high ionic conductivity to facilitate sodium ion transport, low electronic conductivity to minimize selfdischarge of the cell, as well as low toxicity, environmental impact and cost. ${ }^{175}$ Small amounts of additives $(<5 \mathrm{wt} \%)$ such as fluorinated ethylene carbonate (FEC) may help to meet these criteria by creating an ionically conducting, electronically insulating surface layer (SL) at the electrode surface, thereby improving the reversibility of sodium intercalation. ${ }^{176}$

The electrochemical stability of an electrolyte is determined by the salt anion onset potentials for oxidation or reduction. $\mathrm{ClO}_{4}{ }^{-}$and $\mathrm{PF}_{6}{ }^{-}$are known to be stable up to $4.5 \mathrm{~V}$ vs. $\mathrm{Na} / \mathrm{Na}^{+}$ which, in combination with their good chemical stability, and low cost makes them suitable components in sodium-ion batteries. ${ }^{177}$ Despite being suitable candidates, they do present some limitations: $\mathrm{ClO}_{4}{ }^{-}$is a strong oxidant, meaning it is primarily of academic interest, while $\mathrm{PF}_{6}{ }^{-}$has safety issues at elevated temperatures and is particularly moisture sensitive. ${ }^{\mathbf{1 7 5}}$ Alternative $\mathrm{Na}$ counter ions that have been reported such as $\mathrm{BF}_{4}{ }^{-}, \mathrm{CF}_{3} \mathrm{SO}_{3}{ }^{-}$(Tf) and $\left[\mathrm{N}\left(\mathrm{CF}_{3} \mathrm{SO}_{2}\right)_{2}\right]^{-}$(TFSI) display more significant drawbacks. $\mathrm{BF}_{4}{ }^{-}$and $\mathrm{Tf}$ have stronger interactions with $\mathrm{Na}^{+}$which reduces the availability of charge carriers, reducing the ionic conductivity, while TFSI (and Tf) are corrosive to the $\mathrm{Al}$ current collector. Consequently, $\mathrm{NaClO}_{4}$ and $\mathrm{NaPF}_{6}$ remain the Na salts of choice for organic liquid electrolytes, and so the structural stability of positive electrode materials beyond $4.5 \mathrm{~V}$ is incidental. ${ }^{178,179}$

3.3.2 Ionic liquid electrolytes. Concerns regarding the flammability of organic solvents has motivated research into alternative systems. Ionic liquids are usually much less or nonflammable and non-volatile, but their high viscosity reduces the ionic mobility, limiting battery performance. ${ }^{\mathbf{1 8 0}}$ Chagas et al. identified higher reversibility for the $\mathrm{P} 2-\mathrm{O} 2$ phase transition in P2- $\mathrm{Na}_{0.45} \mathrm{Ni}_{0.22} \mathrm{Co}_{0.11} \mathrm{Mn}_{0.66} \mathrm{O}_{2}$ at high potentials when using a 10 mol\% NaTFSI in PYR14FSI electrolyte. ${ }^{181}$ Furthermore, they reported improved safety in terms of flammability and volatility when using the ionic liquid electrolyte. At low potentials, the increased stability was attributed to lower solubility of Mn into the ionic liquid-based electrolyte.

3.3.3 Solid-state electrolytes. Solid-state electrolytes such as NASICON and Na- $\beta^{\prime \prime}$-alumina offer superior chemical, thermal and electrochemical stability, lower flammability, improved durability, and design simplicity in comparison to conventional liquid organic electrolytes. ${ }^{\mathbf{1 8 2 , 1 8 3}}$ They are a much safer option because they do not suffer from leakage or flammability. ${ }^{\mathbf{1 8 4}}$ However, the application of solid-state electrolytes in sodium-ion batteries is restricted by factors such as low ionic conductivity, poor wettability and in some cases incompatibility with established positive electrode materials. For example, P2$\mathrm{Na}_{2 / 3} \mathrm{Fe}_{0.5} \mathrm{Mn}_{0.5} \mathrm{O}_{2}$ and $\mathrm{P} 2-\mathrm{Na}_{2 / 3} \mathrm{Ni}_{0.33} \mathrm{Mn}_{0.67} \mathrm{O}_{2}$ have been tested in all solid-state sodium-ion batteries with a $\mathrm{Na}-\beta^{\prime \prime}$-alumina electrolyte but the achievable capacity is limited by the combination of materials employed. ${ }^{\mathbf{1 8 5 , 1 8 6}}$ Consequently, research regarding solid-state electrolytes is primarily concerned with improving their ionic conductivity and understanding conduction mechanisms, particularly at the electrode-electrolyte interface. The interface between the electrodes and the solidstate electrolyte is a key factor which determines the electrochemical performance. High internal cell resistances may lead to significant degradation of capacity during cycling. ${ }^{187}$ In order to reduce interfacial resistance, it is imperative for the solidstate electrolyte to be paired with positive electrode materials that display negligible volume changes during cycling. Moreover, large volume changes in the positive electrode may lead to fractures and poor contact at the electrode-electrolyte interface upon cycling. ${ }^{188}$

\subsection{Surface coatings}

An alternative method to modifying the solid electrolyte interface (SEI) of layered materials, and potentially enhancing their performance, is by applying a surface coating. Coatings reduce atmospheric and electrochemical corrosion at the interface, thereby improving the structural and electrochemical stability and in some cases the electronic and ionic conductivity. ${ }^{\mathbf{1 8 9}}$ Minimising structural transformations that take place at the charged state is therefore important in order to preserve the coating throughout cycling. Upon exposure to air, layered oxides easily absorb water leading to the formation of an electrically insulating layer at the surface composed of $\mathrm{NaOH}$ and/or $\mathrm{NaCO}_{3} \cdot{ }^{190,191}$ As such the surface modifications documented for lithium-ion battery electrodes are not all necessarily applicable to sodium-ion battery materials. ${ }^{192}$ Due to the sensitivity of layered transition metal oxides to air, they should ideally be handled in a glovebox during electrode fabrication and cell preparation. It is also possible for coatings to influence the anion redox activity of high voltage positive electrode materials. There are several studies that have focused on limiting the evolution of $\mathrm{O}_{2}$ from Li-based transition metal oxides via application of a surface coating. ${ }^{193-196}$ However, the interplay between coatings and anion redox reactions in $\mathrm{Na}$ layered oxides is relatively unexplored and the mechanism is not well understood. ${ }^{197,198}$

3.4.1 Carbon coatings. To prevent moisture uptake, mitigate side reactions, and decrease polarization, a carbon coating can be applied to prevent direct contact between the electrode material and external environment. Significantly improved cyclability and capacities were found for the carbon coated $\mathrm{NaCrO}_{2}$ electrode. ${ }^{199}$ However, the presence of excessively thick or inhomogeneously distributed carbon layers meant operation at high rates was not possible. Consequently, carbon has not been further explored as a coating for sodium layered oxide materials.

3.4.2 Metal oxide coatings. $\mathrm{Al}_{2} \mathrm{O}_{3}$ is an alternative example of a cheap and effective surface coating for layered oxide materials. Liu et al. found that coating P2- $\mathrm{Na}_{2 / 3}\left[\mathrm{Ni}_{1 / 3} \mathrm{Mn}_{2 / 3}\right] \mathrm{O}_{2}$ with $\mathrm{Al}_{2} \mathrm{O}_{3}$ reduced the propensity of side reactions to take place at higher voltages. ${ }^{\mathbf{2 0 0}}$ The increased cyclability was attributed to the coating suppressing physical exfoliation of the layered material from the electrode. When applied using atomic layer deposition (ALD), improved resistivity was observed. ${ }^{201}$ Relative 
to the uncoated electrode, a greater proportion of $\mathrm{NaF}$ was found at the cathode electrolyte interface (CEI). While NaF on its own is a highly resistive material that may inhibit the CEI, the coated electrode displayed enhanced sodium diffusion kinetics, suggesting upon cycling discrete crystallites that allow the passage of sodium ions forms instead of a consistent $\mathrm{NaF}$ film. Furthermore, this CEI is thought to act as a buffer to volume expansion upon extraction of sodium ions, leading to enhanced structural stability. ${ }^{202}$ Application of an $\mathrm{Al}_{2} \mathrm{O}_{3}$ coating using ALD has also been tested on P2-Na $\mathrm{Na}_{2 / 3}\left(\mathrm{Mn}_{0.54} \mathrm{Ni}_{0.13} \mathrm{Co}_{0.13}\right) \mathrm{O}_{2}$ electrodes; a range of surface thicknesses were tested by coating the electrode with 2, 5 or 10 ALD cycles. The electrode coated with 2 ALD cycles exhibited the best electrochemical stability and rate capability whereas the electrode coated with 10 cycles displayed the highest coulombic efficiency (97\% after 100 cycles).$^{203}$ The coating is thought to provide structural stability against mechanical stresses occurring during cycling and stabilize formation of the CEI, thus having a significant impact upon cycling, especially when utilising a high cut-off voltage. To further improve the kinetics and surface stability of sodium manganese oxide positive electrode materials, Park et al. combined $\mathrm{Al}_{2} \mathrm{O}_{3}$ with highly conductive multi walled carbon nanotubes (MWCNT). ${ }^{204}$ According to their XPS profiles, the formation of $\mathrm{NaF}$ on the surface coated electrode was suppressed relative to the uncoated electrode. Since the coated electrodes displayed better capacity retention, it was suggested that inhibition of the formation of a CEI layer fully covered with $\mathrm{NaF}$, enables the continuation of facile sodium ion diffusion through the CEI.

In addition to $\mathrm{Al}_{2} \mathrm{O}_{3}$, other metal oxide coatings have been investigated as surface coatings for sodium positive electrode materials. Kaliyappan et al. performed a comparative study on $\mathrm{Al}_{2} \mathrm{O}_{3}, \mathrm{ZrO}_{2}$ and $\mathrm{TiO}_{2}$ as surface coatings for $\mathrm{P} 2-\mathrm{Na}_{0.66}\left(\mathrm{Mn}_{0.54^{-}}\right.$ $\left.\mathrm{Co}_{0.13} \mathrm{Ni}_{0.13}\right) \mathrm{O}_{2} \cdot{ }^{205}$ The oxide surface coatings were found to improve the cycle stability of the positive electrode material when cycled up to a high voltage of $4.5 \mathrm{~V}$. The greatest improvement was reported for $\mathrm{Al}_{2} \mathrm{O}_{3}$ which was attributed to its high band gap energy $(9.00 \mathrm{eV})$ relative to $\mathrm{ZrO}_{2}(5.80 \mathrm{eV})$ and $\mathrm{TiO}_{2}(3.18 \mathrm{eV})$ meaning the $\mathrm{Al}_{2} \mathrm{O}_{3}$ surface coating remains redoxinactive throughout cycling. ${ }^{206}$ However, the greatest improvement in rate performance was observed for the $\mathrm{ZrO}_{2}$-coated material due to the its high fracture toughness.

A number of benefits of $\mathrm{MgO}$ coating have been reported including the suppression of side reactions between the cathode and electrolyte, including dissolution of transition metal ions into the electrolyte, and stabilisation of the CEI layer, all of which contribute towards the layered oxide structural stability. ${ }^{207}$ For instance, the capacity retention of $\mathrm{Na}_{0.67} \mathrm{Mn}_{0.5^{-}}$ $\mathrm{Fe}_{0.5} \mathrm{O}_{2}$ after 100 cycles when cycled at $1 \mathrm{C}$ increased from $20 \%$ to $72 \%$ upon application of an $\mathrm{MgO}$ coating. ${ }^{208}$ Moreover, an $\mathrm{MgO}$ coating has been shown to mitigate undesirable high voltage phase transformations and reduce the interfacial resistance during high potential cycling for P2- $\mathrm{Na}_{0.5} \mathrm{Ni}_{0.33} \mathrm{Mn}_{0.67} \mathrm{O}_{2}, \mathrm{P} 2-$ $\mathrm{Na}_{0.67} \mathrm{Mn}_{0.5} \mathrm{Fe}_{0.5} \mathrm{O}_{2}$ and $\mathrm{O} 3-\mathrm{Na}\left[\mathrm{Ni}_{0.5} \mathrm{Mn}_{0.5}\right] \mathrm{O}_{2}$, the mechanism of which is still not fully understood. ${ }^{207-209}$ Similarly, $\mathrm{Na}_{2} \mathrm{Ti}_{3} \mathrm{O}_{7}$ has been shown to be effective in suppressing high voltage $\mathrm{P} 2-\mathrm{O} 2$ phase transitions in $\mathrm{P} 2-\mathrm{Na}_{2 / 3} \mathrm{Ni}_{1 / 3} \mathrm{Mn}_{2 / 3} \mathrm{O}_{2}$. In the process of increasing the coating content of $\mathrm{Na}_{2} \mathrm{Ti}_{3} \mathrm{O}_{7}$, the $a$ lattice parameter and unit cell volume was found to increase and therefore, in view of larger ionic radius of $\mathrm{Ti}^{4+}(0.605 \AA)$ compared with $\mathrm{Mn}^{4+}(0.53 \AA)$ it was tentatively proposed that $\mathrm{Ti}^{4+}$ had been incorporated into the structure, which suppresses the sodium ion/vacancy ordering and the $\mathrm{P} 2-\mathrm{O} 2$ phase transition during cycling. ${ }^{210,211}$

By coating a layered oxide material with a second, related layered oxide material it is also possible to instigate doping. Zhang et al. demonstrated a facile method to surface coat and dope $\mathrm{P} 2-\mathrm{Na}_{0.7} \mathrm{MnO}_{2}$ in a single step process using $\mathrm{P} 2-\mathrm{Na}_{0.7^{-}}$ $\mathrm{Ni}_{0.33} \mathrm{Mn}_{0.67} \mathrm{O}_{2} \cdot{ }^{212}$ During the process, Ni is doped into the bulk material. The resulting material displays enhanced capacity retention of $68.9 \%$ over 100 cycles, compared to $20.7 \%$ for the unmodified $\mathrm{P} 2-\mathrm{Na}_{0.7} \mathrm{MnO}_{2}$ material, without sacrificing the initial discharge capacity. Conversely, through Ti enrichment to generate the $\mathrm{O} 3-\mathrm{NaMn}_{0.8} \mathrm{Ti}_{0.1} \mathrm{Ni}_{0.1} \mathrm{O}_{2}$ composition, the material was found to form an all-titanium protective layer. Guo et al. showed that the resultant spinel-like titanium oxide coating improved the structural and electrochemical stability relative to the Ti-free equivalent. The coating prevents contact between manganese and the external environment, thereby suppressing dissolution of Mn at the electrode/electrolyte interface as well as degradation of the positive electrode material upon cycling. ${ }^{189}$ The synergy of $\mathrm{Ti}^{4+}$ doping and $\mathrm{TiO}_{2}$ coating has also been reported for the $\mathrm{O} 3-\mathrm{NaMn}_{0.33} \mathrm{Fe}_{0.33} \mathrm{Ni}_{0.33} \mathrm{O}_{2}$ composition. ${ }^{213}$ The $\mathrm{TiO}_{2}$ layer mitigates side reactions at the surface, while $\mathrm{Ti}^{4+}$ doping enlarges the interslab spacing, facilitating sodium ion diffusion.

3.4.3 Metal phosphate coatings. Metal phosphate protective layers including $\mathrm{AlPO}_{4}, \mathrm{Mg}_{3}\left(\mathrm{PO}_{4}\right)_{2}$ and $\mathrm{NaPO}_{3}$ can effectively suppress irreversible oxidation of oxygen in the high voltage region while inhibiting the loss of lattice oxygen. ${ }^{197,198}$ Upon exposure to air, the metal phosphate coated $\mathrm{P} 3-\mathrm{Na}_{0.65} \mathrm{Mn}_{0.75^{-}}$ $\mathrm{Ni}_{0.25} \mathrm{O}_{2}$ material was found to retain high electrochemical activity. ${ }^{197}$ While the coating led to enhanced air stability and cycling longevity, a slight decrease of discharge capacity for the coated materials was observed. In comparison to metal oxides and metal phosphates, NASICON-type titanium phosphate coating layers such as $\mathrm{NaTi}_{2}\left(\mathrm{PO}_{4}\right)_{3}$ have the added advantage of being good sodium ion conductors, thus leading to faster sodium diffusion kinetics at the CEI. For example, coating the $\mathrm{P} 2-\mathrm{Na}_{0.67} \mathrm{Ni}_{0.33} \mathrm{Mn}_{0.67} \mathrm{O}_{2}$ layered oxide stabilizes the interface, while facilitating the migration of sodium ions at the surface. ${ }^{214}$

3.4.4 Conductive polymer coatings. Primarily during the extraction of sodium ions from Mn-rich layered oxides (i.e. at low voltages), Jahn-Teller active $\mathrm{Mn}^{3+}$ centres may undergo a disproportionation reaction, leading to the formation of $\mathrm{Mn}^{4+}$ and $\mathrm{Mn}^{2+}$, the latter of which can readily dissolve into organic carbonate-based electrolytes. ${ }^{\mathbf{1 8 1}}$ The repeated dissolution of $\mathrm{Mn}$ upon cycling is known to give rise to considerable strains in the crystal structure, resulting in poor cycling performance. ${ }^{215}$ Conductive polymer coatings such as polypyrrole (PPy) or polydopamine (PDA) can be used to prevent the dissolution of $\mathrm{Mn}$ during cycling, thus increasing the stability of Mn-rich layered oxides, while enhancing the materials electrical conductivity. ${ }^{216,217}$ Compared to the bare sample without surface modification, $\mathrm{P} 2-\mathrm{Na}_{0.80} \mathrm{Ni}_{0.22} \mathrm{Zn}_{0.06} \mathrm{Mn}_{0.66} \mathrm{O}_{2}$ coated with 
carbonized PDA exhibits superior rate capability and cycling performance. ${ }^{217}$ An additional advantage of using conductive polymer coatings is that their application can be carried out at lower temperatures.

The above examples demonstrate that optimizing the particle surface composition and morphology of positive electrode materials is critical for improving the electrode-electrolyte interface and thus enhancing the materials cycling performance. Moreover, surface coatings have been shown to improve the stability of layered oxides in high voltage regions which facilitates the extraction of sodium ions and therefore the attainable capacity. Although limiting the cut-off voltage enables detrimental, high voltage phase transitions to be avoided, it decreases the reversible capacity and energy density of the battery. Although surface coatings are a promising means to improving the high voltage structural stability of layered oxide positive electrode materials without compromising the maximum cell voltage, the mechanism by which the coatings acts remain elusive to probe and likely require the combined analysis of both surface and bulk in situ techniques.

\subsection{Sodium compensation additives}

While sodium-ion half-cells are suitable for laboratory-scale material characterization, it is important to acknowledge that the behaviour of electrode materials in half-cells does not translate directly into full cells. When cycled against a hard carbon anode material, the formation of the SEI at the anodeelectrolyte interface results in the irreversible consumption of sodium ions from the positive electrode material. ${ }^{218}$ The irreversible consumption of sodium ions can pose a significant problem for P2-type layered oxide structures which are inherently sodium deficient. On top of methods discussed earlier, such as electrolyte optimization (Section 3.3) and surface modifications (Section 3.4), the addition of sacrificial sodiation reagents to the anode and/or cathode material, such as sodium powder, ${ }^{214} \mathrm{NaN}_{3},{ }^{219} \mathrm{Na}_{3} \mathrm{P},{ }^{220} \mathrm{Na}_{2} \mathrm{NiO}_{2},{ }^{221} \mathrm{Na}_{2} \mathrm{C}_{4} \mathrm{O}_{4},{ }^{218} \mathrm{Na}_{2} \mathrm{CO}_{3},{ }^{222}$ or $\mathrm{NaNO}_{2},{ }^{223}$ has been reported to compensate for the sodium deficiency and significantly improve the performance of sodium ion full cells. For example, Guo et al. showed that the capacity retention in a full cell based on a hard carbon negative electrode and a $\mathrm{P} 2-\mathrm{Na}_{2 / 3} \mathrm{Ni}_{1 / 3} \mathrm{Mn}_{1 / 3} \mathrm{Ti}_{1 / 3} \mathrm{O}_{2}$ positive electrode can be increased from $63 \%$ to $85 \%$ after 200 cycles at $0.2 \mathrm{C}$ with a voltage window of $2.0-4.3 \mathrm{~V}$ by the addition of $\mathrm{Na}_{2} \mathrm{C}_{2} \mathrm{O}_{4}{ }^{218}$ Exactly how these additives alter the charged state behaviour of layered oxide positive electrode materials remains an interesting avenue for future studies to explore.

\section{Techniques for probing the charged state}

The studies discussed above have highlighted that a variety of useful information can be gained using various complimentary analytical techniques. During cycling, batteries present a complex system in which both chemical and physical changes are taking place simultaneously, such as structural expansion/ contraction, phase transitions, and side reactions which may result in gas evolution or parasitic capacity loss. Improving understanding of the behaviour of the positive electrode material at high voltages could provide a route to improving the energy density and cycle life of sodium-ion batteries. Recent advances in both instrumentation and methodology continue to push the boundaries of materials characterisation, while better accessibility has enabled routine, comprehensive evaluation of potential positive electrode materials for sodium-ion batteries. ${ }^{224-226}$

In situ studies have generated great interest as they allow for these changes to be correlated directly to the electrochemical state of the battery. In situ or operando characterisation is favoured for its ability to study the active materials under operating conditions. Typically, these studies require the use of modified cells or specially designed cells which allow for the materials of interest to probed. When modifying or designing cells, care must be taken to ensure that alterations do not have an adverse effect on the electrochemical behaviour of the system. For example, modified coin cells for in situ X-ray scattering studies have shown different electrochemical performance to identical cells prepared in unmodified casings. ${ }^{227}$ These considerations are of particular importance when attempting to resolve complex electrochemical processes which occur at the charged state, where the electrochemical system is not at equilibrium. For example, phenomena such as phase separation or reaction inhomogeneities may be kinetically driven, and can hence only be observed using operando studies. Contemporary characterisation techniques enable a wealth of complimentary information to be gathered, at various dimensions and scales, focusing on localised regions or bulk samples, and with varying time resolution. The charged state behaviour of positive electrodes may be illustrated via bulk phenomena such as structural changes or diffusion mechanisms. However, subtle inhomogeneities in sodium distribution within the electrode or transport mechanisms may be masked in these measurements. Use of other techniques, such as PDF analysis, to probe the local environment are particularly important when attempting to elucidate the subtle transition metal migration pathways and ARR. It should be noted that the challenges with low concentrations of elements and environments, e.g. small amounts of vacancies, small phase fractions, small percentage of transition metal migration, all make data analysis significantly challenging. These are compounded at the charged state where multiple pathways are possible. Meanwhile, ex situ analysis of electrode materials can also provide complimentary information and offers compatibility with a greater variety of characterisation techniques. For ex situ studies, electrode materials may be extracted from cells which have been charged to high voltages, but care is required to ensure that measurement results are not perturbed by contamination while handling the sample between battery cycling and characterisation, or relaxation effects.

\subsection{Analysis of cycling data}

Electrochemical characterisation techniques can provide a wealth of insight into the chemical behaviour of electrode 
materials at various states of charge (or levels of sodiation). The voltage vs. capacity profile observed during charge and discharge of batteries and can be used to elucidate a variety of information beyond the capacities delivered by the electrode materials. Characteristic features in the voltage profile can provide indications about the electrochemical reactions taking place in the electrode materials, such as kinetics, phase transitions and or reveal unfavourable side reactions which may contribute to capacity fade. ${ }^{228,229}$ For example, steps in the profile may be indicative of phase transitions. Furthermore, the relative change in shape and features of the voltage profile over successive cycles can indicate which electrochemical features contribute to capacity loss or impedance growth. ${ }^{230} \mathrm{~A}$ shift in the potential at which the features are observed may also be observed as the applied current is varied, which can be indicative of electrode polarisation. ${ }^{116,231}$ More recently, the application of statistical analysis and machine learning to voltage capacity profiles has also highlighted the potential for them to be a useful prognostic indicator to predict cycle life and cell failures. ${ }^{232}$

The measured cell voltage is defined by the difference in sodium electrochemical potential between the two electrodes, and in the case of half-cells typically reported in literature, this means the potential is measured vs. sodium metal. The measured voltage varies with the sodium content in the electrode. Further inferences about the sodium intercalation mechanism in host materials can be drawn from the voltage $(V)$ $v s$. capacity $(Q)$ profile by derivation of the data. Two derivatives can be used to produce differential capacity $(\mathrm{d} Q / \mathrm{d} V v s . V)$ or differential voltage $(\mathrm{d} V / \mathrm{d} Q$ vs. $Q)$ curves. Peaks in $\mathrm{d} Q / \mathrm{d} V$ curves provide information about phase equilibria, while peaks in $\mathrm{d} V /$ $\mathrm{d} Q$ curves provide information about phase transitions. ${ }^{229}$ Some studies correlate these peaks to changes in oxidation state or phase transitions. ${ }^{25,29,233}$ However, this is typically implied using data from complementary techniques such as XPS, XANES or in situ XRD. More literally, $\mathrm{d} Q / \mathrm{d} V$ curves describe the incremental

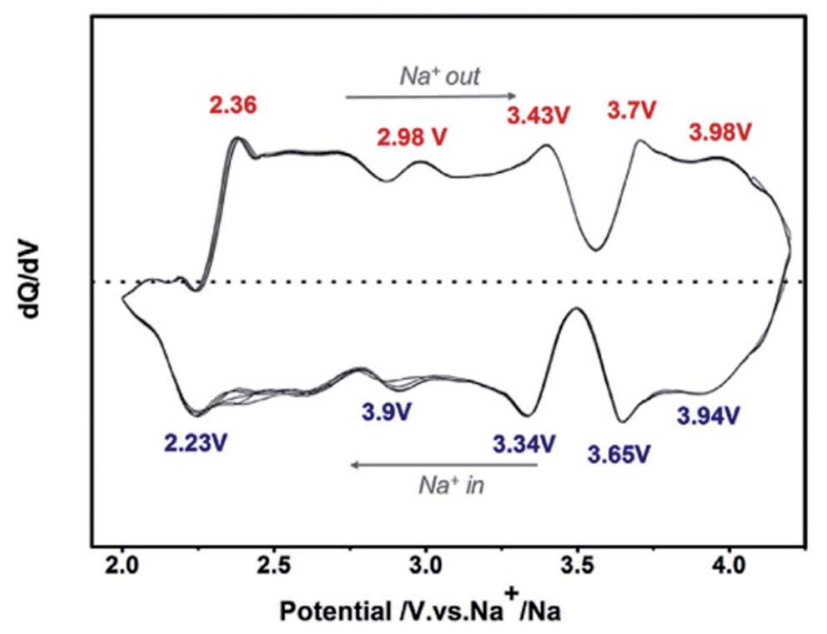

Fig. 17 Differential capacity $(\mathrm{d} Q / \mathrm{d} V)$ vs. potential $(V)$ of $\mathrm{P} 2-\mathrm{Na}_{2 / 3} \mathrm{Co}_{1 / 2} \mathrm{Ti}_{1 / 2} \mathrm{O}_{2}$, cycled vs. $\mathrm{Na} / \mathrm{Na}^{+}$in an electrochemical halfcell. Reproduced with permission from ref. 240 . capacity delivered by a device measured as a function of applied voltage. An example of a $\mathrm{d} Q / \mathrm{d} V$ curve and the corresponding measured $Q$ vs. $V$ curve for the $\mathrm{P} 2-\mathrm{Na}_{2 / 3} \mathrm{Co}_{1 / 2} \mathrm{Ti}_{1 / 2} \mathrm{O}_{2}$ vs. $\mathrm{Na} / \mathrm{Na}^{+}$ half-cell is shown in Fig. 17. The peaks in these curves indicate the potentials at which the majority of the capacity is delivered by the battery. The position, height and shape of peaks in the differential curves can therefore be indicative of changes in electrochemical processes over time. For example, the width of peaks may provide information about the inhomogeneity of processes occurring in the electrode material. In summary, differential voltage analysis makes features in the $V v s$. $Q$ data clearer and allows for possible quantification of the electrochemical processes taking place, which can particularly be useful to decipher the complex behaviours of positive electrode materials at high voltages..$^{234}$

Other electrochemical techniques such as electrochemical impedance spectroscopy (EIS) or potentiostatic/galvanostatic intermittent titration techniques (PITT/GITT) can provide insight into the bulk conductivity of the electrode material. In both of these techniques, extracting meaningful information can be difficult due to impedance contributions from the various cell components. Three-electrode cell configurations have been demonstrated as a way to deconvolute the different impedance components in EIS measurements. ${ }^{235}$ PITT or GITT measurements can be conducted as part of conventional electrochemical testing, by using current pulses and open-circuit sequences to measure the resulting overpotential and its decay. However, as these measurements are applied to the entire cell, variations in the electrode's resistance must be decoupled from other sources of resistance such as the electrolyte, electronic contact resistance, or charge transfer resistance. ${ }^{236,237}$ Repeated cycling to high voltages may further increase the cell resistance, typically due to electrolyte decomposition. ${ }^{238}$ Furthermore, the occurrence of phase transitions creates additional challenges for interpreting PITT or GITT measurements when investigating the performance of positive electrode materials at the charged state. ${ }^{239}$

\subsection{Structural characterisation using scattering studies}

Scattering techniques, such as powder X-ray diffraction (XRD) or neutron powder diffraction (NPD) can be used to reveal structural information of electrode materials before, after or during cycling, including identifying phase transitions, lattice expansion and contraction or even atomic scale information about site occupancies or the movement of elements within the structure. X-ray radiation and neutron radiation differ in the way they interact with the sample, with X-rays scattering from electron density of atoms, while neutrons scatter from the nuclei of atoms in the sample. ${ }^{241,242}$ Hence compared to X-rays, neutrons tend to scatter more strongly from certain lighter elements in the presence of heavier elements, which can be useful for detecting sodium distributions in the electrode materials. ${ }^{243}$ The use of in situ diffraction to study structural changes in real-time has been well documented and used to study a variety of different functional materials. ${ }^{244}$ These techniques are especially useful for energy storage materials as they 
allow for the electrochemical state of the cell to be controlled and directly correlated to the structural changes taking place. ${ }^{245-250}$ During electrochemical cycling, the electrode materials are not under equilibrium conditions, allowing dynamic structural changes which can occur at high levels of desodiation to be captured..$^{30,63}$ The structural evolution of positive electrode materials for sodium-ion batteries during high voltage cycling has been investigated using in situ scattering in several studies. $^{35,41,164,251-256}$ Typically, quantification of diffraction data can be undertaken using peak fitting or Rietveld refinement to fit structural models to the Bragg reflections in the diffraction data. $^{\mathbf{2 4 2}}$ More recently, PDF analysis of scattering data has become more accessible to researchers, thanks to developments in instrumentation, software and expertise. ${ }^{257}$ This method of analysis takes advantage of the entire diffraction pattern, both Bragg scattering and underlying diffuse scattering, to extract information about short-range ordering using information contained in the broad, less well-defined features of the diffraction pattern. ${ }^{242}$ PDF analysis of diffraction data collected from energy storage materials has been reported in a number of studies. ${ }^{258-261}$ A particularly relevant example was presented by Talaie et al., who studied the effect of Ni substitution on the layered $\mathrm{P} 2-\mathrm{Na}_{2 / 3-z}\left[\mathrm{Mn}_{1 / 2} \mathrm{Fe}_{1 / 2}\right] \mathrm{O}_{2}$ system using a combination of operando XRD and PDF analysis. ${ }^{43}$ The PDF profiles presented in this study are shown in Fig. 18. These functions are generated by applying a Fourier transform to the diffraction data, yielding a spectra with characteristic peaks which can be assigned to various interatomic distances in the structure. ${ }^{\mathbf{2 4 2}}$ By producing fits for the PDF data, the authors were able to model the structure of the $z \approx 0.5$ material, and find evidence for the migration of transition metal ions into tetrahedral sites at high potential. Despite significant electrode polarization, the migration was found to be completely reversible in this P2-type system.

\subsection{X-ray absorption spectroscopy}

$\mathrm{X}$-ray absorption spectroscopy (XAS) is an X-ray scattering technique in which the absorption coefficient of the sample is measured as a function of the wavelength of the incident radiation. XAS offers good elemental selectivity and chemical sensitivity, and can be used to probe the local chemical environment of elements of interest within the sample, thereby providing information about changes in oxidation state as well as corresponding atomic co-ordination. ${ }^{262}$ The absorption spectrum is typically considered in two major regions, the near edge region which covers from a few eV below the absorption edge to $50 \mathrm{eV}$ above the edge, and the far from edge region which covers from $50 \mathrm{eV}$ above the absorption edge and beyond. The analysis of these two regions is considered independently and are referred to as X-ray absorption near-edge structure (XANES) and extended X-ray absorption fine-structure (EXAFS) respectively. ${ }^{263}$ XANES data is relatively straightforward to analyse and can be used to provide qualitative and quantitative data about the oxidation states of elements of interest, site symmetries and the strength of covalent bonding within the structure. The interpretation of EXAFS data can be quite involved, but fitting results can be used to reveal information about site co-ordination, bond lengths, and identify neighbouring elements. Soft XAS, where the energy range of the X-ray source is $<1 \mathrm{keV}$, is sufficient for the analysis of low- $Z$ elements

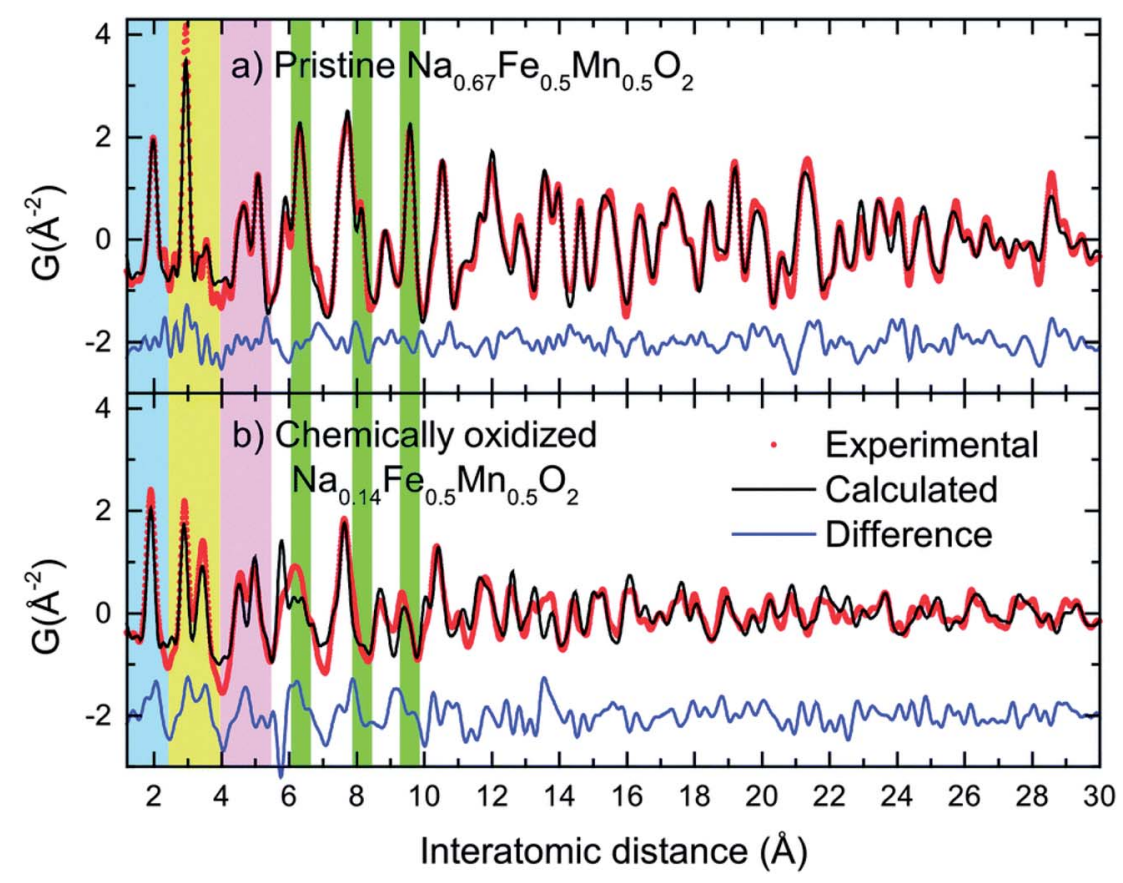

Fig. 18 Example of PDF data for (a) $\mathrm{P} 2-\mathrm{Na}_{0.67} \mathrm{Fe}_{0.5} \mathrm{Mn}_{0.5} \mathrm{O}_{2}$ and (b) $\mathrm{Na}_{0.14} \mathrm{Fe}_{0.5} \mathrm{Mn}_{0.5} \mathrm{O}_{2}$. PDF analysis can provide information about the interatomic bond lengths in the structure. In this example $\mathrm{M}-\mathrm{O}$ and $\mathrm{M}-\mathrm{M}$ distances are highlighted in blue and yellow respectively; second neighbour in-plane $\mathrm{M}-\mathrm{O}$ and $\mathrm{M}-\mathrm{M}$ distances are highlighted in lavender, and characteristic interlayer $\mathrm{M}-\mathrm{M}$ distances are highlighted in green. Reproduced with permission from ref. 43 under a CC BY 4.0 licence. 

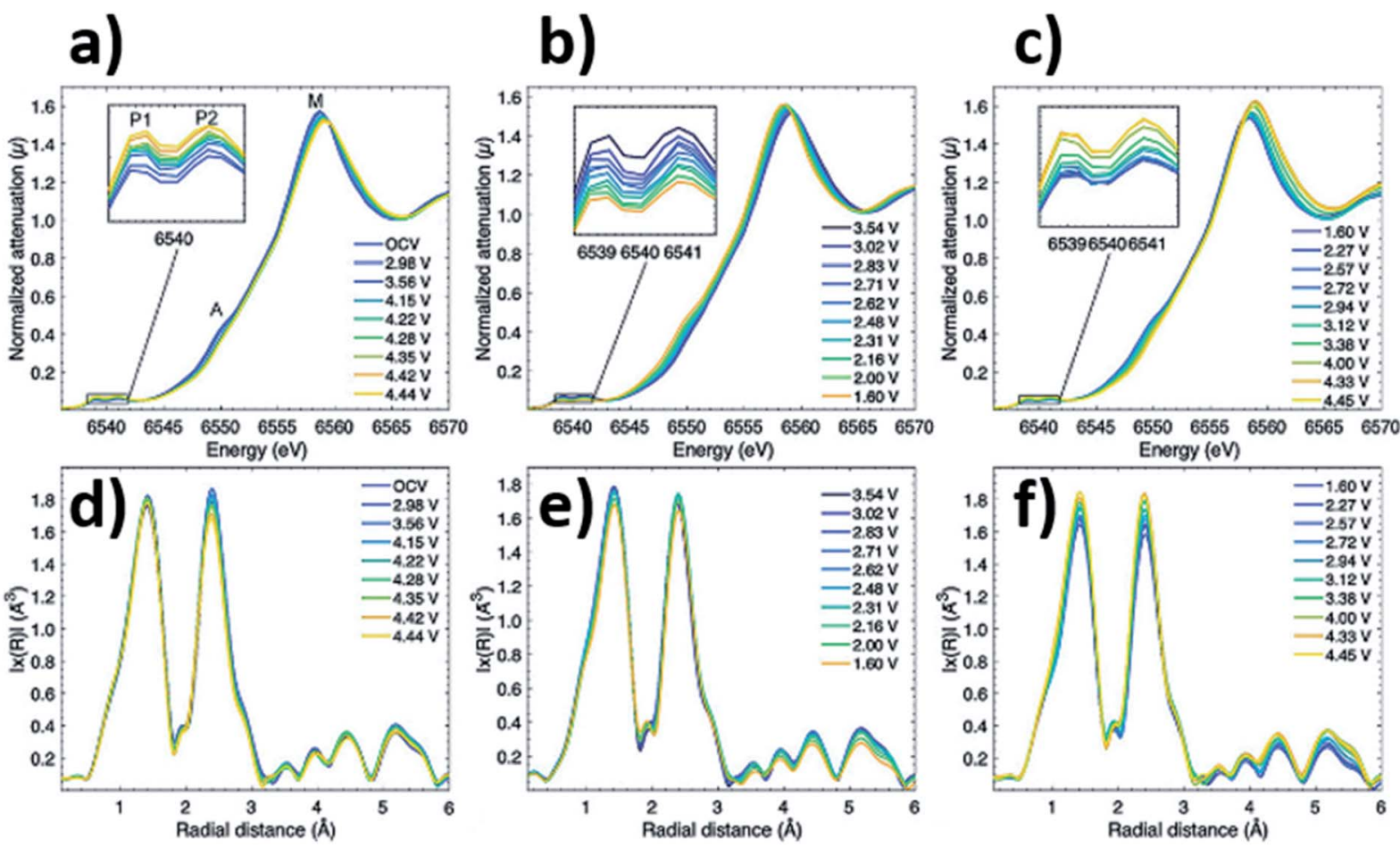

Fig. $19 \mathrm{X}$-ray absorption spectra collected at various states of charge from the $\mathrm{Na}_{2 / 3} \mathrm{Zn}_{1 / 4} \mathrm{Mn}_{3 / 4} \mathrm{O}_{2}$ electrode at the Mn K-edge. (a-c) Show XANES data and $(\mathrm{d}-\mathrm{f})$ show the Fourier transformed EXAFS during the first charge, first discharge, and second charge processes, respectively. Reproduced with permission from ref. 265.

and also the L-edges of $3 \mathrm{~d}$ transition metal elements which are commonly present in layered positive electrode materials. Both ex situ and in situ studies have been carried out on sodium-ion battery systems. ${ }^{264}$ Recently, Wang et al. studied a P2-type layered material with composition $\mathrm{Na}_{2 / 3} \mathrm{Zn}_{1 / 4} \mathrm{Mn}_{3 / 4} \mathrm{O}_{2}$ in which the unfavourable $\mathrm{P} 2-\mathrm{O} 2$ transition is suppressed, which significantly improves the cycling stability and rate capability of the $\mathrm{Na}_{x} \mathrm{MnO}_{2}$ system. ${ }^{265}$ In situ XRD confirmed that the transitions were suppressed during cycling to $4.5 \mathrm{~V}$. The authors coupled this with in situ XAS studies to investigate the influence of $\mathrm{Zn}$-doping on the electronic structure of the material. In situ XAS data, see Fig. 19, collected at the Mn K-edge exhibited a smaller energy shift in the Zn-substituted material compared to the pristine material, suggesting the redox activity of $\mathrm{Zn}$ allows the Mn to maintain a higher oxidation state during cycling. This in turn avoids the Jahn-Teller distortion associated with the reduction of $\mathrm{Mn}^{4+}$ to $\mathrm{Mn}^{3+}$, thereby suppressing the $\mathrm{P} 2-\mathrm{O} 2$ transition.

\subsection{Mössbauer spectroscopy}

Mössbauer spectroscopy is an isotope specific technique, sensitive to elements that have low lying excited states as well as a long-lived excited state, that provides information about the local environment of a nucleus. It is based on the phenomenon discovered by Rudolf Mössbauer in 1957 that the absorption and emission of gamma rays by nuclei bound in a solid takes place with minimal loss of energy from recoil of the nuclei. ${ }^{266}$ To record a Mössbauer spectrum, the sample is irradiated by an oscillating radiative source and absorption of gamma-rays are recorded as a function of oscillating velocity, see Fig. 20. When the energy of the gamma-rays matches the energy of a nuclear transition in the element under investigation, the radiation is absorbed giving rise to a peak in the spectrum. To this end, the sample must be sufficiently thin to allow for the penetration of gamma-rays. ${ }^{267}$ Since the energy levels of the absorbing nuclei is dependent on its environment, the technique can be used to provide information about the oxidation state of specific atoms.

Unlike in lithium-ion batteries and sodium super ion conductor (NASICON) iron phosphate-based materials, reversibility of the $\mathrm{Fe}^{3+/ 4+}$ redox couple has been shown in a variety of sodium layered oxide materials. ${ }^{268}$ In the context of sodium-ion batteries, ${ }^{57} \mathrm{Fe}$ Mössbauer spectroscopy is employed to probe the valence state of $\mathrm{Fe}$ at various states of charge/discharge. For example, Yabuuchi et al. used the technique to show that the $\mathrm{Fe}^{3+}$ present in $\mathrm{P} 2-\mathrm{Na}_{x}\left[\mathrm{Fe}_{1 / 2} \mathrm{Mn}_{1 / 2}\right] \mathrm{O}_{2}$, made from earthabundant elements, is electrochemically active based on the $\mathrm{Fe}^{3+/ 4+}$ redox couple. ${ }^{33}$ For $\mathrm{P} 2-\mathrm{Na}_{2 / 3} \mathrm{Mn}_{1 / 3} \mathrm{Fe}_{1 / 3} \mathrm{Co}_{1 / 3} \mathrm{O}_{2}$, simultaneous oxidation of $\mathrm{Co}^{3+}$ and $\mathrm{Fe}^{3+}$ was found to take place upon charging up to $4.1 \mathrm{~V}^{269}$ At the cut-off voltage of $4.1 \mathrm{~V}$, approximately $40 \%$ of Fe present in the sample was found to be in the $4+$ oxidation state. Given the low voltage hysteresis observed, it was suggested that the use of Co in combination with Fe may stabilize the oxidation of $\mathrm{Fe}^{3+}$ to $\mathrm{Fe}^{4+}$.

Due to their effect on neighbouring $\mathrm{Fe}^{3+}$ ions, ${ }^{57} \mathrm{Fe}$ Mössbauer spectra can also be used to detect $\mathrm{Na}$ vacancies. Upon extraction of sodium ions from O3-Na $\mathrm{Fe}_{x} \mathrm{Ti}_{1-x} \mathrm{O}_{2}(x \geq$ $0.75)$, Thorne et al. were able to identify several Na vacancies 


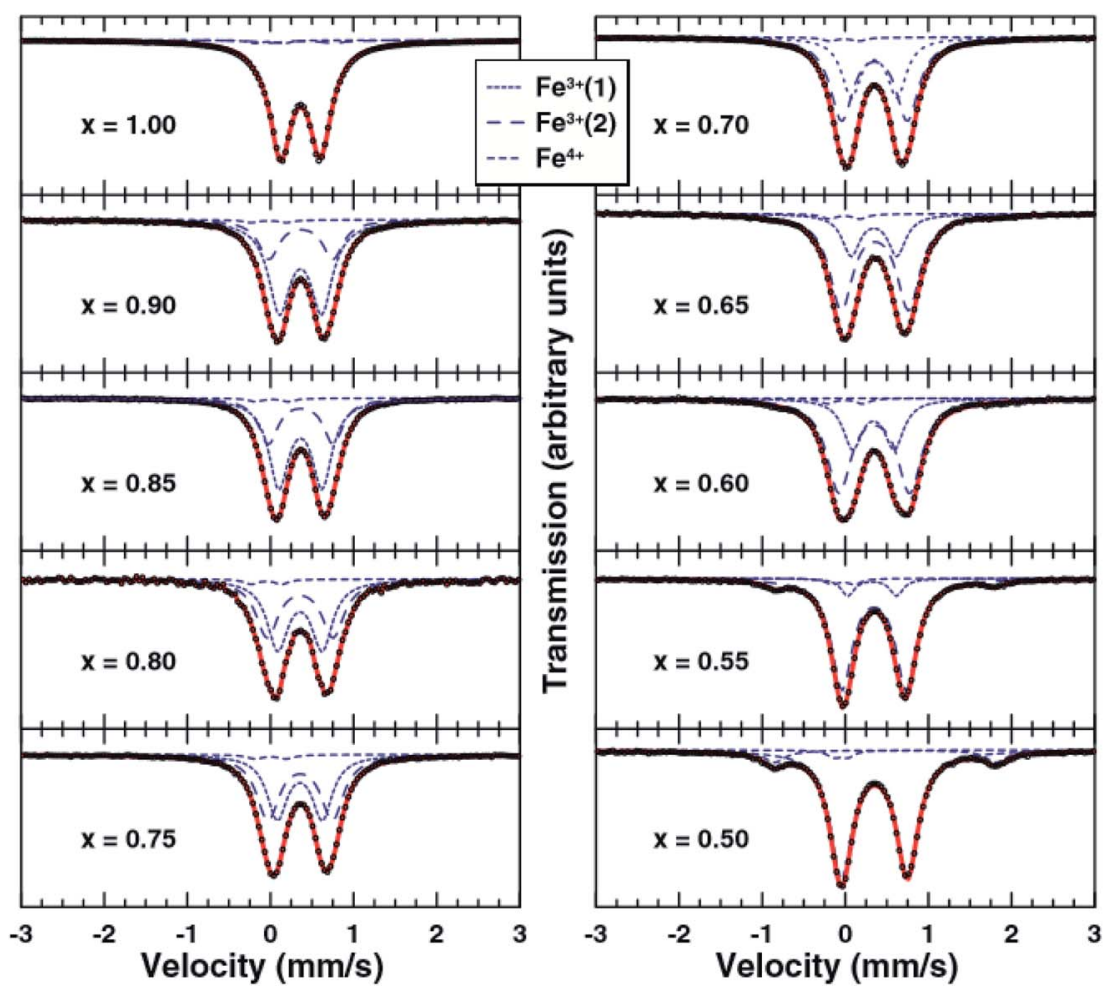

Fig. $20{ }^{57} \mathrm{Fe}$ Mössbauer spectra of $\mathrm{Na}_{x} \mathrm{Fe}_{x} \mathrm{Mn}_{1-x} \mathrm{O}_{2}$. The dashed lines represent the fitting components which sum together to yield the solid lines. The data are represented by black circles. Reproduced with permission from ref. 271.

located near $\mathrm{Fe}^{3+}$ sites. ${ }^{270}$ Moreover, the concurrent oxidation of $\mathrm{Fe}^{3+}$ to $\mathrm{Fe}^{4+}$, accompanied by significant structural distortion, was proposed to be a major source of hysteresis and capacity fade. Analogous to the electrochemical behaviour of the O3$\mathrm{Na}_{x} \mathrm{Fe}_{x} \mathrm{Mn}_{1-x} \mathrm{O}_{2}(x>0.65)$ system, the Mössbauer spectra showed that the cyclability can be improved by restricting the upper voltage so that the $\mathrm{Fe}^{3+/ 4+}$ redox couple is not utilized. ${ }^{271}$ Alternatively, inactivity of the $\mathrm{Fe}^{3+/ 4+}$ redox couple can be achieved by careful choice of composition. For instance, Mössbauer spectroscopy showed that the $\mathrm{Fe}^{3+/ 4+}$ redox reaction is not active up to $4.3 \mathrm{~V}$ in $\mathrm{P} 2-\mathrm{Na}_{2 / 3} \mathrm{Mn}_{0.8} \mathrm{Fe}_{0.1} \mathrm{Ti}_{0.1} \mathrm{O}_{2}{ }^{75}$

While studying the changes in $\mathrm{Fe}$ oxidation states of O3$\mathrm{NaFeO}_{2}$ electrodes during cycling via ex situ Mössbauer spectroscopy, Lee et al. noticed the instability of $\mathrm{Fe}^{4+}$ in a battery environment. ${ }^{46}$ During open circuit storage of the desodiated electrode, more than $20 \%$ of the $\mathrm{Fe}^{4+}$ species that had been generated upon charging spontaneously reduced back to $\mathrm{Fe}^{3+}$. Noting that $\mathrm{Fe}^{4+}$ is not stable outside electrochemical cells and therefore ex situ investigations may not provide accurate results, a limited number of in situ Mössbauer studies characterising the reversible oxidation of $\mathrm{Fe}^{3+}$ to $\mathrm{Fe}^{4+}$ have been published on Li-based electrochemical systems. ${ }^{272,273}$ To the best of our knowledge there are no reports of in situ Mössbauer studies on sodium-ion battery systems.

\subsection{Nuclear magnetic resonance spectroscopy}

Nuclear magnetic resonance (NMR) spectroscopy measures the magnetic field around atomic nuclei in order to provide information about the local environment of particular atoms. The technique is based on the principle that nuclei are electrically charged and certain nuclei have a spin which causes them to act as a magnet. In most molecular spectroscopy techniques, the excitation of molecules or electrons to higher states is measured. In the case of NMR spectroscopy an external magnetic field must be applied to the sample in order to generate two different energy levels. ${ }^{274}$ When an external magnetic field is applied to the sample, a radio frequency emission can be used to excite the nucleus to a higher spin state. The energy transfer required for this excitation process is dependent on the effective magnetic field at the nucleus. This field is dependent on the electron shielding around the nucleus, which is in turn dependant on the chemical environment or coordination of the atom, and thus information about the nucleus' local environment may derived from the spectra. For solid-phase media, such as battery electrodes, solid-state NMR (SS-NMR) of particular nuclei, such as ${ }^{6} \mathrm{Li},{ }^{7} \mathrm{Li}$ or ${ }^{23} \mathrm{Na}$, can be used to study the lithium or sodium storage mechanism. ${ }^{275}$ Several studies have successfully used SS-NMR to study the atomic environments and lattice dynamics (including the diffusion of ions) in various sodium-ion battery materials. ${ }^{276-279}$

Recently, Yang et al. investigated the effect of lithium and iron co-doping in the layered $\mathrm{Na}_{x} \mathrm{MO}_{2}$ system by characterising P2- $\mathrm{Na}_{0.66} \mathrm{Li}_{0.18} \mathrm{Fe}_{0.12} \mathrm{Mn}_{0.7} \mathrm{O}_{2}{ }^{278}$ Using ${ }^{7} \mathrm{Li}$ NMR studies, the authors were able to identify three different local environments of lithium within the material's structure, see Fig. 21. The resonances at $\approx 1600 \mathrm{ppm}$ and $\approx 1450 \mathrm{ppm}$ were attributed to 

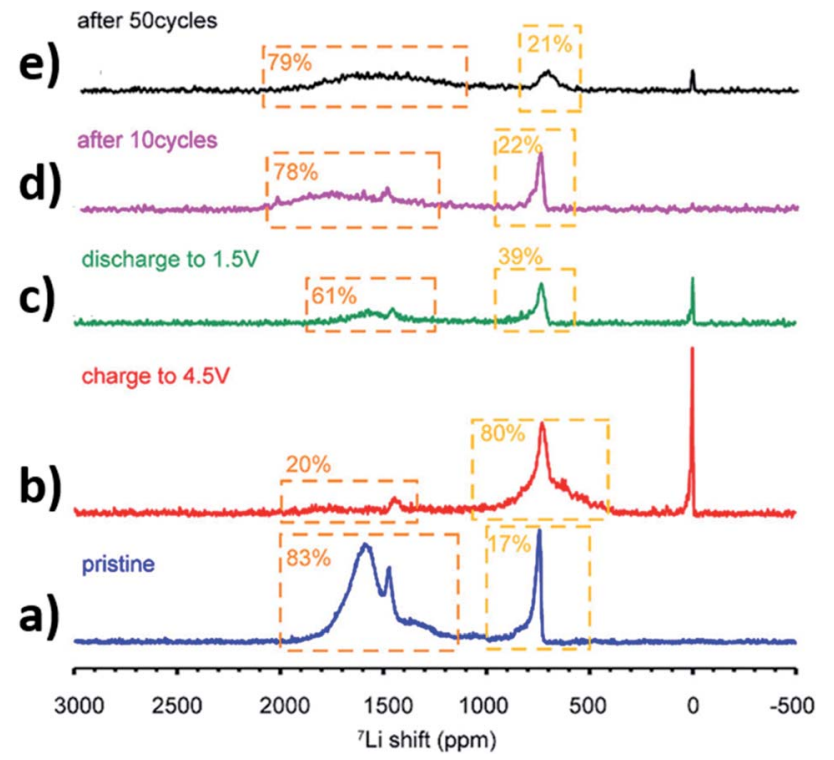

Fig. $21{ }^{7} \mathrm{Li}$ NMR spectra of $\mathrm{Na}_{0.66} \mathrm{Li}_{0.18} \mathrm{Fe}_{0.12} \mathrm{Mn}_{0.7} \mathrm{O}_{2}$ electrode samples at various states of charge: (a) pristine powder (blue), (b) after initial charge to $4.5 \mathrm{~V}$ (red), (c) after first discharge to $1.5 \mathrm{~V}$ (olive), (d) after 10 cycles (violet), and (e) after 50 cycles (black). Reproduced with permission from ref. 278 .

lithium nuclei in an ordered honeycomb arrangement within the transition metal layers, and the resonance at $\approx 750 \mathrm{ppm}$ was attributed to lithium in the sodium layer. NMR quantification showed that at the charged state a significant amount of lithium had migrated from the transition metal layers into the sodium layers, $17 \%$ to $80 \%$. After discharging to $1.5 \mathrm{~V}$, the fraction of lithium in the transition metal layer decreased to $39 \%$ and appears to reach an equilibrium value around $\approx 21 \%$ after 50 cycles. Complementary in situ XRD data showed that the unfavourable $\mathrm{P} 2-\mathrm{O} 2$ transition was avoided during cycling of this material, enabling good capacity retention during cycling to $4.5 \mathrm{~V}$. The migration of lithium between the sodium and transition metal layers appears to help stabilise the P2 structure even at high levels of de-sodiation at the charged state.

\subsection{Electron paramagnetic resonance spectroscopy}

As opposed to the utilisation of the inherent spin of the atomic nuclei to perform NMR experiments, electron paramagnetic resonance (EPR) spectroscopy utilises the spin of electrons in paramagnetic materials. While information about $\mathrm{Na}-\mathrm{O}-\mathrm{M}$ interactions between the distinct layers can be obtained by NMR spectroscopy, EPR spectroscopy probes paramagnetic ions within the $\mathrm{MO}_{2}$ layer directly. The data obtained provides information about the oxidation state of transition metal ions and their relation to the local structure of sodium nuclei, which complements the information about the sodium environment that can be obtained via $^{23} \mathrm{Na}$ NMR spectroscopy. ${ }^{56}$

EPR has been used to show that the charge compensation of P3- $\mathrm{Na}_{y} \mathrm{Co}_{1 / 3} \mathrm{Ni}_{1 / 3} \mathrm{Mn}_{1 / 3} \mathrm{O}_{2}(0.38<y \leq 0.75)$ upon extraction of sodium ions is achieved by selective oxidation of $\mathrm{Ni}^{2+}$ to $\mathrm{Ni}^{3+}$ and $\mathrm{Ni}^{4+}$, while the $\mathrm{Co}$ and $\mathrm{Mn}$ ions retain their valance states of +3 and +4 respectively, see Fig. $22 . .^{58}$ It was also found that a Mn

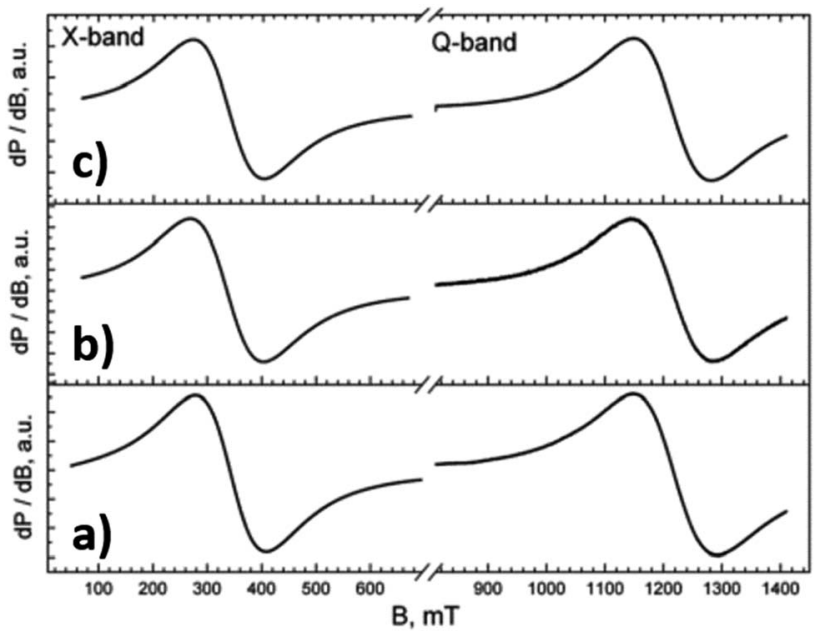

Fig. 22 EPR spectra of (a) $\mathrm{P3}-\mathrm{Na}_{2 / 3} \mathrm{CO}_{1 / 3} \mathrm{Ni}_{1 / 3} \mathrm{Mn}_{1 / 3} \mathrm{O}_{2}$ (b) P3- $\mathrm{Na}_{1 / 2} \mathrm{Ni}_{1 / 2} \mathrm{Mn}_{1 / 2} \mathrm{O}_{2}$ (c) $\mathrm{P} 2-\mathrm{Na}_{2 / 3} \mathrm{Ni}_{1 / 3} \mathrm{Mn}_{2 / 3} \mathrm{O}_{2}$. Information about the transition metal oxidation states can be extracted by fitting Hamiltonian parameters the spectra. Reproduced with permission from ref. 56.

oxidation state of +4 is maintained for the P3- $\mathrm{Na}_{y} \mathrm{Ni}_{1 / 2} \mathrm{Mn}_{1 / 2} \mathrm{O}_{2}$ $(0.5 \leq y<0.75)$ composition, thereby minimising phase transitions induced by Jahn-Teller distortion of $\mathrm{Mn}^{3+}{ }^{380}$

\subsection{Microscopy}

A variety of microscopy techniques are available for studying materials at the microscale and nanoscale such as optical, electron, X-ray and scanning probe microscopy. Compared to other characterisation techniques discussed, which typically characterise the bulk electrode material or specific regions, microscopy can resolve materials' details at the particle level. For batteries in particular, these techniques can be used to derive information about particle size distributions, morphology, packing density, or porosity, and also monitor for signs of strain or stress such as particle cracking, electrode contact or degradation of interfacial layers. ${ }^{281}$

4.7.1 Electron microscopy. Electron microscopy has proven to be a useful tool for examining the evolution of electrode's particle morphology before and after cycling. In scanning electron microscopy (SEM), a beam of electrons is used to scan the sample's surface. The focused beam interacts with a small volume of material at the surface of the sample which generates backscattered or secondary electrons. The scattered electrons are then detected and used to form an image of the sample surface. ${ }^{282}$ SEM offers 2D visualisation of sample morphology and can be coupled with energy-dispersive X-ray spectroscopy (EDX) analysis to deliver elemental contrast. This technique is routinely used for ex situ characterisation of battery materials. ${ }^{283,284}$ Compared to SEM or optical microscopy, transmission electron microscopy (TEM) is advantageous in offering higher resolution when imaging detailed features. TEM utilises a much higher voltage to accelerate the electron beam, which allows the beam to be transmitted through a typically thin sample and generate a projection. TEM also allows for electron diffraction which can provide information about the crystal 
structure and its features such as dislocations or grain boundaries.

In their study of the P2-type $\mathrm{Na}_{2 / 3} \mathrm{Ni}_{1 / 3} \mathrm{Mn}_{2 / 3} \mathrm{O}_{2}$ system, Wang et al. were able to identify a correlation between the $\mathrm{P} 2-\mathrm{O} 2$ phase transition, observed when the cell was charged to $4.2 \mathrm{~V}$, and the generation of a high density of intragranular cracks using a combination of complementary techniques including SEM and TEM. ${ }^{233}$ This correlation explains the significant decay in performance after repeated cycling to high cut-off voltages. The transition generates unfavourable stress/strain at the $\mathrm{P} 2 / \mathrm{O} 2$ phase boundary which was identified as the preferential site of crack initialisation. Similar observations of particle cracking have been observed in several lithium-ion battery systems, where performance degradation has also been attributed to the exposure of new surfaces to the electrolyte causing electrode surface decomposition and electrolyte consumption. ${ }^{285-288}$

A number of in situ electron microscopy studies have also been used to study the dynamic processes occurring in working batteries which have been summarised in some informative review articles. ${ }^{289,290}$

4.7.2 Scanning transmission electron microscopy/electron energy loss spectroscopy. TEM, SEM and Electron Energy Loss Spectroscopy (EELS) can be combined to provide information about the ordering of transition metals and the onset of oxygen activity. Taking advantage of the (S)TEM setup, electrons are fired at the sample, the electrons interact with the sample and subsequently the post-interaction electron energy is measured to produce an energy loss spectrum. The electrons may interact elastically, without losing energy, inelastically with weakly bond electrons in the sample or inelastically with tightly bound core electrons in the atoms of the sample. ${ }^{256}$ The latter corresponds to ionization edges in a plot of intensity $v s$. energy, as shown in Fig. 23.

Using the combined STEM-EELS technique, Li et al. observed the presence of $\mathrm{Mn}$ charge ordering in $\mathrm{Na}_{5 / 8} \mathrm{MnO}_{2}$. Alongside findings that there exists a superstructure, the cooperative Jahn Teller effect was found to be linked with sodium ion/vacancy ordering. Overall, the work emphasises the important role that structural details play in determining electronic behaviour of a material. ${ }^{129}$ Participation of oxygen anions in the initial charge compensation mechanism of $\mathrm{P} 2-\mathrm{Na}_{0.78} \mathrm{Ni}_{0.23} \mathrm{Mn}_{0.69} \mathrm{O}_{2}$ has also been explored using EELS and XAS. ${ }^{26}$ In the electrochemically cycled particles, a difference in the electronic structure of the bulk and surface was found, whereby transition metal ions are in a lower valence state relative to the bulk. Moreover, loss of the $\mathrm{O}$ K-edge pre-peak at the surface signifies oxygen activity upon charging, see Fig. 23. It was therefore proposed that the charge compensation mechanism during the first cycle involves oxygen redox activity, resulting in a surface to bulk transition metal gradient.

4.7.3 Transmission X-ray microscopy. Synchrotron scanning transmission X-ray microscopy (TXM) enables high resolution mapping of samples at scales of down to $20 \mathrm{~nm}$ and can be used in conjunction with XAS data collection. High energy $\mathrm{X}$-rays are focused into a small diameter and used scan the sample surface, while the intensity of transmitted X-rays is
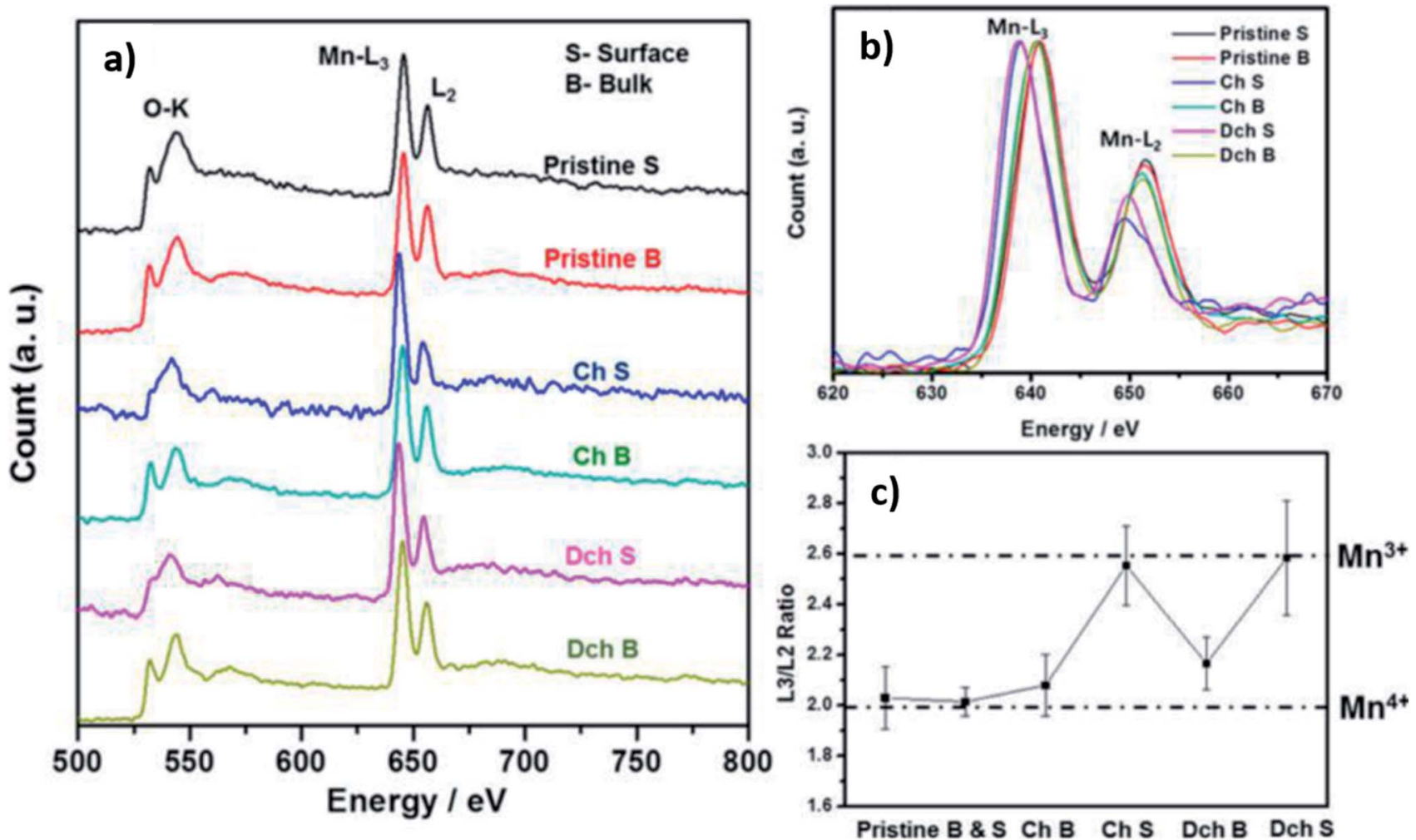

Fig. 23 EELS spectra measured at the surface (S) and in the bulk (B) of $\mathrm{Na}_{x} \mathrm{Ni}_{0.23} \mathrm{Mn}_{0.69} \mathrm{O}_{2}$ corresponding to (a) the O K-edge and $\mathrm{Mn} \mathrm{L}$-edge (b) $\mathrm{Mn} \mathrm{L-edge} \mathrm{only} \mathrm{(c)} \mathrm{the} \mathrm{Mn} \mathrm{L}_{3} / \mathrm{L}_{2}$ ratio, which is inversely proportional to the $\mathrm{Mn}$ charge state. Reproduced with permission from ref. 26 . Copyright 2017 American Chemical Society. 
measured as a function of position. ${ }^{291}$ The data can provide information about the distribution of phases or chemical species within individual particles in the electrode, allowing for the $3 \mathrm{D}$ distribution of chemical environments in the electrode to be determined. ${ }^{292}$

Using a combination of operando XRD and TXM-XANES, Xie et al. studied the high voltage structural evolution of O3- $\mathrm{Na}\left[\mathrm{Ni}_{1 / 3} \mathrm{Fe}_{1 / 3} \mathrm{Mn}_{1 / 3}\right] \mathrm{O}_{2} .{ }^{293}$ The TXM-XANES mapping was able to complement the structural evolution observed in the XRD data to reveal the distribution of phases in the solid-solution which forms during (de-)sodiation. The mapping revealed non-uniform distribution of mixed-phase zones, with compositions spanning a range varying between two thermodynamic phases, $\mathrm{NaNi}_{1 / 3} \mathrm{Fe}_{1 / 3} \mathrm{Mn}_{1 / 3} \mathrm{O}_{2}$ and $\mathrm{Ni}_{1 / 3} \mathrm{Fe}_{1 / 3} \mathrm{Mn}_{1 / 3} \mathrm{O}_{2}$, essentially providing a visualisation of the reaction front during the (de-) sodiation.

4.7.4 Scanning probe microscopy. Unlike the techniques discussed above, scanning probe microscopy techniques use a physical probe to scan the surface of the sample. An image may be formed using either contact interaction mode where the probe maintains a constant height above the sample surface using a feedback loop, or constant height mode where the probe height remains constant and the change in interaction between the probe and the sample surface is used to map the surface. ${ }^{294}$ The use of scanning probe microscopy techniques for studying energy storage materials is relatively uncommon. However, their ability to characterise materials at the atomic scale has enabled researchers to examine more minute physiochemical properties of battery electrodes, such as interfacial reactions at the electrode surface, ionic diffusion within particles, or the presence of microstructural features and their effect on charge transport. ${ }^{295}$

\subsection{Computational studies}

The use of computational simulation studies to assist with the atomic-scale prediction of a material's structure, reaction pathways, and ion mobility has played a vital role in the characterisation of layered positive electrode materials. ${ }^{296} \mathrm{Compu}$ tational studies are complimentary to experimental studies; computational results can be used to determine appropriate experimental parameters, while experimental results can help to inform simulation input parameters for improved accuracy of computational models.

For the study of solid-state materials, two main classes of computation modelling are typically used: interatomic potential-minimisation methods, which may use static lattice or molecular dynamics models, and electronic structure methods, which may employ density functional theory (DFT), for example. Several in-depth reviews have discussed how these techniques have been employed to study a variety of energy storage and energy generation materials. In particular, the versatility of computational studies in revealing atomic scale structures, processes and parameters which contribute to the behaviour of functional materials is considered. ${ }^{296-299}$

Sodium layered oxides exhibit numerous stable polymorphs and vacancy ordering arrangements at various levels of (de-)
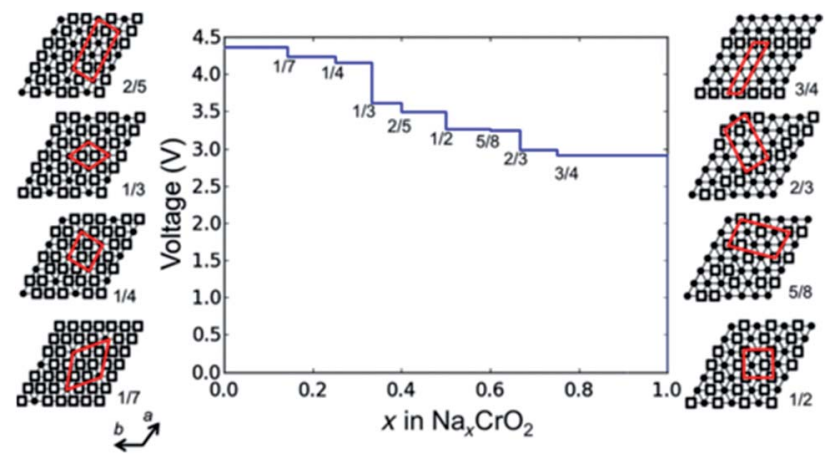

Fig. 24 Computed O3-lattice voltage curve with illustrations of the predicted ground-state sodium ion/vacancy orderings for $\mathrm{Na}_{x} \mathrm{CrO}_{2}$ at various states of charge. Reproduced with permission from ref. 301.

sodiation. ${ }^{125}$ By using the free energies determined from first principles calculations, the equilibrium voltages between the various stable structures can be determined, and this subsequently allows for the voltage profile of these materials to be constructed as a function of sodium concentration. ${ }^{299}$ Several studies have used the simulated voltage profile in tandem with experimental observations to identify the intermediate phases which form during cycling. ${ }^{300}$ This is of particular interest for studying the high voltage behaviour of sodium layered oxide materials where complex vacancy ordering mechanisms arise to compensate for the sodium deficient structure. For example, Toumar et al. used DFT calculations to generate theoretical electrochemical voltages curves for various O3-type layered oxides. ${ }^{301}$ Fig. 24 shows an example of the computed voltage curve for O3-type $\mathrm{Na}_{x} \mathrm{CrO}_{2}$, along with the predicted groundstate vacancy orderings. Voltage curves were also calculated for other $\mathrm{Na}_{x} \mathrm{MO}_{2}$ systems, where $\mathrm{M}=\mathrm{Ti}, \mathrm{V}, \mathrm{Mn}, \mathrm{Fe}, \mathrm{Co}$, and $\mathrm{Ni}$. The authors were able to identify 18 orderings which appear as ground states in one or more of the seven systems which were studied. In another study, Bai et al. also made use of DFT calculations to investigate the anionic redox activity of the P2$\mathrm{Na}_{2 / 3} \mathrm{Mn}_{7 / 9} \mathrm{Zn}_{2 / 9} \mathrm{O}_{2}$ system at high voltages. ${ }^{107}$

\section{Summary and outlook}

Layered oxides with the chemical formula $\mathrm{Na}_{x} \mathrm{MO}_{2}$ are a promising class of positive electrode material for application in rechargeable sodium-ion batteries. However, their performance is often limited by structural instability at the charged state, as a result of the host lattice being sodium deficient. This structrual instability gives rise to various structural phenomena as the lattice rearranges to accommodate the vacancies, such as phase transitions, migration of transition metals into the sodium layer and charge balancing via reduction of anions. If exploited appropriately, the reversible migration of atoms between the transition metal layer and alkali metal layer upon charging can stabilise the structure enabling more sodium and hence capacity to be extracted; the same outcome could be achieved through utilization of the oxygen redox reaction without loss of $\mathrm{O}_{2}$; or optimising the phase transitions to remain reversible. 
Continual advancement in knowledge regarding transition metal migration, phase transitions and the oxygen redox reaction in sodium layered oxides are essential to their development.

As summarized in this review, there are several options for improving the structural stability of layered oxides at the charged state. Tuning the chemical composition is the method that has been most widely explored to date. Research in this space highlights the cooperative ability of several elements to compensate for structural instability and optimise reactions at high voltage. While there are still opportunities to fine tune the chemical composition of sodium layered oxides, investigations into alternative modifications such as composite materials, which exploit the assets of multiple-phase materials, or optimization of the cathode electrode interface could be more rewarding. Developing electrolytes and understanding the interaction between solid-state electrolytes and sodium layeredoxides could deliver viable solutions for long term, safe and reliable cycling.

To gain a mechanistic and structural understanding of layered materials on the atomic scale, cutting edge characterisation techniques are required. The wide range of complementary techniques available today has enabled numerous prospective sodium layered oxide materials to be scrutinised. While ex situ techniques may be more accessible, the development of in situ techniques has and will continue to facilitate the acquisition of more accurate information, correlated directly to device performance. Furthermore, the high resolution and intensity offered at synchrotron facilities will be key for characterising battery materials, probing both their long-range and short-range ordering. The knowledge and understanding gained from both existing and state-of-the-art techniques will be imperative for the continual development of next generation battery materials for large scale storage of renewable energy.

\section{Conflicts of interest}

The authors declare there are no conflicts of interest to address.

\section{Acknowledgements}

J. S. and D. G. contributed equally to this work. J. S. acknowledges the support of UNSW/ANSTO for the PhD scholarship. N. S. would like to thank the Australian Research Council (ARC) for financial support provided via grants DP200100959 and FT200100707. The authors acknowledge support by the KITPublication Fund of the Karlsruhe Institute of Technology.

\section{References}

1 D. Lindley, Nature, 2010, 463, 18.

2 B. Nykvist and M. Nilsson, Nat. Clim. Change, 2015, 5, 329332.

3 G. L. Soloveichik, Annu. Rev. Chem. Biomol. Eng., 2011, 2, 503-527.

4 M. M. Thackeray, C. Wolverton and E. D. Isaacs, Energy Environ. Sci., 2012, 5, 7854-7863.
5 D. Kamath, R. Arsenault, H. C. Kim and A. Anctil, Environ. Sci. Technol., 2020, 54, 6878-6887.

6 H. Pan, Y.-S. Hu and L. Chen, Energy Environ. Sci., 2013, 6, 2338.

7 A. Poullikkas, Renewable Sustainable Energy Rev., 2013, 27, 778-788.

8 H. S. Hirsh, Y. X. Li, D. H. S. Tan, M. H. Zhang, E. Y. Zhao and Y. S. Meng, Adv. Energy Mater., 2020, 10(32), 2001274.

9 J. Barker, M. Saidi and J. Swoyer, Electrochem. Solid-State Lett., 2003, 6, A1-A4.

10 D. Kundu, E. Talaie, V. Duffort and L. F. Nazar, Angew. Chem., Int. Ed., 2015, 54, 3431-3448.

11 Y. Lu, L. Wang, J. Cheng and J. B. Goodenough, Chem. Commun., 2012, 48, 6544-6546.

12 M. H. Han, E. Gonzalo, G. Singh and T. Rojo, Energy Environ. Sci., 2015, 8, 81-102.

13 C. Delmas, Adv. Energy Mater., 2018, 1703137, DOI: 10.1002/ aenm.201703137.

14 N. Sharma, N. Tapia-Ruiz, G. Singh, A. R. Armstrong, J. C. Pramudita, H. E. A. Brand, J. Billaud, P. G. Bruce and T. Rojo, Chem. Mater., 2015, 27, 6976-6986.

15 C. Delmas, C. Fouassier and P. Hagenmuller, Phys. $B+C$, 1980, 99, 81-85.

16 M. Bianchini, J. Wang, R. J. Clement, B. Ouyang, P. Xiao, D. Kitchaev, T. Shi, Y. Zhang, Y. Wang, H. Kim, M. Zhang, J. Bai, F. Wang, W. Sun and G. Ceder, Nat. Mater., 2020, 19, 1088-1095.

17 D. Zhou, W. Huang, X. Lv and F. Zhao, J. Power Sources, 2019, 421, 147-155.

18 N. Yabuuchi, K. Kubota, M. Dahbi and S. Komaba, Chem. Rev., 2014, 114, 11636-11682.

19 P. Hou, F. Li, Y. Wang, J. Yin and X. Xu, J. Mater. Chem. A, 2019, 7, 4705-4713.

20 S.-H. Bo, X. Li, A. J. Toumar and G. Ceder, Chem. Mater., 2016, 28, 1419-1429.

21 Y. Sun, S. Guo and H. Zhou, Energy Environ. Sci., 2019, 12, 825-840.

22 D. H. Lee, J. Xu and Y. S. Meng, Phys. Chem. Chem. Phys., 2013, 15, 3304.

23 R. J. Clément, P. G. Bruce and C. P. Grey, J. Electrochem. Soc., 2015, 162, A2589.

24 K. Kubota and S. Komaba, J. Electrochem. Soc., 2015, 162, A2538-A2550.

25 Z. Lu and J. R. Dahn, J. Electrochem. Soc., 2001, 148, A1225A1229.

26 C. Ma, J. Alvarado, J. Xu, R. J. Clément, M. Kodur, W. Tong, C. P. Grey and Y. S. Meng, J. Am. Chem. Soc., 2017, 139, 4835-4845.

27 E. Talaie, S. Y. Kim, N. Chen and L. F. Nazar, Chem. Mater., 2017, 29, 6684-6697.

28 L. Zheng, J. Li and M. N. Obrovac, Chem. Mater., 2017, 29, 1623-1631.

29 X. Wu, J. Guo, D. Wang, G. Zhong, M. J. McDonald and Y. Yang, J. Power Sources, 2015, 281, 18-26.

30 P. F. Wang, Y. You, Y. X. Yin, Y. S. Wang, L. J. Wan, L. Gu and Y. G. Guo, Angew. Chem., Int. Ed., 2016, 55, 7445-7449. 
31 G. Singh, J. M. López del Amo, M. Galceran, S. Pérez-Villar and T. Rojo, J. Mater. Chem. A, 2015, 3, 6954-6961.

32 A. Gutierrez, W. M. Dose, O. Borkiewicz, F. Guo, M. Avdeev, S. Kim, T. T. Fister, Y. Ren, J. Bareño and C. S. Johnson, J. Phys. Chem. C, 2018, 122, 23251-23260.

33 N. Yabuuchi, M. Kajiyama, J. Iwatate, H. Nishikawa, S. Hitomi, R. Okuyama, R. Usui, Y. Yamada and S. Komaba, Nat. Mater., 2012, 11, 512-517.

34 N. Sharma, M. H. Han, J. C. Pramudita, E. Gonzalo, H. E. A. Brand, T. Rojo, V. K. Peterson, T. Rojo, X. Huang, Z. Ogumi, A. Wattiaux and C. Delmas, J. Mater. Chem. A, 2015, 3, 21023-21038.

35 W. M. Dose, N. Sharma, J. C. Pramudita, J. A. Kimpton, E. Gonzalo, M. H. Han and T. Rojo, Chem. Mater., 2016, 28, 6342-6354.

36 J. Billaud, G. Singh, A. R. Armstrong, E. Gonzalo, V. Roddatis, M. Armand, T. Rojo and P. G. Bruce, Energy Environ. Sci., 2014, 7, 1387-1391.

37 J. W. Somerville, A. Sobkowiak, N. Tapia-Ruiz, J. Billaud, J. G. Lozano, R. A. House, L. C. Gallington, T. Ericsson, L. Häggström, M. R. Roberts, U. Maitra and P. G. Bruce, Energy Environ. Sci., 2019, 12, 2223-2232.

38 W. K. Pang, S. Kalluri, V. K. Peterson, N. Sharma, J. Kimpton, B. Johannessen, H. K. Liu, S. X. Dou and Z. Guo, Chem. Mater., 2015, 27, 3150-3158.

39 L. Liu, X. Li, S.-H. Bo, Y. Wang, H. Chen, N. Twu, D. Wu and G. Ceder, Adv. Energy Mater., 2015, 5, 1500944.

40 J. W. Somerville, A. Sobkowiak, N. Tapia-Ruiz, J. Billaud, J. G. Lozano, R. A. House, L. C. Gallington, T. Ericsson, L. Häggström, M. R. Roberts, U. Maitra and P. G. Bruce, Energy Environ. Sci., 2019, 12, 2223-2232.

41 B. Mortemard de Boisse, D. Carlier, M. Guignard, L. Bourgeois and C. Delmas, Inorg. Chem., 2014, 53, 11197-11205.

42 W. Zhao, Y. Tsuchiya and N. Yabuuchi, Small Methods, 2019, 3(4), 1800032.

43 E. Talaie, V. Duffort, H. L. Smith, B. Fultz and L. F. Nazar, Energy Environ. Sci., 2015, 8, 2512-2523.

44 S. Komaba, T. Nakayama, A. Ogata, M. Shimizu, C. Takei, S. Takada, A. Hokura and I. Nakai, ECS Trans., 2009, 16, 43-55.

45 P. F. Wang, Y. You, Y. X. Yin and Y. G. Guo, Adv. Mater., 2018, 8, 1701912.

46 E. Lee, D. E. Brown, E. E. Alp, Y. Ren, J. Lu, J.-J. Woo and C. S. Johnson, Chem. Mater., 2015, 27, 6755-6764.

47 C. Didier, M. Guignard, C. Denage, O. Szajwaj, S. Ito, I. Saadoune, J. Darriet and C. Delmas, Electrochem. SolidState Lett., 2011, 14(5), A75.

48 E. Gonzalo, M. H. Han, J. M. López del Amo, B. Acebedo, M. Casas-Cabanas and T. Rojo, J. Mater. Chem. A, 2014, 2, 18523-18530.

49 C. Zhao, M. Avdeev, L. Chen and Y. S. Hu, Angew. Chem., Int. Ed., 2018, 57, 7056-7060.

50 X. Li, D. Wu, Y.-N. Zhou, L. Liu, X.-Q. Yang and G. Ceder, Electrochem. Commun., 2014, 49, 51-54.
51 K. Kubota, T. Asari, H. Yoshida, N. Yaabuuchi, H. Shiiba, M. Nakayama and S. Komaba, Adv. Funct. Mater., 2016, 26, 6047-6059.

52 M. Sathiya, K. Hemalatha, K. Ramesha, J. M. Tarascon and A. S. Prakash, Chem. Mater., 2012, 24, 1846-1853.

53 M. H. Han, E. Gonzalo, M. Casas-Cabanas and T. Rojo, J. Power Sources, 2014, 258, 266-271.

54 F. Ding, C. Zhao, D. Zhou, Q. Meng, D. Xiao, Q. Zhang, Y. Niu, Y. Li, X. Rong, Y. Lu, L. Chen and Y.-S. Hu, Energy Storage Mater., 2020, 30, 420-430.

55 Y. Wang, X. Wang, X. Li, R. Yu, M. Chen, K. Tang and X. Zhang, Chem. Eng. J., 2019, 360, 139-147.

56 M. Kalapsazova, S. Ivanova, R. Kukeva, S. Simova, S. Wegner, E. Zhecheva and R. Stoyanova, Phys. Chem. Chem. Phys., 2017, 19, 27065-27073.

57 M. Kalapsazova, G. F. Ortiz, J. L. Tirado, O. Dolotko, E. Zhecheva, D. Nihtianova, L. Mihaylov and R. Stoyanova, ChemPlusChem, 2015, 80, 1642-1656.

58 S. Ivanova, E. Zhecheva, R. Kukeva, G. Tyuliev, D. Nihtianova, L. Mihailov and R. Stoyanova, J. Phys. Chem. C, 2016, 120, 3654-3668.

59 S. Guo, Y. Sun, J. Yi, K. Zhu, P. Liu, Y. Zhu, G.-z. Zhu, M. Chen, M. Ishida and H. Zhou, NPG Asia Mater., 2016, 8, e266.

60 O. Arcelus and J. Carrasco, ACS Appl. Mater. Interfaces, 2019, 11, 12562-12569.

61 C. Zhao, Z. Yao, Q. Wang, H. Li, J. Wang, M. Liu, S. Ganapathy, Y. Lu, J. Cabana, B. Li, X. Bai, A. AspuruGuzik, M. Wagemaker, L. Chen and Y. S. Hu, J. Am. Chem. Soc., 2020, 142, 5742-5750.

62 M. D. Radin, J. Alvarado, Y. S. Meng and A. Van der Ven, Nano Lett., 2017, 17, 7789-7795.

63 X. Zhang, S. Guo, P. Liu, Q. Li, S. Xu, Y. Liu, K. Jiang, P. He, M. Chen, P. Wang and H. Zhou, Adv. Energy Mater., 2019, 1900189, DOI: 10.1002/aenm.201900189.

64 H. Yu, Y. Qian, M. Otani, D. Tang, S. Guo, Y. Zhu and H. Zhou, Energy Environ. Sci., 2014, 7(3), 1068-1078.

65 W. Liu, P. Oh, X. Liu, M. J. Lee, W. Cho, S. Chae, Y. Kim and J. Cho, Angew. Chem., Int. Ed., 2015, 54, 4440-4457.

66 K. Ku, B. Kim, S. K. Jung, Y. Gong, D. Eum, G. Yoon, K. Y. Park, J. Hong, S. P. Cho, D. H. Kim and H. Kim, Energy Environ. Sci., 2020, 13(4), 1269-1278.

67 A. Maazaz, C. Delmas and P. Hagenmuller, J. Inclusion Phenom., 1983, 1, 45-51.

68 K. Kubota, I. Ikeuchi, T. Nakayama, C. Takei, N. Yabuuchi, H. Shiiba, M. Nakayama and S. Komaba, J. Phys. Chem. C, 2014, 119, 166-175.

69 N. Yabuuchi, H. Yoshida and S. Komaba, Electrochemistry, 2012, 80, 716-719.

70 X. Li, Y. Wang, D. Wu, L. Liu, S.-H. Bo and G. Ceder, Chem. Mater., 2016, 28, 6575-6583.

71 B. Silván, E. Gonzalo, L. Djuandhi, N. Sharma, F. Fauth and D. Saurel, J. Mater. Chem. A, 2018, 6, 15132-15146.

72 S. Guo, Y. Sun, P. Liu, J. Yi, P. He, X. Zhang, Y. Zhu, R. Senga, K. Suenaga, M. Chen and H. Zhou, Sci. Bull., 2018, 63, 376-384.

73 M. Wagemaker, Sci. Bull., 2018, 63, 529-530. 
74 B. Silván, E. Gonzalo, L. Djuandhi, N. Sharma, F. Fauth and D. Saurel, J. Mater. Chem. A, 2018, 6, 15132-15146.

75 M. H. Han, E. Gonzalo, N. Sharma, J. M. López Del Amo, M. Armand, M. Avdeev, J. J. Saiz Garitaonandia and T. Rojo, Chem. Mater., 2016, 28, 106-116.

76 D. H. Lee, J. Xu and Y. S. Meng, Phys. Chem. Chem. Phys., 2013, 15, 3304-3312.

77 X. Zhang, S. Guo, P. Liu, Q. Li, S. Xu, Y. Liu, K. Jiang, P. He, M. Chen, P. Wang and H. Zhou, Adv. Energy Mater., 2019, 9, 1900189-1900196.

78 Y. Li, Y. Gao, X. Wang, X. Shen, Q. Kong, R. Yu, G. Lu, Z. Wang and L. Chen, Nano Energy, 2018, 47, 519-526.

79 C. Chen, Z. Ding, Z. Han, C. Liang, X. Lan, P. Wang, P. Gao and W. Wei, J. Phys. Chem. Lett., 2020, 11, 5464-5470.

80 Y. N. Zhang, S. Kim, G. Y. Feng, Y. Wang, L. Liu, G. Ceder and X. Li, J. Electrochem. Soc., 2018, 165, A1184-A1192.

81 A. Grimaud, W. T. Hong, Y. Shao-Horn and J. M. Tarascon, Nat. Mater., 2016, 15, 121.

82 M. Jia, Y. Qiao, X. Li, F. Qiu, X. Cao, P. He and H. Zhou, ACS Appl. Mater. Interfaces, 2020, 12, 851-857.

83 W. Jiang, C. Yin, Y. Xia, B. Qiu, H. Guo, H. Cui, F. Hu and Z. Liu, ACS Appl. Mater. Interfaces, 2019, 11(15), 1402314034.

84 K. Luo, M. R. Roberts, N. Guerrini, N. Tapia-Ruiz, R. Hao, F. Massel, D. M. Pickup, S. Ramos, Y.-S. Liu and J. Guo, J. Am. Chem. Soc., 2016, 138, 11211-11218.

85 C. Zhao, Q. Wang, Y. Lu, Y.-S. Hu, B. Li and L. Chen, J. Phys. D: Appl. Phys., 2017, 50, 183001.

86 Y. Zhang, M. Wu, J. Ma, G. Wei, Y. Ling, R. Zhang and Y. Huang, ACS Cent. Sci., 2020, 6, 232-240.

87 G. Assat and J.-M. Tarascon, Nat. Energy, 2018, 3, 373-386.

88 B. Su, H. Liang, J. Liu, J. Wu, N. Sharma, Q. Gu, B. Johannessen and D. Y. W. Yu, Chem. Commun., 2020, 56, 8245-8248.

89 Y. Qiao, S. Guo, K. Zhu, P. Liu, X. Li, K. Jiang, C.-J. Sun, M. Chen and H. Zhou, Energy Environ. Sci., 2018, 11, 299305.

90 X. Bai, M. Sathiya, B. Mendoza-Sánchez, A. Iadecola, J. Vergnet, R. Dedryvère, M. Saubanère, A. M. Abakumov, P. Rozier and J. M. Tarascon, Adv. Energy Mater., 2018, 8, 1802379.

91 M. Jia, Y. Qiao, X. Li, F. Qiu, X. Cao, P. He and H. Zhou, ACS Appl. Mater. Interfaces, 2019, 12(1), 851-857.

92 C. Li, F. Geng, B. Hu and B. Hu, Mater. Today Energy, 2020, 17, 100474.

93 M. Saubanère, E. McCalla, J. M. Tarascon and M. L. Doublet, Energy Environ. Sci., 2016, 9, 984-991.

94 C. Zhao, Q. Wang, Y. Lu, Y.-S. Hu, B. Li and L. Chen, J. Phys. D: Appl. Phys., 2017, 50(18), 183001.

95 A. R. Armstrong, M. Holzapfel, P. Novák, C. S. Johnson, S.-H. Kang, M. M. Thackeray and P. G. Bruce, J. Am. Chem. Soc., 2006, 128, 8694-8698.

96 R. A. House, U. Maitra, L. Jin, J. G. Lozano, J. W. Somerville, N. H. Rees, A. J. Naylor, L. C. Duda, F. Massel, A. V. Chadwick, S. Ramos, D. M. Pickup, D. E. McNally, X. Lu, T. Schmitt, M. R. Roberts and P. G. Bruce, Chem. Mater., 2019, 31, 3293-3300.
97 E. de la Llave, E. Talaie, E. Levi, P. K. Nayak, M. Dixit, P. T. Rao, P. Hartmann, F. Chesneau, D. T. Major, M. Greenstein, D. Aurbach and L. F. Nazar, Chem. Mater., 2016, 28, 9064-9076.

98 P. Rozier, M. Sathiya, A.-R. Paulraj, D. Foix, T. Desaunay, P.-L. Taberna, P. Simon and J.-M. Tarascon, Electrochem. Commun., 2015, 53, 29-32.

99 N. Yabuuchi, M. Takeuchi, M. Nakayama, H. Shiiba, M. Ogawa, K. Nakayama, T. Ohta, D. Endo, T. Ozaki and T. Inamasu, Proc. Natl. Acad. Sci. U. S. A., 2015, 112, 76507655.

100 M. Freire, N. V. Kosova, C. Jordy, D. Chateigner, O. Lebedev, A. Maignan and V. Pralong, Nat. Mater., 2016, 15, 173-177.

101 A. J. Perez, D. Batuk, M. Saubanère, G. Rousse, D. Foix, E. McCalla, E. J. Berg, R. Dugas, K. H. W. van den Bos, M.-L. Doublet, D. Gonbeau, A. M. Abakumov, G. Van Tendeloo and J.-M. Tarascon, Chem. Mater., 2016, 28, 8278-8288.

102 B. Su, J. Zhang, M. Fujita, W. Zhou, P. H.-L. Sit and Y. Denis, J. Electrochem. Soc., 2019, 166, A5075-A5080.

103 Q. Wang, W. Yang, F. Kang and B. Li, Energy Storage Mater., 2018, 14, 361-366.

104 B. Mortemard de Boisse, S.-I. Nishimura, E. Watanabe, L. Lander, A. Tsuchimoto, J. Kikkawa, E. Kobayashi, D. Asakura, M. Okubo and A. Yamada, Adv. Energy Mater., 2018, 8(20), 1800409.

105 X. Zhang, Y. Qiao, S. Guo, K. Jiang, S. Xu, H. Xu, P. Wang, P. He and H. Zhou, Adv. Mater., 2019, 31, e1807770.

106 U. Maitra, R. A. House, J. W. Somerville, N. Tapia-Ruiz, J. G. Lozano, N. Guerrini, R. Hao, K. Luo, L. Jin, M. A. Perez-Osorio, F. Massel, D. M. Pickup, S. Ramos, X. Lu, D. E. McNally, A. V. Chadwick, F. Giustino, T. Schmitt, L. C. Duda, M. R. Roberts and P. G. Bruce, Nat. Chem., 2018, 10, 288-295.

107 X. Bai, M. Sathiya, B. Mendoza-Sánchez, A. Iadecola, J. Vergnet, R. Dedryvère, M. Saubanère, A. M. Abakumov, P. Rozier and J.-M. Tarascon, Adv. Energy Mater., 2018, 8, 1802379.

108 A. Konarov, J. H. Jo, J. U. Choi, Z. Bakenov, H. Yashiro, J. Kim and S.-T. Myung, Nano Energy, 2019, 59, 197-206.

109 A. Konarov, H. J. Kim, J. H. Jo, N. Voronina, Y. Lee, Z. Bakenov, J. Kim and S. T. Myung, Adv. Energy Mater., 2020, 2001111, DOI: 10.1002/aenm.202001111.

110 H. J. Kim, A. Konarov, J. H. Jo, J. U. Choi, K. Ihm, H. K. Lee, J. Kim and S. T. Myung, Adv. Energy Mater., 2019, 9, 1901181.

111 W. Kong, R. Gao, Q. Li, W. Yang, J. Yang, L. Sun and X. Liu, J. Mater. Chem. A, 2019, 7, 9099-9109.

112 T. Risthaus, D. Zhou, X. Cao, X. He, B. Qiu, J. Wang, L. Zhang, Z. Liu, E. Paillard, G. Schumacher, M. Winter and J. Li, J. Power Sources, 2018, 395, 16-24.

113 C. Ma, J. Alvarado, J. Xu, R. l. J. Clément, M. Kodur, W. Tong, C. P. Grey and Y. S. Meng, J. Am. Chem. Soc., 2017, 139, 4835-4845.

114 E. J. Kim, L. A. Ma, L. C. Duda, D. M. Pickup, A. V. Chadwick, R. Younesi, J. T. S. Irvine and A. R. Armstrong, ACS Appl. Energy Mater., 2019, 3, 184-191. 
115 X. Rong, E. Hu, Y. Lu, F. Meng, C. Zhao, X. Wang, Q. Zhang, X. Yu, L. Gu, Y.-S. Hu, H. Li, X. Huang, X.-Q. Yang, C. Delmas and L. Chen, Joule, 2019, 3, 503-517.

116 C. Liu, Z. G. Neale and G. Cao, Mater. Today, 2016, 19, 109123.

117 S. P. Ong, V. L. Chevrier, G. Hautier, A. Jain, C. Moore, S. Kim, X. Ma and G. Ceder, Energy Environ. Sci., 2011, 4, 3680-3688.

118 Y. Nanba, T. Iwao, B. M. D. Boisse, W. Zhao, E. Hosono, D. Asakura, H. Niwa, H. Kiuchi, J. Miyawaki, Y. Harada and M. Okubo, Chem. Mater., 2016, 28(4), 1058-1065.

119 H. Su, S. Jaffer and H. Yu, Energy Storage Mater., 2016, 5, 116-131.

120 X. Xia and J. R. Dahn, Electrochem. Solid-State Lett., 2012, 15, A1.

121 D. Wu, X. Li, B. Xu, N. Twu, L. Liu and G. Ceder, Energy Environ. Sci., 2015, 8, 195-202.

122 P. Vassilaras, X. Ma, X. Li and G. Ceder, J. Electrochem. Soc., 2012, 160, A207-A211.

123 L. Wang, J. Wang, X. Zhang, Y. Ren, P. Zuo, G. Yin and J. Wang, Nano Energy, 2017, 34, 215-223.

124 C. Delmas, J.-J. Braconnier, C. Fouassier and P. Hagenmuller, Solid State Ionics, 1981, 3, 165-169.

125 R. Berthelot, D. Carlier and C. Delmas, Nat. Mater., 2011, 10, 74-80.

126 L. W. Shacklette, J. Electrochem. Soc., 1988, 135, 2669.

127 X. Ma, H. Chen and G. Ceder, J. Electrochem. Soc., 2011, 158, A1307.

128 J. Billaud, R. J. Clement, A. R. Armstrong, J. CanalesVazquez, P. Rozier, C. P. Grey and P. G. Bruce, J. Am. Chem. Soc., 2014, 136, 17243-17248.

129 X. Li, X. Ma, D. Su, L. Liu, R. Chisnell, S. P. Ong, H. Chen, A. Toumar, J. C. Idrobo, Y. Lei, J. Bai, F. Wang, J. W. Lynn, Y. S. Lee and G. Ceder, Nat. Mater., 2014, 13, 586-592.

130 N. Yabuuchi and S. Komaba, Sci. Technol. Adv. Mater., 2014, 15, 043501.

131 T. Or, K. Kaliyappan, Z. Bai and Z. Chen, ChemElectroChem, 2020, 7, 3284-3290.

132 Y. Huang, Z. Yan, W. Luo, Z. Hu, G. Liu, L. Zhang, X. Yang, M. Ou, W. Liu, L. Huang, H. Lin, C.-T. Chen, J. Luo, S. Li, J. Han, S. Chou and Y. Huang, Energy Storage Mater., 2020, 29, 182-189.

133 J. L. Yue, W. W. Yin, M. H. Cao, S. Zulipiya, Y. N. Zhou and Z. W. Fu, Chem. Commun., 2015, 51, 15712-15715.

134 C. Zhao, F. Ding, Y. Lu, L. Chen and Y.-S. Hu, Angew. Chem., Int. Ed., 2020, 59, 264-269.

135 J. H. Stansby, W. M. Dose, N. Sharma, J. A. Kimpton, J. M. López del Amo, E. Gonzalo and T. Rojo, Electrochim. Acta, 2020, 135978, DOI: 10.1016/j.electacta.2020.135978.

136 D. Yuan, X. Hu, J. Qian, F. Pei, F. Wu, R. Mao, X. Ai, H. Yang and Y. Cao, Electrochim. Acta, 2014, 116, 300-305.

137 H. Yoshida, N. Yabuuchi, K. Kubota, I. Ikeuchi, A. Garsuch, M. Schulz-Dobrick and S. Komaba, Chem. Commun., 2014, 50, 3677-3680.

138 Q. C. Wang, E. Hu, Y. Pan, N. Xiao, F. Hong, Z. W. Fu, X. J. Wu, S. M. Bak, X. Q. Yang and Y. N. Zhou, Adv. Sci., 2017, 4, 1700219.
139 M. Jeong, H. Lee, J. Yoon and W.-S. Yoon, J. Power Sources, 2019, 439, 227064.

140 S. Doubaji, M. Valvo, I. Saadoune, M. Dahbi and K. Edström, J. Power Sources, 2014, 266, 275-281.

141 C. Hakim, N. Sabi, M. Dahbi, D. Brandell, K. Edström, L. C. Duda, I. Saadoune and R. Younesi, Commun. Chem., 2020, 3, 1-9.

142 K. Wang, P. Yan, Z. Wang, J. Fu, Z. Zhang, X. Ke and M. Sui, J. Mater. Chem. A, 2020, 8, 16690-16697.

143 T. A. Eriksson, Y. J. Lee, J. Hollingsworth, J. A. Reimer, E. J. Cairns, X.-f. Zhang and M. M. Doeff, Chem. Mater., 2003, 15, 4456-4463.

144 S. Patoux, M. Dollé and M. M. Doeff, Chem. Mater., 2005, 17, 1044-1054.

145 M. Dollé, S. Patoux and M. M. Doeff, Chem. Mater., 2005, 17, 1036-1043.

146 Q. Huang, S. Xu, L. Xiao, P. He, J. Liu, Y. Yang, P. Wang, B. Huang and W. Wei, Inorg. Chem., 2018, 57, 15584-15591.

147 Y. P. Deng, Z. G. Wu, R. Liang, Y. Jiang, D. Luo, A. Yu and Z. Chen, Adv. Funct. Mater., 2019, 29(19), 1808522.

148 Y. Xiao, N. M. Abbasi, Y. F. Zhu, S. Li, S. J. Tan, W. Ling, L. Peng, T. Yang, L. Wang, X. D. Guo, Y. X. Yin, H. Zhang and Y. G. Guo, Adv. Funct. Mater., 2020, 2001334, DOI: 10.1002/adfm.202001334.

149 X. Qi, L. Liu, N. Song, F. Gao, K. Yang, Y. Lu, H. Yang, Y. S. Hu, Z. H. Cheng and L. Chen, ACS Appl. Mater. Interfaces, 2017, 9, 40215-40223.

150 J. Chen, L. Li, L. Wu, Q. Yao, H. Yang, Z. Liu, L. Xia, Z. Chen, J. Duan and S. Zhong, J. Power Sources, 2018, 406, 110-117.

151 Z.-Y. Li, J. Zhang, R. Gao, H. Zhang, L. Zheng, Z. Hu and X. Liu, J. Phys. Chem. C, 2016, 120, 9007-9016.

152 G. K. Veerasubramani, Y. Subramanian, M.-S. Park, B. Senthilkumar, A. Eftekhari, S. J. Kim and D.-W. Kim, Electrochim. Acta, 2019, 296, 1027-1034.

153 M. Bianchini, E. Gonzalo, N. E. Drewett, N. Ortiz-Vitoriano, J. M. López del Amo, F. J. Bonilla, B. Acebedo and T. Rojo, J. Mater. Chem. A, 2018, 6, 3552-3559.

154 S. Guo, P. Liu, H. Yu, Y. Zhu, M. Chen, M. Ishida and H. Zhou, Angew. Chem., Int. Ed., 2015, 54, 5894-5899.

155 Q. Huang, P. He, L. Xiao, Y. Feng, J. Liu, Y. Yang, B. Huang, X. Cui, P. Wang and W. Wei, ACS Appl. Mater. Interfaces, 2020, 12, 2191-2198.

156 L. Yang, J. M. L. Amo, Z. Shadike, S. M. Bak, F. Bonilla, M. Galceran, P. K. Nayak, J. R. Buchheim, X. Q. Yang, T. Rojo and P. Adelhelm, Adv. Funct. Mater., 2020, 2003364, DOI: 10.1002/adfm.202003364.

157 B. Hu, F. Geng, C. Zhao, B. Doumert, J. Trebosc, O. Lafon, C. Li, M. Shen and B. Hu, ACS Appl. Mater. Interfaces, 2020, 12(37), 41485-41494, DOI: 10.1021/acsami.0c11427.

158 E. Lee, J. Lu, Y. Ren, X. Luo, X. Zhang, J. Wen, D. Miller, A. DeWahl, S. Hackney, B. Key, D. Kim, M. D. Slater and C. S. Johnson, Adv. Energy Mater., 2014, 4, 1400458.

159 L. G. Chagas, D. Buchholz, C. Vaalma, L. Wu and S. Passerini, J. Mater. Chem. A, 2014, 2, 20263-20270.

160 X. Chen, X. Zhou, M. Hu, J. Liang, D. Wu, J. Wei and Z. Zhou, J. Mater. Chem. A, 2015, 3, 20708-20714. 
161 Z. Yan, L. Tang, Y. Huang, W. Hua, Y. Wang, R. Liu, Q. Gu, S. Indris, S. L. Chou, Y. Huang, M. Wu and S. X. Dou, Angew. Chem., Int. Ed., 2019, 58, 1412-1416.

162 Q. Huang, J. Liu, S. Xu, P. Wang, D. G. Ivey, B. Huang and W. Wei, Chem. Mater., 2018, 30, 4728-4737.

163 M. Keller, D. Buchholz and S. Passerini, Adv. Energy Mater., 2016, 6, 1501555-1501566.

164 G.-L. Xu, R. Amine, Y.-F. Xu, J. Liu, J. Gim, T. Ma, Y. Ren, C.-J. Sun, Y. Liu, X. Zhang, S. M. Heald, A. Solhy, I. Saadoune, W. L. Mattis, S.-G. Sun, Z. Chen and K. Amine, Energy Environ. Sci., 2017, 10, 1677-1693.

165 J. Zheng, P. Yan, W. H. Kan, C. Wang and A. Manthiram, J. Electrochem. Soc., 2016, 163, A584-A591.

166 C. Deng, P. Skinner, Y. Liu, M. Sun, W. Tong, C. Ma, M. L. Lau, R. Hunt, P. Barnes, J. Xu and H. Xiong, Chem. Mater., 2018, 30, 8145-8154.

167 Y. Xiao, P.-F. Wang, Y.-X. Yin, Y.-F. Zhu, X. Yang, X.-D. Zhang, Y. Wang, X.-D. Guo, B.-H. Zhong and Y.-G. Guo, Adv. Energy Mater., 2018, 8, 1800492.

168 P. Hou, J. Yin, X. Lu, J. Li, Y. Zhao and X. Xu, Nanoscale, 2018, 10, 6671-6677.

169 J. Y. Hwang, S. M. Oh, S. T. Myung, K. Y. Chung, I. Belharouak and Y. K. Sun, Nat. Commun., 2015, 6, 6865.

170 Y. K. Sun, S. T. Myung, M. H. Kim, J. Prakash and K. Amine, J. Am. Chem. Soc., 2005, 127, 13411-13418.

171 S. Bao, S.-h. Luo, Z.-y. Wang, S.-x. Yan, Q. Wang and J.-y. Li, J. Power Sources, 2018, 396, 404-411.

172 J. Ren, R. Dang, Y. Yang, K. Wu, Y. Lee, Z. Hu, X. Xiao and M. Wang, Energy Technol., 2020, 8, 1901504.

173 C. Chen, Z. Han, S. Chen, S. Qi, X. Lan, C. Zhang, L. Chen, P. Wang and W. Wei, ACS Appl. Mater. Interfaces, 2020, 12, 7144-7152.

174 G. G. Eshetu, G. A. Elia, M. Armand, M. Forsyth, S. Komaba, T. Rojo and S. Passerini, Adv. Energy Mater., 2020, 10, 2000093.

175 A. Ponrouch, D. Monti, A. Boschin, B. Steen, P. Johansson and M. R. Palacín, J. Mater. Chem. A, 2015, 3, 22-42.

176 S. Komaba, T. Ishikawa, N. Yabuuchi, W. Murata, A. Ito and Y. Ohsawa, ACS Appl. Mater. Interfaces, 2011, 3, 4165-4168.

177 A. Bhide, J. Hofmann, A. K. Durr, J. Janek and P. Adelhelm, Phys. Chem. Chem. Phys., 2014, 16, 1987-1998.

178 C.-H. Wang, Y.-W. Yeh, N. Wongittharom, Y.-C. Wang, C.-J. Tseng, S.-W. Lee, W.-S. Chang and J.-K. Chang, J. Power Sources, 2015, 274, 1016-1023.

179 G. G. Eshetu, S. Grugeon, H. Kim, S. Jeong, L. Wu, G. Gachot, S. Laruelle, M. Armand and S. Passerini, ChemSusChem, 2016, 9, 462-471.

180 P. B. Balbuena, Electrolyte materials - Issues and challenges, in AIP Conference Proceedings, American Institute of Physics, June 2014, vol. 1597, ch. 1, pp. 82-97.

181 L. G. Chagas, D. Buchholz, L. Wu, B. Vortmann and S. Passerini, J. Power Sources, 2014, 247, 377-383.

182 J.-J. Kim, K. Yoon, I. Park and K. Kang, Small Methods, 2017, $1,1700219$.

183 Y. Wang, S. Song, C. Xu, N. Hu, J. Molenda and L. Lu, Nano Mater. Sci., 2019, 1, 91-100.
184 A. Hayashi, K. Noi, A. Sakuda and M. Tatsumisago, Nat. Commun., 2012, 3, 856.

185 T. Wei, Y. Gong, X. Zhao and K. Huang, Adv. Funct. Mater., 2014, 24, 5380-5384.

186 L. Liu, X. Qi, Q. Ma, X. Rong, Y. S. Hu, Z. Zhou, H. Li, X. Huang and L. Chen, ACS Appl. Mater. Interfaces, 2016, 8, 32631-32636.

187 E. Quartarone and P. Mustarelli, Chem. Soc. Rev., 2011, 40, 2525-2540.

188 J. B. Goodenough and P. Singh, J. Electrochem. Soc., 2015, 162, A2387-A2392.

189 S. Guo, Q. Li, P. Liu, M. Chen and H. Zhou, Nat. Commun., 2017, 8, 135.

190 M. H. Han, N. Sharma, E. Gonzalo, J. C. Pramudita, H. E. A. Brand, J. M. López del Amo and T. Rojo, J. Mater. Chem. A, 2016, 4, 18963-18975.

191 H. L. Andersen, E. A. Cheung, M. Avdeev, H. E. MaynardCasely, D. P. Abraham and N. Sharma, J. Power Sources, 2020, 470, 228370.

192 J.-Y. Hwang, S.-T. Myung, J. U. Choi, C. S. Yoon, H. Yashiro and Y.-K. Sun, J. Mater. Chem. A, 2017, 5, 23671-23680.

193 F. Wu, X. Zhang, T. Zhao, L. Li, M. Xie and R. Chen, ACS Appl. Mater. Interfaces, 2015, 7, 3773-3781.

194 J. Liu and A. Manthiram, J. Mater. Chem., 2010, 20, 3961.

195 J. Zheng, M. Gu, J. Xiao, B. J. Polzin, P. Yan, X. Chen, C. Wang and J.-G. Zhang, Chem. Mater., 2014, 26, 63206327.

196 S. J. Shi, J. P. Tu, Y. Y. Tang, X. Y. Liu, Y. Q. Zhang, X. L. Wang and C. D. Gu, Electrochim. Acta, 2013, 88, 671679.

197 Y. Wang, K. Tang, X. Li, R. Yu, X. Zhang, Y. Huang, G. Chen, S. Jamil, S. Cao, X. Xie, Z. Luo and X. Wang, Chem. Eng. J., 2019, 372, 1066-1076.

198 J. H. Jo, J. U. Choi, A. Konarov, H. Yashiro, S. Yuan, L. Shi, Y.-K. Sun and S.-T. Myung, Adv. Funct. Mater., 2018, 28, 1705968.

199 J.-J. Ding, Y.-N. Zhou, Q. Sun and Z.-W. Fu, Electrochem. Commun., 2012, 22, 85-88.

200 Y. Liu, X. Fang, A. Zhang, C. Shen, Q. Liu, H. A. Enaya and C. Zhou, Nano Energy, 2016, 27, 27-34.

201 J. Alvarado, C. Ma, S. Wang, K. Nguyen, M. Kodur and Y. S. Meng, ACS Appl. Mater. Interfaces, 2017, 9, 2651826530.

202 H. V. Ramasamy, P. N. Didwal, S. Sinha, V. Aravindan, J. Heo, C. J. Park and Y. S. Lee, J. Colloid Interface Sci., 2020, 564, 467-477.

203 K. Kaliyappan, J. Liu, A. Lushington, R. Li and X. Sun, ChemSusChem, 2015, 8, 2537-2543.

204 J.-H. Park, K. Park, R.-H. Kim, D.-J. Yun, S.-Y. Park, D. Han, S.-S. Lee and J.-H. Park, J. Mater. Chem. A, 2015, 3, 1073010737.

205 K. Kaliyappan, J. Liu, B. Xiao, A. Lushington, R. Li, T.-K. Sham and X. Sun, Adv. Funct. Mater., 2017, 27, 1701870.

206 H.-M. Cheng, F.-M. Wang, J. P. Chu, R. Santhanam, J. Rick and S.-C. Lo, J. Phys. Chem. C, 2012, 116, 7629-7637. 
207 H. V. Ramasamy, K. Kaliyappan, R. Thangavel, V. Aravindan, K. Kang, D. U. Kim, Y. Park, X. Sun and Y.-S. Lee, J. Mater. Chem. A, 2017, 5, 8408-8415.

208 W. Kong, H. Wang, L. Sun, C. Su and X. Liu, Appl. Surf. Sci., 2019, 497, 143814.

209 J.-Y. Hwang, T.-Y. Yu and Y.-K. Sun, J. Mater. Chem. A, 2018, 6, 16854-16862.

210 R. Dang, M. Chen, Q. Li, K. Wu, Y. L. Lee, Z. Hu and X. Xiao, ACS Appl. Mater. Interfaces, 2019, 11, 856-864.

211 Y. Zhang, Y. Pei, W. Liu, S. Zhang, J. Xie, J. Xia, S. Nie, L. Liu and X. Wang, Chem. Eng. J., 2020, 382, 122697.

212 J. Zhang and D. Y. W. Yu, J. Power Sources, 2018, 391, 106112.

213 Y. Yu, W. Kong, Q. Li, D. Ning, G. Schuck, G. Schumacher, C. Su and X. Liu, ACS Appl. Energy Mater., 2020, 3, 933-942.

214 K. Tang, Y. Huang, X. Xie, S. Cao, L. Liu, M. Liu, Y. Huang, B. Chang, Z. Luo and X. Wang, Chem. Eng. J., 2020, 384, 123234.

215 K. W. Nam, S. Kim, E. Yang, Y. Jung, E. Levi, D. Aurbach and J. W. Choi, Chem. Mater., 2015, 27, 3721-3725.

216 D. Lu, Z. Yao, Y. Zhong, X. Wang, X. Xia, C. Gu, J. Wu and J. Tu, ACS Appl. Mater. Interfaces, 2019, 11, 15630-15637.

217 J. Xia, W. Wu, K. Fang and X. Wu, Carbon, 2020, 157, 693702.

218 Y. B. Niu, Y. J. Guo, Y. X. Yin, S. Y. Zhang, T. Wang, P. Wang, S. Xin and Y. G. Guo, Adv. Mater., 2020, 32, e2001419.

219 J. Martinez De Ilarduya, L. Otaegui, J. M. López del Amo, M. Armand and G. Singh, J. Power Sources, 2017, 337, 197-203.

220 B. Zhang, R. Dugas, G. Rousse, P. Rozier, A. M. Abakumov and J. M. Tarascon, Nat. Commun., 2016, 7, 10308.

221 K. Park, B.-C. Yu and J. B. Goodenough, Chem. Mater., 2015, 27, 6682-6688.

222 M. Sathiya, J. Thomas, D. Batuk, V. Pimenta, R. Gopalan and J.-M. Tarascon, Chem. Mater., 2017, 29, 5948-5956.

223 C.-H. Jo, J. U. Choi, H. Yashiro and S.-T. Myung, J. Mater. Chem. A, 2019, 7, 3903-3909.

224 C. Grey and J. Tarascon, Nat. Mater., 2017, 16, 45.

225 P. Harks, F. Mulder and P. Notten, J. Power Sources, 2015, 288, 92-105.

226 J. Yang, S. Muhammad, M. R. Jo, H. Kim, K. Song, D. A. Agyeman, Y. I. Kim, W. S. Yoon and Y. M. Kang, Chem. Soc. Rev., 2016, 45(20), 5717-5770.

227 C. Tan, S. R. Daemi, O. O. Taiwo, T. M. Heenan, D. J. Brett and P. R. Shearing, Materials, 2018, 11, 2157.

228 H. Kato, Y. Kobayashi and H. Miyashiro, J. Power Sources, 2018, 398, 49-54.

229 I. Bloom, A. N. Jansen, D. P. Abraham, J. Knuth, S. A. Jones, V. S. Battaglia and G. L. Henriksen, J. Power Sources, 2005, 139, 295-303.

230 M. Lewerenz, A. Marongiu, A. Warnecke and D. U. Sauer, J. Power Sources, 2017, 368, 57-67.

231 D. Goonetilleke, T. Faulkner, V. K. Peterson and N. Sharma, J. Power Sources, 2018, 394, 1-8.

232 K. A. Severson, P. M. Attia, N. Jin, N. Perkins, B. Jiang, Z. Yang, M. H. Chen, M. Aykol, P. K. Herring and D. Fraggedakis, Nat. Energy, 2019, 4, 383-391.
233 K. Wang, P. Yan and M. Sui, Nano Energy, 2018, 54, 148155.

234 H. M. Dahn, A. Smith, J. Burns, D. Stevens and J. Dahn, J. Electrochem. Soc., 2012, 159, A1405-A1409.

235 L. A. Middlemiss, A. J. R. Rennie, R. Sayers and A. R. West, Energy Rep., 2020, 6, 232-241.

236 G. Yan, S. Mariyappan, G. Rousse, Q. Jacquet, M. Deschamps, R. David, B. Mirvaux, J. W. Freeland and J. M. Tarascon, Nat. Commun., 2019, 10, 585.

237 J. Li, X. Xiao, F. Yang, M. W. Verbrugge and Y.-T. Cheng, J. Phys. Chem. C, 2011, 116, 1472-1478.

238 K. J. Nelson, G. L. d'Eon, A. T. B. Wright, L. Ma, J. Xia and J. R. Dahn, J. Electrochem. Soc., 2015, 162, A1046-A1054.

239 Y. Zhu and C. Wang, J. Phys. Chem. C, 2010, 114, 2830-2841. 240 N. Sabi, S. Doubaji, K. Hashimoto, S. Komaba, K. Amine, A. Solhy, B. Manoun, E. Bilal and I. Saadoune, J. Power Sources, 2017, 342, 998-1005.

241 R. E. Dinnebier and S. J. Billinge, Powder diffraction: theory and practice, Royal Society of Chemistry, 2008.

242 T. Egami and S. J. Billinge, Underneath the Bragg peaks: structural analysis of complex materials, Newnes, 2012.

243 E. H. Kisi and C. J. Howard, Applications of neutron powder diffraction, Oxford University Press, 2012.

244 V. K. Peterson and C. M. Papadakis, IUCrJ, 2015, 2, 292-304.

245 M. Morcrette, Y. Chabre, G. Vaughan, G. Amatucci, J. B. Leriche, S. Patoux, C. Masquelier and J. M. Tarascon, Electrochim. Acta, 2002, 47, 3137-3149.

246 X. L. Wang, K. An, L. Cai, Z. Feng, S. E. Nagler, C. Daniel, K. J. Rhodes, A. D. Stoica, H. D. Skorpenske, C. Liang, W. Zhang, J. Kim, Y. Qi and S. J. Harris, Sci. Rep., 2012, 2, 747.

247 N. Sharma, W. K. Pang, Z. Guo and V. K. Peterson, ChemSusChem, 2015, 8, 2826-2853.

248 P. Shearing, Y. Wu, S. J. Harris and N. Brandon, Interface, 2011, 20, 43.

249 A. Senyshyn, M. J. Mühlbauer, O. Dolotko, M. Hofmann, T. Pirling and H. Ehrenberg, J. Power Sources, 2014, 245, 678-683.

250 S.-M. Bak, Z. Shadike, R. Lin, X. Yu and X.-Q. Yang, NPG Asia Mater., 2018, 10(7), 563-580.

251 T.-Y. Chen, B. Han, C.-W. Hu, Y.-f. Su, Y.-X. Zhou, H.-Y. Chen, P.-I. Pan, C.-M. Wu, A. Hu and J.-J. Kai, J. Phys. Chem. C, 2018, 122(24), 12623-12632.

252 W. M. Dose, N. Sharma, J. C. Pramudita, M. Avdeev, E. Gonzalo and T. Rojo, Chem. Mater., 2018, 30, 7503-7510.

253 D. Goonetilleke, S. Wang, E. Gonzalo, M. Galcerán, D. Saurel, S. J. Day, F. Fauth, T. Rojo and N. Sharma, J. Mater. Chem. A, 2019, 7, 12115-12125.

254 S. Kjeldgaard, S. Birgisson, A. G. Kielland and B. B. Iversen, J. Appl. Crystallogr., 2018, 51(5), 1304-1310.

255 B. Mortemard de Boisse, J. H. Cheng, D. Carlier, M. Guignard, C. J. Pan, S. Bordère, D. Filimonov, C. Drathen, E. Suard, B. J. Hwang, A. Wattiaux and C. Delmas, J. Mater. Chem. A, 2015, 3, 10976-10989.

256 N. Tapia-Ruiz, W. M. Dose, N. Sharma, H. Chen, J. Heath, J. W. Somerville, U. Maitra, M. S. Islam and P. G. Bruce, Energy \& Environmental Science, 2018, 11, 1470-1479. 
257 X. Qiu, J. W. Thompson and S. J. Billinge, J. Appl. Crystallogr., 2004, 37, 678.

258 P. K. Allan, J. M. Griffin, A. Darwiche, O. J. Borkiewicz, K. M. Wiaderek, K. W. Chapman, A. J. Morris, P. J. Chupas, L. Monconduit and C. P. Grey, J. Am. Chem. Soc., 2016, 138, 2352-2365.

259 K. W. Chapman, MRS Bull., 2016, 41, 231-240.

260 J. Sottmann, M. Di Michiel, H. Fjellvåg, L. Malavasi, S. Margadonna, P. Vajeeston, G. B. M. Vaughan and D. S. Wragg, Angew. Chem., Int. Ed., 2017, 56, 11385-11389.

261 K. M. Wiaderek, O. J. Borkiewicz, E. Castillo-Martínez, R. Robert, N. Pereira, G. G. Amatucci, C. P. Grey, P. J. Chupas and K. W. Chapman, J. Am. Chem. Soc., 2013, 135, 4070-4078.

262 J. Yano and V. K. Yachandra, Photosynth. Res., 2009, 102, 241. 263 F. de Groot, Chem. Rev., 2001, 101, 1779-1808.

264 M. Chen, S.-L. Chou and S.-X. Dou, Batteries Supercaps, 2019, 2, 842-851.

265 Y. Wang, L. Wang, H. Zhu, J. Chu, Y. Fang, L. Wu, L. Huang, Y. Ren, C.-J. Sun, Q. Liu, X. Ai, H. Yang and Y. Cao, Adv. Funct. Mater., 2020, 30, 1910327.

266 R. L. Mössbauer, Z. Phys., 1958, 151, 124-143.

267 P. Gütlich, R. Link and A. Trautwein, Mössbauer Spectroscopy and Transition Metal Chemistry, Springer, Berlin Heidelberg, 2013.

268 R. Rajagopalan, B. Chen, Z. Zhang, X. L. Wu, Y. Du, Y. Huang, B. Li, Y. Zong, J. Wang, G. H. Nam, M. Sindoro, S. X. Dou, H. K. Liu and H. Zhang, Adv. Mater., 2017, 29(12), 1605694.

269 J. S. Thorne, R. A. Dunlap and M. N. Obrovac, J. Electrochem. Soc., 2014, 161, A2232-A2236.

270 J. S. Thorne, S. Chowdhury, R. A. Dunlap and M. N. Obrovac, J. Electrochem. Soc., 2014, 161, A1801-A1805.

271 J. S. Thorne, R. A. Dunlap and M. N. Obrovac, J. Electrochem. Soc., 2013, 160, A361-A367.

272 E. McCalla, M. T. Sougrati, G. Rousse, E. J. Berg, A. Abakumov, N. Recham, K. Ramesha, M. Sathiya, R. Dominko, G. Van Tendeloo, P. Novak and J. M. Tarascon, J. Am. Chem. Soc., 2015, 137, 4804-4814.

273 C. Drager, F. Sigel, R. Witte, R. Kruk, L. Pfaffmann, S. Mangold, V. Mereacre, M. Knapp, H. Ehrenberg and S. Indris, Phys. Chem. Chem. Phys., 2018, 21, 89-95.

274 B. Diehl, in NMR Spectroscopy in Pharmaceutical Analysis, Elsevier, 2008, pp. 1-41.

275 O. Pecher, J. Carretero-Gonzalez, K. J. Griffith and C. P. Grey, Chem. Mater., 2017, 29(1), 213-242.

276 D. L. Smiley, D. Carlier and G. R. Goward, Solid State Nucl. Magn. Reson., 2019, 103, 1-8.

277 M. Miroshnikov, K. Kato, G. Babu, N. Kumar, K. Mahankali, E. Hohenstein, H. Wang, S. Satapathy, K. P. Divya, H. Asare, L. M. R. Arava, P. M. Ajayan and G. John, ACS Appl. Energy Mater., 2019, 2, 8596-8604.

278 L. Yang, X. Li, J. Liu, S. Xiong, X. Ma, P. Liu, J. Bai, W. Xu, Y. Tang, Y.-Y. Hu, M. Liu and H. Chen, J. Am. Chem. Soc., 2019, 141, 6680-6689.
279 R. J. Clément, J. Xu, D. S. Middlemiss, J. Alvarado, C. Ma, Y. S. Meng and C. P. Grey, J. Mater. Chem. A, 2017, 5, 41294143.

280 M. Kalapsazova, R. Stoyanova, E. Zhecheva, G. Tyuliev and D. Nihtianova, J. Mater. Chem. A, 2014, 2, 19383-19395.

281 J. Wu, M. Fenech, R. F. Webster, R. D. Tilley and N. Sharma, Sustainable Energy Fuels, 2019, 3, 1623-1646.

282 R. F. Egerton, Physical principles of electron microscopy, Springer, 2005.

283 Y. Wang, D. Dang, D. Li, J. Hu, X. Zhan and Y.-T. Cheng, J. Power Sources, 2019, 438, 226938.

284 J. Li, A. R. Cameron, H. Li, S. Glazier, D. Xiong, M. Chatzidakis, J. Allen, G. Botton and J. Dahn, J. Electrochem. Soc., 2017, 164, A1534-A1544.

285 P. Barai and P. P. Mukherjee, J. Electrochem. Soc., 2013, 160, A955-A967.

286 F. P. McGrogan, S. R. Bishop, Y.-M. Chiang and K. J. Van Vliet, J. Electrochem. Soc., 2017, 164, A3709.

287 Y. Zhang, C. Zhao and Z. Guo, Int. J. Mech. Sci., 2019, 155, 178-186.

288 R. Ruess, S. Schweidler, H. Hemmelmann, G. Conforto, A. Bielefeld, D. A. Weber, J. Sann, M. T. Elm and J. Janek, J. Electrochem. Soc., 2020, 167, 100532.

289 J. Wu, M. Fenech, R. F. Webster, R. D. Tilley and N. Sharma, Sustainable Energy Fuels, 2019, 3(7), 1623-1646.

290 Y. Yuan, K. Amine, J. Lu and R. Shahbazian-Yassar, Nat. Commun., 2017, 8, 1-14.

291 A. L. D. Kilcoyne, T. Tyliszczak, W. F. Steele, S. Fakra, P. Hitchcock, K. Franck, E. Anderson, B. Harteneck, E. G. Rightor, G. E. Mitchell and A. P. Hitchcock, J. Synchrotron Radiat., 2003, 10(2), 125-136.

292 M. Wolf, B. M. May and J. Cabana, Chem. Mater., 2017, 29, 3347-3362.

293 Y. Xie, H. Wang, G. Xu, J. Wang, H. Sheng, Z. Chen, Y. Ren, C.-J. Sun, J. Wen, J. Wang, D. J. Miller, J. Lu, K. Amine and Z.-F. Ma, Adv. Energy Mater., 2016, 6(24), 1601306.

294 S. M. Salapaka and M. V. Salapaka, IEEE Contr. Syst. Mag., 2008, 28(2), 65-83.

295 R. Kempaiah, G. Vasudevamurthy and A. Subramanian, Nano Energy, 2019, 65, 103925.

296 M. S. Islam and C. A. Fisher, Chem. Soc. Rev., 2014, 43, 185204.

297 C. R. A. Catlow, Z. X. Guo, M. Miskufova, S. A. Shevlin, A. G. H. Smith, A. A. Sokol, A. Walsh, D. J. Wilson and S. M. Woodley, Philos. Trans. R. Soc., A, 2010, 368, 3379-3456.

298 A. Urban, D.-H. Seo and G. Ceder, npj Comput. Mater., 2016, 2, 16002.

299 Q. Bai, L. Yang, H. Chen and Y. Mo, Adv. Energy Mater., 2018, 1702998 , DOI: 10.1002/aenm.201702998.

300 W. Song, X. Cao, Z. Wu, J. Chen, Y. Zhu, H. Hou, Q. Lan and X. Ji, Langmuir, 2014, 30, 12438-12446.

301 A. J. Toumar, S. P. Ong, W. D. Richards, S. Dacek and G. Ceder, Phys. Rev. Appl., 2015, 4, 064002. 